INTERNATIONAL MONETARY FUND

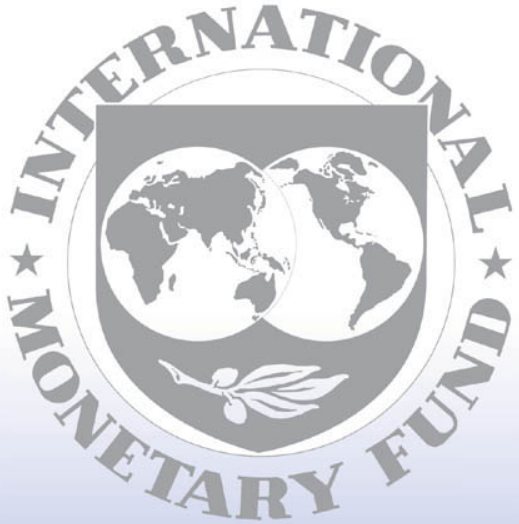

Staff

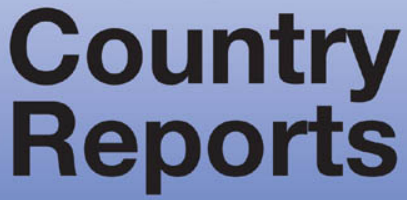




\section{Togo: Poverty Reduction Strategy Paper (2009-11)}

This paper was prepared based on the information available at the time it was completed on November 11, 2009. The views expressed in this document are those of the staff team and do not necessarily reflect the views of the government of Togo or the Executive Board of the IMF.

The policy of publication of staff reports and other documents by the IMF allows for the deletion of market-sensitive information.

Copies of this report are available to the public from

International Monetary Fund • Publication Services

700 19th Street, N.W. • Washington, D.C. 20431

Telephone: (202) 623-7430 • Telefax: (202) 623-7201

E-mail: publications@imf.org • Internet: http://www.imf.org

\section{International Monetary Fund \\ Washington, D.C.}




\section{TOGOLESE REPUBLIC}

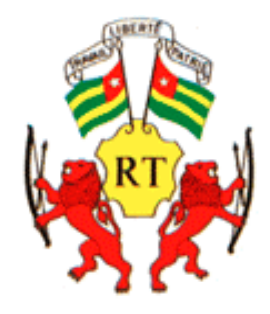

\section{Full Poverty Reduction Strategy Paper}

\section{9-2011}

Final Version

\section{May 2009}

CInternational Monetary Fund. Not for Redistribution 
1. THE F-PRSP DRAFTING CONTEXT

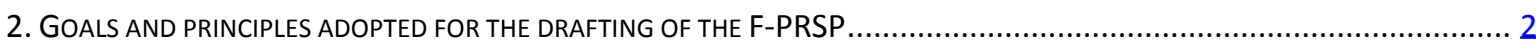

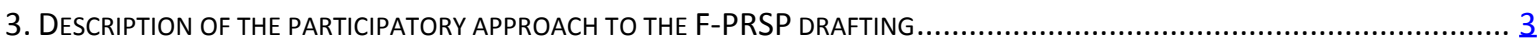

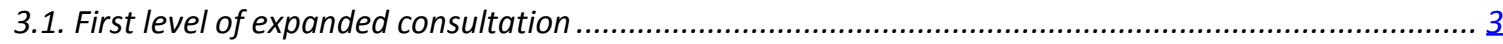

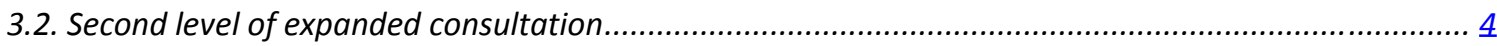

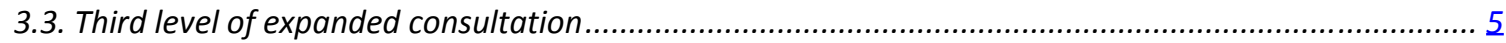

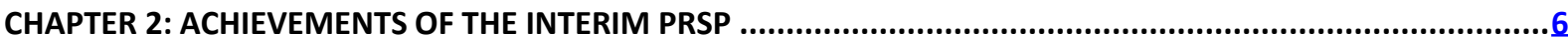

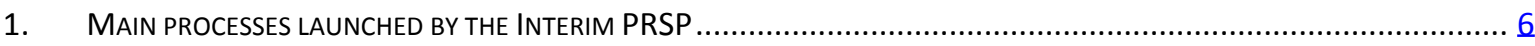

2. STATUS OF IMPLEMENTATION OF THE INTERIM STRATEGY ........................................................................

2.1 Improvement of political and economic governance ........................................................................ 8

2.2 Consolidation of the process of economic recovery and promotion of sustainable development ..... 10

2.3 Development of social sectors, human resources and employment ............................................ 11

2.4 Implementation, monitoring and assessment mechanism ........................................................ 13

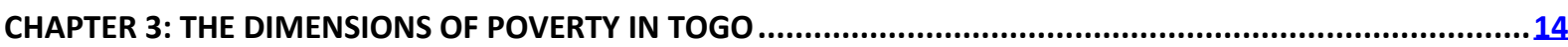

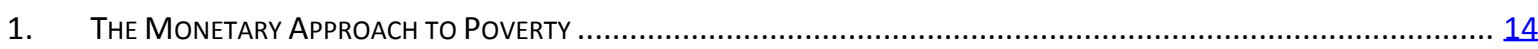

1.1 The profile of monetary poverty nation wide .................................................................... 14

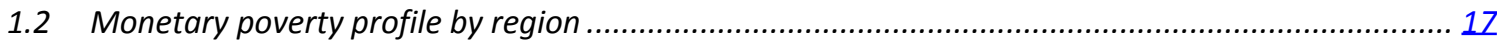

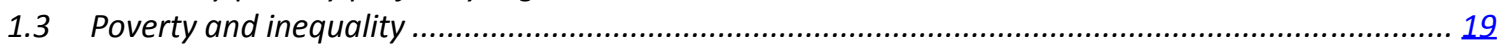

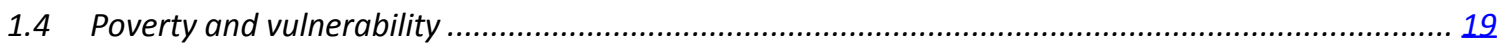

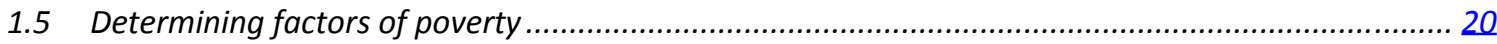

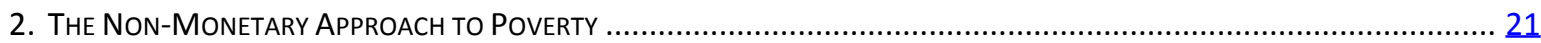

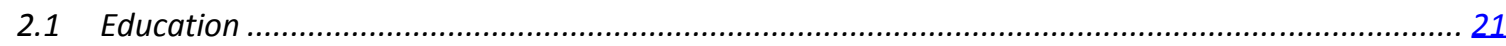

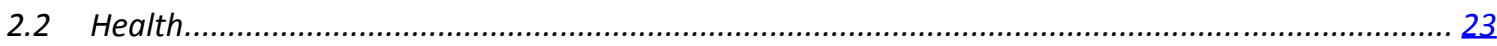

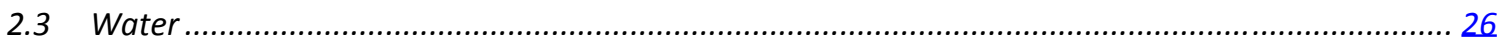

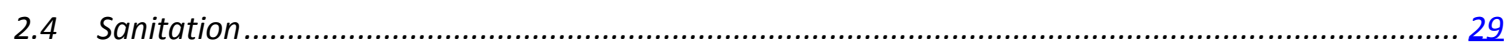

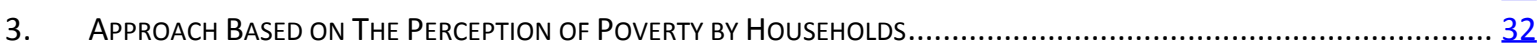

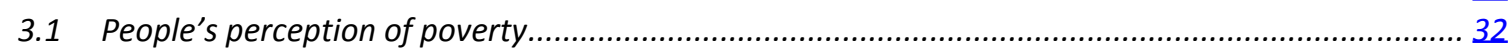

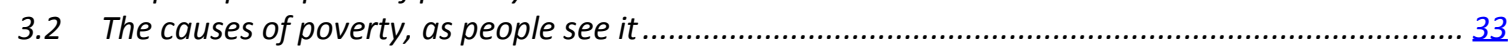

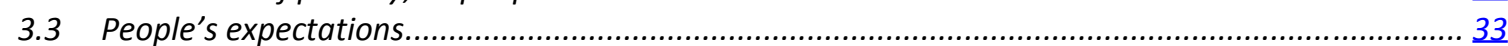

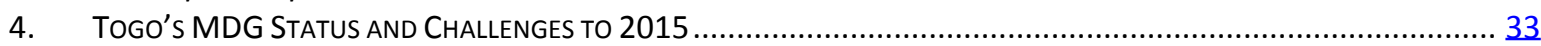

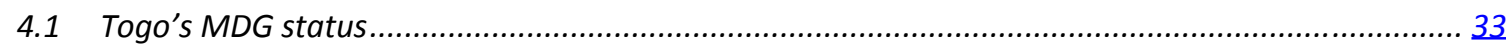

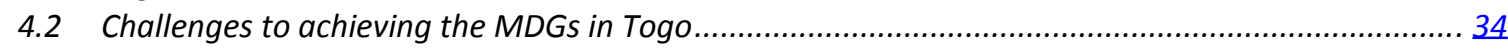

CHAPTER 4: PILLARS OF THE FULL POVERTY REDUCTION STRATEGY .....................................................

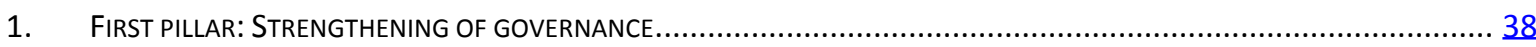

1.1 Strengthening of political governance ................................................................................... 38

1.2 Promotion of institutional governance ........................................................................... 40

1.3 Implementation of administrative reform ......................................................................... 41

1.4 Improvement of economic governance........................................................................ 44

2. Second Pillar: Consolidation of the Foundations of Strong And Sustainable Growth............................... 46

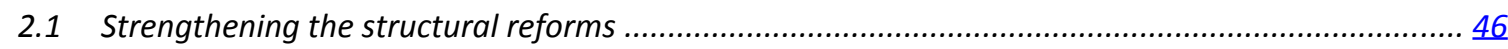

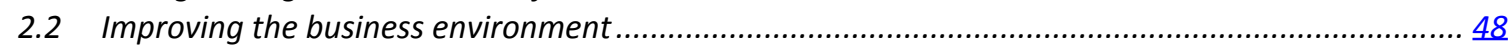

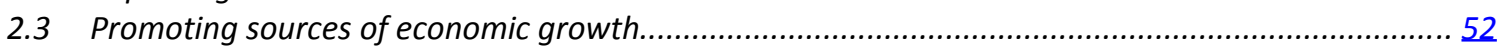

2.4 Development of infrastructures to support economic growth ..................................................

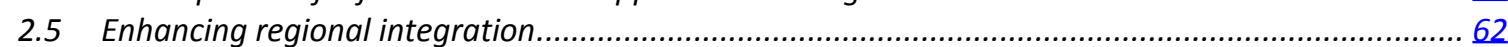

2.6 Effective management of natural resources, the environment, the living environment, and natural

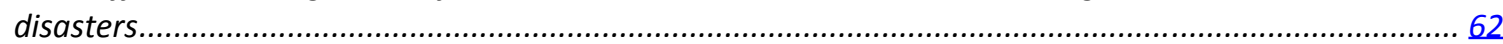

2.7 Redistributing the fruits of economic growth ................................................................... 
2.8 Job creation.

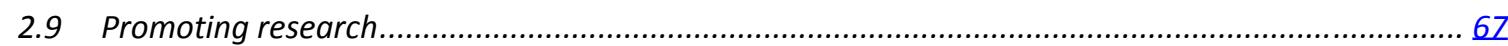

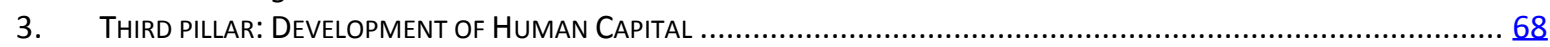

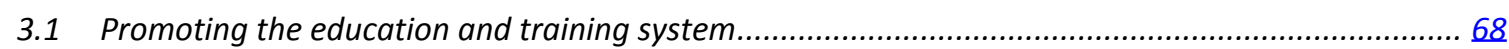

3.2 Development of the health system and health services...........................................................

3.3 Improving the nutritional status of the general public .................................................................

3.4 Improving access to safe drinking water and to sanitation infrastructure ..................................... 73

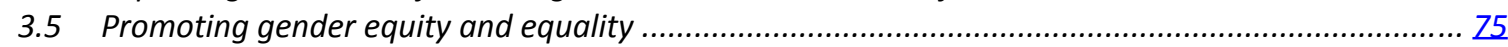

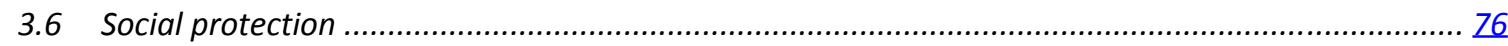

3.7 Promoting youth, sports, and recreational activities ........................................................... 77

4. Fourth Pillar: Community Development ANd Reduction of Regional IMBALANCES ...................................... 77

4.1. Strengthening local governance and community development support mechanisms................. Z8

4.1 Reduction of regional imbalances through the development of regional and local potential........... $\underline{81}$

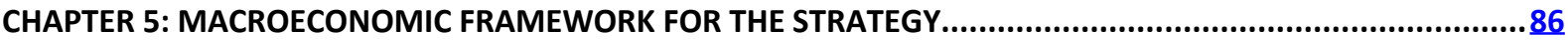

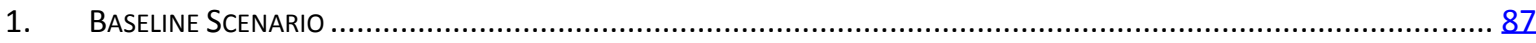

2. Alternative Scenario for Acceleration Towards Meeting the MDGs ............................................... 91

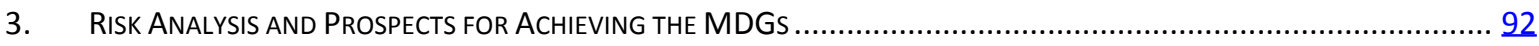

CHAPTER 6: INSTITUTIONAL FRAMEWORK AND MECHANISMS FOR IMPLEMENTING AND MONITORING THE

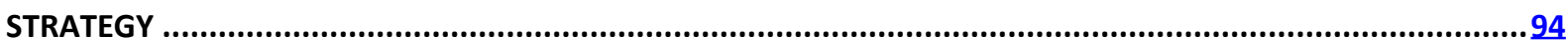

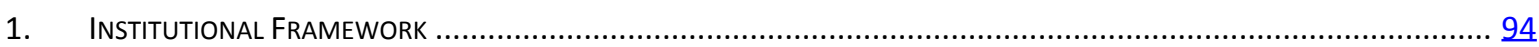

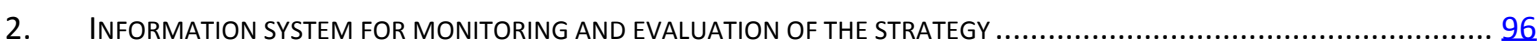

2.1 Sub-system for "Monitoring of Household Living Conditions" .................................................... 97

2.2 Sub-system for "Monitoring of Programs and Projects" .............................................................. 97

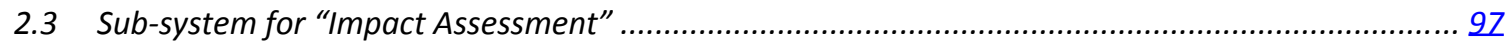

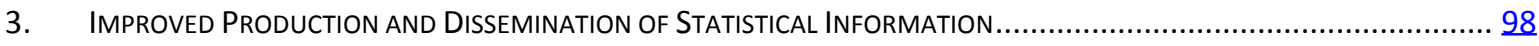

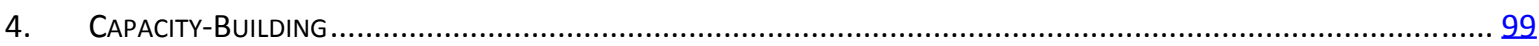

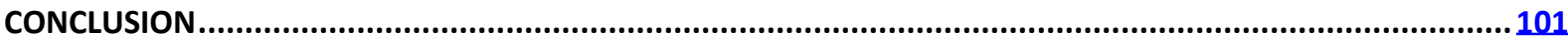




\section{ACRONYMS AND ABBREVIATIONS}

\begin{tabular}{|c|c|}
\hline ABEDA & Arab Bank for Economic Development in Africa \\
\hline AEPA & Safe Drinking Water Supply and Sanitation \\
\hline AfDB & African Development Bank \\
\hline AIDS & Acquired Immuno-Deficiency Syndrome \\
\hline BCEAO & Central Bank of West African States \\
\hline $\mathrm{BIAO}$ & Banque Internationale pour l'Afrique de l'Ouest \\
\hline BOAD & West African Development Bank \\
\hline $\mathrm{BTCl}$ & Banque Togolaise pour le Commerce et I'Industrie \\
\hline BTD & Banque Togolaise de Développement \\
\hline BTP & Construction and Public Works \\
\hline CAGIA & $\begin{array}{l}\text { Centrale d'Achat et de Gestion des Intrants Agricoles [Agricultural Inputs Purchasing and Management } \\
\text { Office] }\end{array}$ \\
\hline CAS-IMEC & $\begin{array}{l}\text { Cellule d'Appui et de Suivi des Institutions Mutualistes ou coopératives d'Epargne et de Crédit [ Mutual } \\
\text { Institutions and Savings and Credit Cooperatives Support and Monitoring Unit] }\end{array}$ \\
\hline CCFCC & Comité de Coordination de la Filière Café-Cacao [Coffee-Cocoa Industry Coordinating Committee] \\
\hline CDQ & Comité de Développement de Quartier [Neighborhood Development Committee] \\
\hline CEB & Communauté Electrique du Bénin \\
\hline CEET & Compagnie Energie Electrique du Togo \\
\hline CFE & Centre de Formalité des Entreprises [Business Formalities Center] \\
\hline CFAF & CFA franc \\
\hline CISLP & $\begin{array}{l}\text { Comité Interministériel chargé des Stratégies de Lutte contre la Pauvreté [Interministerial Committee } \\
\text { Responsible for Poverty Reduction Strategies] }\end{array}$ \\
\hline CLP & Local Planning Committee \\
\hline CLSP & Local Participatory Monitoring Committee \\
\hline CNPDLP & $\begin{array}{l}\text { Conseil National des Politiques de Développement et de Lutte contre la Pauvreté [National Council on } \\
\text { Development Policy and Poverty Reduction] }\end{array}$ \\
\hline CPA & Comprehensive Political Agreement \\
\hline CRP & Regional Planning Committee \\
\hline CRSP & Regional Participatory Monitoring Committee \\
\hline CRT & Caisse de Retraite du Togo \\
\hline CSO & Civil Society Organization \\
\hline CTP-SRP & $\begin{array}{l}\text { Comité Technique de Pilotage de la Stratégie de Réduction de la Pauvreté [Technical Steering Committee } \\
\text { for the Poverty Reduction Strategy] }\end{array}$ \\
\hline CU-PRSP & Coordination Unit for the Poverty Reduction Strategy Paper \\
\hline CVD & Village Development Committee \\
\hline DEPONAT & National Land Use Policy Statement \\
\hline DGI & Directorate General of Taxation \\
\hline DGSCN & Directorate General of Statistics and National Accounts \\
\hline DGTCP & Directorate General for the Treasury and Public Accounting \\
\hline DOTS & Directly Observed Treatment Short course \\
\hline EBID & ECOWAS Bank for Investment and Development \\
\hline EC & European Commission \\
\hline ECOWAS & Economic Community of West African States \\
\hline EDF & European Development Fund \\
\hline EDILs & Ecoles d'Initiative Locale [Local Initiative Schools] \\
\hline EGAP & Etats Généraux de I'Administration Publique [Estates General of Public Administration] \\
\hline EIB & European Investment Bank \\
\hline EITI & Extractive Industries Transparency Initiative \\
\hline EPA & Economic Partnership Agreement \\
\hline
\end{tabular}


FAO Food and Agriculture Organization of the United Nations

F-PRS Full poverty reduction strategy

GDP Gross Domestic Product

GER Gross Enrollment Ratio

ISFM Integrated Soil Fertility Management

IWRM Integrated Water Resource Management

GPS Global Positioning System

HIPC Heavily Indebted Poor Countries

HIPC-I Heavily Indebted Poor Countries Initiative

HIV Human Immuno-Deficiency Virus

ICT Information and Communication Technologies

IFAD International Fund for Agricultural Development

IFG International Fertilizer Group

IMF International Monetary Fund

IPAP Interim Priority Action Plan

I-PRS Interim poverty reduction strategy

JITAP Joint Integrated Technical Assistance Program

MDGs Millennium Development Goals

MDRI Multilateral Debt Relief Initiative

MFI Microfinance Institution

MICS Multiple Indicator Cluster Survey

MTEF Medium-Term Expenditure Framework

MTFF Medium-Term Fiscal Framework

NFIU National Financial Intelligence Unit

NGO Non-Governmental Organization

OECD Organisation for Economic Co-operation and Development

OHADA Organization for the Harmonization of Business Law in Africa

OTP Office Togolais des Phosphates

OTP/IFG Office Togolais des Phosphates / International Fertilizer Group

PAP Priority Action Program

PASNAM National Microfinance Strategy Support Program

PAV Village Action Plan

PDC Community Development Program

PEFA Public Expenditure and Financial Accountability

PEMFAR Public Expenditure Management and Financial Accountability Review

PMCT Prevention of Mother to Child Transmission

PNDS National Health Development Plan

PNMJ National Program for the Modernization of Justice

PNSA National Food Security Program

PPMR Multiyear Microproject Program

PRGF Poverty Reduction and Growth Facility

PRIP Regional Public Investment Program

PRSP Poverty Reduction Strategy Paper

PTS Permanent Technical Secretariat

QUIBB 
Indicators of Wellbeing]

SAZOF Société d'Administration de la Zone Franche

SC Sectoral Committee

SIGFIP Integrated System of Public Finance Management

SISE Système d'Information et de Suivi-Evaluation [Information, Monitoring and Assessment System]

SLAT Schéma Local d'Aménagement du Territoire [Local Land Use Plan]

SME /SMI Small and medium-size enterprises/small and medium-size industries

SMETF Sectoral Medium-Term Expenditure Framework

SNAT Schéma National d'Aménagement du Territoire [National Land Use Plan]

SNDS Stratégie Nationale de Développement de la Statistique [National Statistics Development Strategy]

SNMF Stratégie Nationale de la Microfinance [National Microfinance Strategy]

SNPT Société Nouvelle des Phosphates du Togo

SOTOCO Société Togolaise de Coton

SRAT Schéma Régional d'Amélioration du Territoire [Regional Land Use Plan]

TdE Togolaise des Eaux

TFPs Technical and Financial Partners

TOFE Tableau des Opérations Financières de l'Etat [Table of Government Financial Operations]

UNCDF United Nations Capital Development Fund

UNDP United Nations Development Programme

UNESCO United Nations Educational, Scientific and Cultural Organization

UNFPA United Nations Population Fund

UNICEF United Nations Children's Fund

UNS United Nations System

UTB Union Togolaise de Banque

WAEMU West African Economic and Monetary Union

WAMU West African Monetary Union

WB World Bank

WHO World Health Organization

WTO World Trade Organization 
The drafting of the Poverty Reduction Strategy Paper (PRSP), which was commenced in February 2001 in Togo, resulted in the adoption of an interim paper in March 2008. The directions followed in this paper, prepared by the Government with the participation of all components of the Togolese Nation and the technical and financial partners (TFPs), indicated the path towards national reconstruction and the resumption of cooperation with all development partners.

The same approach was followed for the preparation of the Full Poverty Reduction Strategy Paper (FPRSP) in order to refine the diagnosis of the economic and social situation and to propose further prioritized measures for better mobilization and better use of resources to achieve a marked reduction in poverty.

\section{CONTEXT AND METHOD FOR DRAFTING OF THE F-PRSP}

\section{Context for drafting of the F-PRSP}

The Interim Poverty Reduction Strategy Paper (I-PRSP) adopted by the Government in March 2008 allowed Togo once again to benefit from international financial cooperation. The Government requested and obtained from the International Monetary Fund (IMF) a three-year program under the Poverty Reduction and Growth Facility (PRGF). Agreements were concluded with bilateral and multilateral creditors on arrears clearance or debt restructuring and Togo reached the Heavily Indebted Poor Countries (HIPC) Initiative decision point in November 2008.

Because reaching completion point is the next crucial stage in the formulation of the strategic poverty reduction framework in Togo, the Government embarked on the preparation of the Full Poverty Reduction Strategy Paper (F-PRSP). Its implementation, through the Priority Action Program (PAP), will promote the interests of all the various development actors and thus enhance the synergy of sectoral and multi-sectoral measures to promote development and reduce poverty.

The F-PRSP drafting process had four (04) main goals: (i) refining of the diagnosis made in the Interim PRSP and adaptation of proposed measures to it; (ii) growth based on solid and sustainable foundations for the country; (iii) consideration of regional specificities in the poverty reduction strategy; and (iv) greater involvement of non-State actors.

Accordingly, the Government based this process on two principles: (i) broader and more autonomous participation of all development actors; and (ii) strengthening of the foundations laid by the interim poverty reduction strategy.

\section{Participatory approach in the F-PRSP drafting process}

The F-PRSP was drafted using a participatory approach, involving all development actors and all regions of the country, to promote ownership of the strategy by the local communities and, above all, by the people who are to implement it. There were thus three main levels of expanded consultation: (i) during the drafting and adoption of the road map for the process; (ii) during the diagnostic phase; and (iii) during the drafting of the F-PRSP and the consultations for its finalization. All the TFPs were therefore consulted at all these stages in order to facilitate implementation of the principle of alignment advocated in the Paris Declaration.

\section{ACHIEVEMENTS OF THE INTERIM PRSP}

The adoption of the Interim PRSP made a major contribution to the process whereby cooperation resumed with the entire international community. For instance, the Government prepared the Interim 
Plan of Priority Measures (IPPM) and the overall Medium-Term Fiscal Framework (MTFF) in order to improve fiscal programming of the priority measures resulting from the strategic objectives of the Interim PRSP.

With a view to improving political and economic governance, the Government continued the ongoing process of national reconciliation and political reform, strengthening of the rule of law and of the security of persons and property and implementation of institutional reforms. In the context of economic recovery, the Government introduced reforms designed to improve governance in nonperforming State enterprises and in the banking sector. It also embarked on rehabilitation of infrastructures and took action to promote the principal growth sectors and in particular agriculture. As regards development of social sectors, human resources and employment, efforts were made but much remains to be done to accelerate Togo's progress towards the MDGs. As regards monitoring and evaluation arrangements, the institutional framework has not been created, and this has adversely affected implementation monitoring.

\section{THE DIMENSIONS OF POVERTY IN TOGO}

\section{The poverty situation}

According to the various surveys, over 60 percent of the Togolese population lives below the poverty line. The incidence of poverty is very high in rural areas, where three households out of four are poor, as opposed to two out of five in urban areas. The regions hardest hit by poverty are the Savanes region (90.5 percent), the Centrale region ( 77.7 percent) and the Kara region (75 percent). Furthermore, poverty is strongly correlated with undernutrition to the extent that 64.2 percent of the poor community is undernourished.

These data from the 2006 QUIBB survey do not really reflect the current poverty situation, because of the outside shocks experienced by Togo including the rise in food prices in 2008 and floods in 2007 and 2008. The incidence of poverty probably increased by over 8.4 percent on average following the sharp price increases in 2008; growth was not strong enough to increase household earnings and offset the price increases.

\section{Situation with regard to the MDGs in Togo and issues to be resolved by 2015}

The second national report on progress towards the MDGs, validated in December 2008, concluded that at the current rate of progress of the indicators and by means of sustained efforts, only MDG goals 2 and 6 ("Achieve universal primary education" and "Combat HIV and HIV/AIDS") can be reached by 2015 . It is therefore unlikely that the other Goals will be reached by 2015 . However, they could be achieved later on, if certain issues could be resolved, including (i) consolidation of political dialogue and national consensus; (ii) mobilization of domestic and external resources; (iii) more efficient public spending; and (iv) institutional and human capacity-building.

\section{PILLARS OF THE FULL POVERTY REDUCTION STRATEGY}

The ultimate goal of the full poverty reduction strategy which the Government intends to implement, with the participation of all development actors and of the target population groups, is to achieve an effective and sustainable improvement in the people's living conditions by tackling the main causes of poverty. The full strategy is thus the logical outcome of the interim strategy and builds on its achievements. It therefore consolidates the foundations on which the country's recovery will be built.

In order to achieve this goal, the Government's action rests on four (4) strategic pillars: (i) improvement of governance; (ii) consolidation of the foundations of strong and sustainable growth; (iii) development of human capital; and (iv) reduction of regional imbalances and promotion of 
community development. These various pillars include cross-cutting topics relating to the environment, HIV/AIDS, gender and human rights.

\section{First pillar: Improvement of governance}

Following up on the consolidated governance efforts made since the signature of the Comprehensive Political Agreement (CPA) on August 20, 2006, this pillar provides for four (4) priority areas of intervention for the next three years: (i) improving political governance; (ii) promoting institutional governance; (iii) implementing administrative reform; and (iv) improving economic governance.

\section{Second pillar: Consolidation of the foundations of strong and sustainable growth}

This second strategic pillar reflects the Government's determination over the next three years to create new foundations for progressively strong, sustainable and sustained growth. For this purpose, nine (9) priority areas will channel growth-promotion actions. These priority areas are: (i) strengthening the structural reforms; (ii) improving the business environment; (iii) promoting sources of growth; (iv) developing infrastructures to support growth; (v) enhancing regional integration; (vi) effectively managing natural resources, the environment and the living environment; (vii) redistributing the fruits of growth; (viii) creating jobs; and (ix) promoting research.

\section{Third pillar: Development of human capital}

With this pillar, the Government intends to provide an effective response to the concerns of Togolese citizens whose poverty basically takes the form of inability to meet basic social needs: education, health, water and sanitation, food, etc. Activities will therefore focus on: (i) promoting the education and training system; (ii) developing the health system and health services; (iii) improving the nutritional level of the general public; (iv) improving access to safe water and to sanitation infrastructure; and (v) promoting gender equity and social protection.

\section{Fourth pillar: Reduction of regional imbalances and community development}

This pillar, which is a new strategic orientation compared with the objectives of the interim poverty reduction strategy, will take into account inter- and intra-regional imbalances which affect the incidence of poverty. The goal is to create suitable conditions for improving implementation of the poverty reduction strategy at the local level. The Government thus intends: (i) to improve local governance for effective participation of local organizations in the poverty reduction process; and (ii) to develop regional and local potential with a view to promoting local development and thus preventing the aggravation of inter- and intra-regional imbalances.

\section{MACROECONOMIC FRAMEWORK FOR THE STRATEGY}

The framework for the full poverty reduction strategy determines the profile of the macroeconomic aggregates compatible with the choices resulting from this strategy. On the basis of assumptions about developments in the global economic situation, the subregional economic environment and the national development context, it forecasts trends in the resources that can be mobilized to implement the strategy, the relevant priority expenditure and the expected overall results. This framework also takes into account the overall financing of the strategy, to be described in the Priority Action Program. The macroeconomic framework lists the major absorption risks for which solutions will have to be found if the framework is to be realistic and the measures planned under the full poverty reduction strategy are to be effective. 
The baseline scenario consisting of a medium-term reform strategy is based on: (i) resumption of growth; (ii) price stability; (iii) consolidation of public finances; (iv) a strong domestic contribution to the financing of the strategy; (v) alignment of resources with national priorities; (vi) sustainability of the balance of payments deficit; and (vii) control of money supply. The result would be growth rising from 1.7 percent in 2009 to 4.1 percent in 2011.

The alternative scenario for acceleration towards meeting the MDGs is based on additional amounts of Official Development Assistance (ODA) to be mobilized under the initiative of the Secretary-General of the United Nations for the MDGs in Africa, in connection with the commitment made by the G8 in Gleneagles to increase ODA to poor countries. It would result in higher growth rates over the period.

\section{Risk analysis and prospects for achieving the MDGs}

The reference scenario is based on very realistic targets, but certain risks may complicate its implementation. These risks are connected with: (i) exogenous shocks (natural disasters, lack of good climate conditions, volatility of world prices for agricultural products, higher oil prices, etc.); (ii) resource absorption capacity (cumbersome budgetary procedures, disbursement delays, capacity problems, etc.); (iii) quality of resource assignment; (iv) slow implementation of the various structural reforms, especially in the sectors of energy, roads and telecommunications; (v) pace of reforms to improve the business environment; and (vi) presidential elections without clashes and without violence.

The non-State actors: (i) civil society; (ii) the private sector; (iii) development partners; and (iv) beneficiaries must support the State and involve themselves in implementation, monitoring and assessment of the strategy.

The main constraints have been identified, and priority measures envisaged in order to eliminate them and to accelerate Togo's progress towards effective achievement of the MDGs.

\section{INSTITUTIONAL FRAMEWORK AND MECHANISMS FOR IMPLEMENTING AND MONITORING THE STRATEGY}

\section{Institutional framework}

The institutional arrangements planned for implementation of the strategy include: (i) the National Council for Development Policy and Poverty Reduction (CNPDLP); (ii) the Interministerial Committee Responsible for Poverty Reduction Strategies (CILSP); (iii) the Technical PRSP Steering Committee (CTP); (iv) the Permanent Technical Secretariat for the PRSP ((STP); (v) the Sectoral PRSP Committees (CS); (vi) the Regional Participatory Monitoring Committees (CRSP); and (vii) the Local Participatory Monitoring Committees (CLSP). The Government/Donor Committee and the Network of Civil Society Organizations are also involved.

The information system for monitoring and assessing the strategy has three subsystems for: (i) monitoring households' living conditions; (ii) monitoring programs and projects; and (iii) impact assessment.

\section{Improved production and dissemination of statistical information}

In recognition of the basic role of statistics in development and poverty reduction strategies, and in order to revitalize the national statistics system, the Government formulated a National Statistics Development Strategy (NSDS), validated on December 2, 2008, which gives pride of place to the Directorate General of Statistics and National Accounts (DGSCN) for the supervision and coordination of the production of statistical data. 


\section{Capacity-building}

In order to ensure the success of the institutional framework and of the mechanisms for F-PRSP monitoring and assessment, the Government intends to formulate a national capacity-building strategy to fill the glaring need existing in this area and thus create a framework conducive to effective and efficient implementation of the development projects and programs to be adopted under the Priority Action Program. 
This page intentionally left blank

\section{(CInternational Monetary Fund. Not for Redistribution}




\section{INTRODUCTION}

During the 1980s, Togo built up a world-class reputation as a business hub, mainly thanks to the country's commercial dynamism and export potential at that time. The following decade was marked by considerable political and social tension, which led the main development partners to suspend their financial cooperation with the country. Thus the economic and social situation deteriorated, hampering the national development process. As far as the demographic situation is concerned, the Togolese population was estimated at 5,598,000 inhabitants in 2008 (51.3 percent women and 48.7 percent men). ${ }^{1}$ The 2.4 percent rate of natural increase, compared with average growth of 1.1 percent during the previous decade ${ }^{2}$, is increasing the pressure of the public's demands for well-being.

In its quest for an appropriate response to the deterioration of the economic and social situation in the 1990s, the Government drafted an Interim Poverty Reduction Strategy Paper (Interim PRSP), with the participation of all the components of the Togolese Nation and of its Technical and Financial Partners (TFPs).

The directions followed in this paper indicated the path to national reconstruction and resumption of cooperation with all partners. The achievements of the Interim PRSP strengthened the actors' conviction about the need for a paper that would provide a basis for all the development measures adopted in Togo. Accordingly, the process of drafting the full Poverty Reduction Strategy Paper (FPRSP) was launched in order to refine the diagnosis of the economic and social situation and to propose more specific and better prioritized measures to facilitate their implementation.

This full paper is based on the assumption that the focus of the Interim PRSP is still relevant on the whole in light of the Togolese situation. However, the natural disasters and exogenous shocks experienced by the country in 2007 and 2008 perforce require a readjustment of national priorities. In addition, the new partnership framework resulting from the resumption of cooperation relating to the priority measures of the Interim PRSP reflects a stronger commitment on the part of the international financial community, going beyond its commitment to the interim strategy.

This full poverty reduction strategy, covering the period 2009-2011, is the result of a participatory exercise of strategic planning, in which all the components of Togolese society participated and which received sustained support from the Technical and Financial Partners. The strategic pillars and priority areas of intervention adopted reflect the long-term national development strategy based on the Millennium Development Goals (MDGs) adopted in 2007, along the lines of the social project of the Head of State and the Government Program adopted by the National Assembly on September 16, 2008 .

This full Poverty Reduction Strategy Paper is divided into six (6) chapters. The first chapter, on the drafting of the F-PRSP, describes the context, method, goals and principles of the drafting process, as well as the participatory approach adopted. Chapter 2 summarizes the achievements of the Interim PRSP. Chapter 3 concerns the dimensions of poverty in Togo as shown by the findings of the surveys conducted in 2006 (QUIBB, MICS, etc.). Chapter 4 describes the four (4) strategic pillars and the priority areas of intervention that will guide the action by the Government and its partners during the period 2009-2011. Chapter 5 relates to the macroeconomic framework and the financing of the strategy. Lastly, Chapter 6 concerns the institutional framework and mechanisms for implementation, monitoring and assessment of the strategy.

\footnotetext{
${ }^{1}$ It should be noted that the most recent general population and housing census in Togo dates from 1981.

${ }^{2}$ Period: 1998-2008.
} 


\section{CHAPTER 1: THE F-PRSP DRAFTING CONTEXT AND METHOD}

\section{THE F-PRSP DRAFTING CONTEXT}

With the Interim Poverty Reduction Strategy Paper (I-PRSP), adopted by the Government in March 2008, Togo laid the foundations for a resumption of international financial cooperation. In this connection, the Government requested and obtained from the International Monetary Fund (IMF) a three-year program under the Poverty Reduction and Growth Facility (PRGF). ${ }^{3}$ This opened the way for the country to accede to the Heavily Indebted Poor Countries (HIPC) Initiative. Satisfactory implementation of the PRGF and the conclusion of agreements on arrears clearance or debt rescheduling with multilateral and bilateral creditors enabled Togo to reach the HIPC decision point in November 2008.

Attention is now focused on reaching the completion point, which will be another crucial stage in the creation of the strategic poverty reduction framework in Togo. A number of triggers ${ }^{4}$ for reaching this point were agreed with the Bretton Woods institutions, including drafting and implementation of the Full Poverty Reduction Strategy Paper (F-PRSP), which is proving to be a way of channeling new measures for improved resource mobilization and utilization to achieve a considerable reduction in poverty.

The F-PRSP also provides the framework for accelerating the structural reforms designed to transform the bases of the national economy in order to enable the country to benefit from other important initiatives of the international community, and in particular the Multilateral Debt Relief Initiative (MDRI).

In addition, the F-PRSP will be the unifying framework within which the overall process of development planning will be refocused. The full strategy will consist of, firstly, a Priority Action Program (PAP) related to the sectoral and multisectoral planning and programming frameworks and, secondly, a Medium-Term Expenditure Framework (MTEF), related to the Sectoral Medium-Term Expenditure Frameworks (SMTEF). At the sectoral level, the planning outline will be reviewed from the angle of results-based management, so that the F-PRSP can be translated into operational planning instruments. The F-PRSP thus provides vast opportunities for consolidation of the national development process. Consequently, the full poverty reduction strategy will be the reference framework for all interventions by development actors (including the TFPs, in accordance with the principle of alignment advocated by the Paris declaration). ${ }^{5}$

\section{GOALS AND PRINCIPLES ADOPTED FOR THE DRAFTING OF THE F-PRSP}

Four main goals were pursued throughout the F-PRSP drafting process, namely:

- Refining of the Interim PRSP diagnosis and adaptation of measures to it;

- Growth based on solid and sustainable foundations for the country;

- Consideration of regional specificities in the poverty reduction strategy;

- Greater involvement of non-State actors.

\footnotetext{
${ }^{3}$ The main features of this program are described in the paragraph concerning the resumption of cooperation with all partners (Chapter 2).

${ }^{4}$ Key measures to be implemented as one of the main criteria for reaching the HIPC completion point.

${ }^{5}$ According to this principle, donors undertake to align themselves with national policy to finance development. The Paris Declaration sets out the main principles for cooperation between donor countries and partner (beneficiary) countries in order to ensure more effective management of development assistance.
} 
In order to achieve these goals, the Government adopted two principles that underpinned the F-PRSP drafting process: (i) broader and more autonomous participation of all development actors and (ii) building on the foundations laid by the interim poverty reduction strategy.

Broader and more autonomous participation. This principle takes into consideration two factors: (i) the current absence of political and social unrest; and (ii) the context of the Interim PRSP. In the first case, it is important for the Government to display complete willingness to implement the provisions of the Comprehensive Political Agreement. Participation in the dialogue at all levels was one of the key aspects of the Agreement.

Secondly, the Interim PRSP was a learning exercise that enabled the Togolese people to face the future with renewed confidence. Today, the initial progress towards restoring the basic conditions for harmonious national development has convinced people to believe in the new emerging order. In this way, the Interim PRSP has made Togolese citizens aware of the need to play an active part in the national development process.

Refining of the interim poverty reduction strategy. Implementation of the interim strategy revealed that some concerns of the Togolese people had not been sufficiently addressed. These relate to land use, promotion of tourism, redistribution of the fruits of growth, improvement of the business environment, reduction of inter-and intra-regional imbalances as regards development, etc. In addition, the country is faced with new challenges resulting from recent exogenous shocks: sharp increases in prices of essential goods (foodstuffs, cement, oil, etc.) and the flooding in 2008. These new challenges made it necessary to rethink certain priorities and thus to contextualize the components of the interim poverty reduction strategy. For this purpose, specific studies identified when the interim strategy was being drafted were conducted ${ }^{6}$ prior to the drafting of the F-PRSP.

\section{DESCRIPTION OF THE PARTICIPATORY APPROACH TO THE F-PRSP DRAFTING}

A participatory approach was adopted for the drafting of the F-PRSP, involving consultation of actors involved in all the components of economic and social life, reflecting all points of view and representing all the regions of the country. In addition, the paper was drafted in a spirit of ownership of the strategy by the local communities and, above all, by the actors who are to implement it.

All stages of the process were open to all development actors. For example, there were three main levels of expanded consultation. The first level coincided with the preparation of the road map for the process, the second occurred during the diagnostic phase and the last level consisted of consultations to finalize the F-PRSP in order to ensure ownership by the various actors. All the TFPs were consulted at all stages of this process in order to facilitate implementation of the principle of alignment embodied in the Paris Declaration.

\subsection{First level of expanded consultation}

Preparation of the road map. Once the PRSP technical steering team had agreed on the basic contents of the road map, four preliminary consultations were organized: the first with senior administration officials, the second with the private sector, the third with civil society and the last with the TFPs. The idea was to discuss with them the rough outline to be followed for the process. Five more consultations were held in each of the country's economic regions for the benefit of all the development actors (and were attended by numerous representatives of the communities). These regional consultations were organized in order to brief grassroots development actors on the draft road map and to awaken their interest so as to ensure their effective involvement in the process. The opinions expressed during the various consultations were taken into consideration in the drafting of the

\footnotetext{
${ }^{6}$ The studies were on the following topics: 'Sources of growth and business environment in Togo', 'Contribution of civil society organizations to poverty reduction in Togo', 'Assessment of Government action to reduce poverty', 'Evaluation of public finances using PEFA methodology', 'PRSP communication strategy in Togo'.
} 
road map which was submitted for discussion and adoption at the national forum launching the FPRSP drafting process in May 2008.

Organization of the national forum launching the F-PRSP drafting process. Chaired by the Prime Minister, the forum was attended by heads and senior officials of the administration and of the institutions of the Republic and by non-State actors, including representatives of trade union organizations, the private sector and civil society in all its diversity: non-governmental organizations, development associations, grassroots organizations, etc. The TFPs also participated in this forum.

\subsection{Second level of expanded consultation}

Diagnosis. This consultation had two dimensions. The first concerned the work of the thematic drafting groups ${ }^{7}$ composed of representatives of the administration, civil society and the private sector. The TFPs also participated in the work of these groups. The goal of this first consultation was to reach the broadest possible consensus regarding the major topics of development, identifying and combining the concerns and sectoral priorities of all strata of Togolese society. Specific workshops ${ }^{8}$ were also organized for the benefit of the thematic groups in order to ensure that they included in their work cross-cutting concerns such as gender, human rights, HIV/AIDS and the environment.

The second dimension of this level of expanded consultation concerned the independent contributions ${ }^{9}$ of all components of civil society and the private sector.

In addition, each region was asked to ensure that its contribution took into account regional specificities, so that the full poverty reduction strategy did not lose sight of the spatial dimension of development.

Drafting of the strategy. On the basis of the reports of the thematic groups, the independent contributions of civil society and the private sector, the regional contributions and other key documents of nation-wide significance, a drafting team was established to produce the preliminary version of the F-PRSP. It was composed, in equal numbers, of representatives of the administration and of civil society, the private sector and resource persons. The TFPs also provided technical assistance during this drafting phase. ${ }^{10}$ In addition, resource persons made available by certain TFPs reviewed the initial version of the paper in order to check that cross-cutting concerns relating to the environment, HIV/AIDS, gender and human rights had been covered.

\section{Box 1: Methodology followed for the independent contributions of civil society and of the private sector}

For the independent contribution of civil society, the civil society organizations (CSOs) established a 15-member coordinating group with an executive committee of five persons. In accordance with their action plan, working meetings were held with the PRSP Coordination Unit. These working meetings enhanced the capacity of the coordination group, so that it was better able to understand the PRSP context and the issues at stake, as well as the importance of the participation of civil society in the process. For example, there was a sharing of experience with the President of Social WATCH of Benin on the participation of Beninese civil society in the PRSP process in their country. With financial assistance from UNDP, six consultants (one for each region and one for Lomé) were made available to the coordination group to help it with the exercise throughout the territory. After a discussion with these consultants on priorities, central themes were identified on which the consultations should focus. On the basis of these guidelines, the instruments for data collection and the work methodology were determined. Prior to the collection phase, a one-day information and briefing session was organized for CSOs in the chief town of each of the

\footnotetext{
${ }^{7}$ The work of the thematic drafting groups (eight in number) concerned the following topics: promotion of good governance; social sectors and employment; growth promotion; private sector and improvement of the business environment; land use and decentralization; environment and living environment; agriculture; poverty and targeting. The work was facilitated by resource persons made available by UNFPA and UNDP.

${ }^{8}$ With technical and financial support from UNDP, UNICEF, UNAIDS and UNESCO.

9 All the intrinsic deliberations of civil society organizations and private sector actors on their own perception of the country's problems of socio-economic and sustainable development, separately from their participation in the work of the thematic drafting groups for the full PRSP of which they are members.

${ }^{10}$ In particular the resident missions of the World Bank, UNICEF and WHO.
} 
regions. For data collection, three focus groups were set up in each prefecture. An individual interview with certain leaders identified from among the focus groups and the population completed the sample basis. After data collection, regional workshops were held to inform the CSOs of the results and validate the proposed measures. Following these regional workshops, the data were collated on a nation-wide basis. The result was a national report which, after amendment by the coordination group, was validated at a national workshop.

The independent contribution of the private sector was prepared using a methodology reflecting the principles of the participatory approach followed in the road map for the drafting of the full poverty reduction strategy. This contribution was to provide: (i) a diagnosis reflecting the private sector's perception of the problems affecting the country and describing the concerns of the socio-professional groups concerned; (ii) proposals for measures to remedy this situation; (iii) the role and responsibility of each actor for implementation of these measures; and (iv) specific progress indicators for the emergence of the private sector in Togo. About a dozen national corporations in the private sector were mobilized. Fifteen (15) delegates from all the corporations formed a national committee for the independent contribution to the F-PRSP and set up a four-member national bureau to coordinate the work. In order to ensure proper monitoring of the regional contribution, a regional bureau of four members (the same membership as the national bureau) was set up in the five economic regions. With financial support from UNDP, the National Committee engaged the services of as national consultant to help it to formalize its contribution. In order for the concerns of each corporation to be accurately reflected, the coverage of the diagnosis had to be defined in advance. The Coordination Committee for the private sector contribution thus decided on seven (7) central themes that best reflect the concerns of the various corporations in the private sector. The contribution is formalized in a document divided into two main parts (private sector diagnosis, proposed measures) and a logical framework (annexed) reflecting the progress indicators and the allocation of roles and responsibilities among the main actors. Each part of the document, and the logical framework, is divided into seven chapters or areas, based on the central themes. In the second part, each chapter is followed by a box highlighting the concerns expressed forcefully by the private sector actors in the field during the regional consultations which preceded the national validation.

\subsection{Third level of expanded consultation}

Finalization of the strategy. Once the first draft of the F-PRSP had been prepared, regional and national consultations were organized on the preliminary version in order to enlist the support of the public for the strategic choices, priority areas of intervention and relevant actions. These consultations provided an opportunity both for the public to take ownership of the content of the strategy and for the drafting team to ensure that the full paper actually reflects the wishes of the public. Similarly, consultative workshops were also organized with the National Assembly and the TFPs. In the case of the National Assembly, deputies urged that all development sectors should be taken into account, since the people whom they represent have diversified and complex expectations. The TFPs were mainly concerned about the need for consistency between sectoral needs and the full poverty reduction strategy. They also made specific contributions to clarify the priority areas and corresponding measures.

National validation and adoption of the F-PRSP. After incorporation of the comments made on the preliminary version of the paper during the various consultations, the draft of the full poverty reduction strategy was submitted to a national validation workshop chaired by the Prime Minister. In accordance with the provisions of the road map for the F-PRSP drafting process, this workshop was attended by all development actors, including representatives of Government, the institutions of the Republic, the private sector, civil society, trade unions and technical and financial partners. After this last level of national consensus, the paper was submitted to the Council of Ministers, which adopted it in May 2009. 


\section{CHAPTER 2: ACHIEVEMENTS OF THE INTERIM PRSP}

While implementation of the November 2004 version of the Interim PRSP was very limited in a context of scarce resources, particularly assistance from outside partners, the version adopted in March 2008 became the linchpin of all the recovery and national reconstruction efforts made by the Government with donor support. This chapter describes the main processes launched by the Interim PRSP, thanks to which considerable progress has been made in macroeconomic and structural reforms. It also briefly reports on the implementation status of the interim strategy.

\section{MAIN PROCESSES LAUNCHED BY THE INTERIM PRSP}

The adoption of the Interim PRSP in March 2008 made a considerable contribution to the process of resumption of cooperation with the whole international community. To this end, the Government devised implementing instruments (the Interim Plan of Priority Measures (IPPM) and the overall Medium-Term Fiscal Framework (MTFF)) to improve the fiscal programming of the priority measures resulting from the strategic focus of the Interim PRSP.

The Interim Plan of Priority Measures. This was drawn up as part of the preparations for the Conference of Togo's Development Partners, held in Brussels in September 2008. A precursor of the sectoral Medium-Term Expenditure Frameworks (MTEF), its purpose was to highlight the measures to be adopted as a matter of priority over the period 2008-2010, targeting a number of key sectoral components: health, education, water and sanitation, agriculture, road infrastructure, energy, social action, administrative reform, and democratic and economic governance. Within these priority sectors, it identified the most urgent and the most crucial measures to revitalize the sectors, while respecting the limits of the macroeconomic framework of the Interim PRSP, which defined a global envelope of expenditure compatible with maintenance of the principal macroeconomic balances. One major difficulty for the IPPM was the lack, in certain sectors, of well-formulated programs closely reflecting the thrust of the Interim PRSP.

The Medium-Term Fiscal Framework. In order to give concrete expression to its desire to equip the interim poverty reduction strategy with modern implementing instruments, the Government conducted a process of fiscal consultation culminating in the adoption of a Medium-Term Fiscal Framework. This instrument is based on the macroeconomic framework of the Interim PRSP, establishing an overall expenditure envelope to be divided between the main priority sectors over three (3) years. It also indicates the priorities to be covered by each sectoral envelope in order to provide guidance for preparation of the State budget. For the first time, in 2008, the MTFF is part of the documentation accompanying the draft budget law transmitted to the National Assembly.

The process of resumption of cooperation with all partners. The methodical negotiations which the Government conducted with all Technical and Financial Partners with a view to reaching agreement on the various programs were based on the Interim PRSP.

The three-year program under the Poverty Reduction and Growth Facility (PRGF) agreed with the International Monetary Fund in April 2008 reflects the focus of the Interim PRSP and emphasizes maintenance of a stable macroeconomic framework through transparent management of public finance, fiscal consolidation, reform of the main public enterprises and infrastructure rehabilitation. This program provides a loan of US\$108 million on concessional terms.

Concurrently with the discussions under the PRGF program, negotiations were held with the World Bank to obtain an Economic Recovery and Governance Grant (ERGG), based on the Interim Strategy Note, which reflects the areas covered in the Interim PRSP. As announced in the Interim PRSP, the three action pillars in the Interim Strategy Note are: improvement of economic governance and 
transparency, promotion of economic recovery and sustainable development and response to urgent social needs. The ERGG enabled Togo to clear its payment arrears to the World Bank and to receive budget support in a total amount of about US\$150 million. This operation was conducted with the help of the French Development Agency, which agreed to make a bridge loan to Togo for clearance of arrears to the World Bank.

Discussions similar to those held with the World Bank were initiated with the African Development Bank (AfDB) with the goal of clearing Togo's arrears to that institution in the amount of about US\$20 million. This operation was conducted by means of a grant from the AfDB under the facility to assist fragile States and cleared 99 per cent of the arrears owed by Togo. The remaining arrears were cleared thanks to a grant from France to respect the "pari passu clause". ${ }^{11}$ The AfDB also drafted an Interim Country Strategy Paper (I-CSP) based on the Interim PRSP and focused on two main areas: governance and capacity-building, infrastructure rehabilitation or reconstruction.

Other operations for clearance of payment arrears to multilateral and bilateral creditors were performed on the same occasion and are part of the process of resumption of cooperation with all partners. As regards multilateral creditors, an operation was conducted with the European Investment Bank with European Development Fund financing. Arrears owed to the International Fund for Agricultural Development, the Islamic Development Bank and the Arab Bank for Economic Development in Africa were dealt with in the same way. As far as bilateral creditors are concerned, a meeting was held on June 12, 2008 in Paris with creditors that are members of the Paris Club. The Togolese debt was dealt with under the Naples terms, resulting in cancellation of two thirds of the payment arrears and current maturities and rescheduling of the remainder over a period of 23 years, with a five-year grace period.

All these arrears clearance operations are essential prerequisites for the full resumption of cooperation with the partners and are also part of the process whereby Togo qualifies for the Heavily Indebted Poor Countries (HIPC) Initiative. The satisfactory review of the PRGF program in September 2008 launched the decision point process under that Facility. Decision point was reached on November 25, 2008 following the meetings of the Boards of Governors of the International Monetary Fund and the World Bank.

\section{STATUS OF IMPLEMENTATION OF THE INTERIM STRATEGY}

Implementation of the Interim PRSP started about 12 months ago; this appears to be sufficient for an assessment to be made. However, it is difficult at this stage to give an exhaustive progress report, for at least two reasons. The first is that the process of preparing a progress report has not yet been initiated because there is no comprehensive institutional framework with respondents at the sectoral level for rational and methodical compilation of information on the status of the measures envisaged. ${ }^{12}$ The second reason is that the implementation instruments (IPPM, MTFF) were not properly designed (with specific programs and monitoring indicators) for systematic incorporation in the budget programming to permit organized monitoring.

Consequently, the progress report given here covers measures taken by the Government in the priority areas identified in the interim strategy. It should be noted that, in 2008, the macroeconomic situation was characterized by an unfavorable context dominated by the persistence of the energy crisis, which curtailed business activity for part of the year, the scope of the food crisis, which resulted in a sharp average price increase of 8.4 percent compared with the preceding year, and continuing floods, which

\footnotetext{
${ }^{11}$ Under this clause, debtor countries accord the same treatment to all multilateral donors.

${ }^{12}$ As at the end of December 2008, the institutional framework envisaged under the I-PRSP had not yet been established. The former institutional framework (with no valid sectoral entities to take over) is doing its best to manage the daily activities of the PRSP process. Consequently, not all the accounts at the national level have yet been closed at the time when the FPRSP is being prepared, in order to facilitate assessment of implementation in 2008. This explains the lack of accurate statistics on progress made in 2008. The first progress report to be prepared during 2009 will give a more complete picture of implementation of the interim strategy in 2008 .
} 
caused the collapse of the main bridges on the principal national artery. The combined effect of these shocks was largely responsible for the deterioration of the macroeconomic framework in 2008.

\subsection{Improvement of political and economic governance}

For the component relating to political governance, the priority areas selected are continuation of the process of national reconciliation and political reforms, strengthening of the rule of law and of the security of persons and property, and implementation of institutional reforms.

In the area of national reconciliation, major progress has been made since the signature of the Comprehensive Political Agreement in August 2006. The Government of National Union established under this Agreement managed to organize the early legislative elections of October 2007, thus involving several political parties in the management of public affairs. In addition, a national consultation was conducted, with partners' support, for the creation of a national commission on justice, truth and reconciliation. Similarly, considerable efforts were made for the return to Togo of most of the persons who had sought refuge in neighboring countries after the violence that followed the presidential elections of April 2005. ${ }^{13}$ Some noteworthy progress was also made in the area of political reforms, and particularly the drafting of an opposition statute, adoption of the law on the financing of political parties, reorganization of the Constitutional Court, reorganization of the National Human Rights Commission, etc.

As regards the strengthening of the rule of law and the security of persons and property, significant progress was made in the promotion of human rights and individual freedoms. The National Program for Promotion and Protection of Human Rights was launched with the creation of a unit for the management and organization of regional information and briefing workshops on human rights questions.

With regard to institutional reforms, the National Program for the Modernization of Justice made major progress, including most recently the creation of a legislation and jurisprudence database giving citizens access to the country's laws, regulations and jurisprudence. For the modernization of the administration, a national strategic framework was adopted.

In the area of economic governance, considerable progress was made towards greater transparency in the management of public finance, anti-corruption measures and coordination of official assistance.

For public finance management, the Government has taken steps to reflect the WAEMU directives in national legislation. ${ }^{14}$ Measures have been taken to improve transparency in revenue mobilization and public expenditure management. In addition, the Government has embarked on implementation of the recommendations of PEMFAR and PEFA, ${ }^{15}$ held in 2008 in Togo.

As far as revenue is concerned, reforms have been introduced in the fiscal and customs administration to enhance revenue collection controls. For example, within the Directorate General of

Taxation, the reform consisted mainly of the creation of a Research and Verification Directorate and of a Directorate for Organization and Monitoring of Services; automation of tax return processing and of accounting with a more logical classification of enterprises into three tax categories (large, mediumsize and small enterprises); simplification of taxation and of the procedures applicable to small and medium-size enterprises and streamlining of tax return procedures for medium-size and large taxpayers. In addition, a reform steering committee was created. For the customs administration, improved automation of the main customs offices is resulting in better codification of customs

\footnotetext{
${ }^{13}$ Report of the High Commissioner's Office created for this purpose.

${ }^{14}$ In particular, Decree No. 2008-091/PR of July 29, 2008 establishing general rules on government accounting, orders Nos. 243 and 244/MEFP/CAB of December 20, 2001 concerning, respectively, the State accounting plan, budget nomenclature and adoption by Parliament of the Organic Law on public finance laws.

15 PEMFAR: Public Expenditure Management and Financial Accountability Review; PEFA: Public Expenditure and Financial Accountability
} 
exemptions, better monitoring of the itinerary of goods in transit and introduction of a system of customs valuation.

With regard to public expenditure, spending under exceptional procedures has been practically eliminated, at the same time allowing extrabudgetary expenditure to be limited. In addition, improved cash management and more careful monitoring of budget execution have made it possible to stabilize the primary fiscal balance and eliminate accumulations of domestic payments arrears. In addition, some progress has been made in improving the procurement system in Togo. Evaluation of the whole system in the light of OECD indicators showed that the procurement process did not meet international standards. The reforms introduced in this area resulted in the drafting of a new "Code of government procurement and delegation of public services" supported by a law on government procurement. In addition, to achieve better fiscal management, the Government centralized preparation of the State budget (operating and investment budget) under the responsibility of the Budget Directorate reporting to the Ministry of Economy and Finance. It also embarked on the introduction of the Integrated System of Public Finance Management (SIGFIP) for the preparation and execution of the State budget. Similarly, the revenue collection agencies (régies financières) are being automated in order to improve their performance. To strengthen controls, the Government created the General Inspectorate of Finance and trained staff of the Directorate General of Treasury and Public Accounting in management reporting.

With regard to jurisdictional monitoring of accounts, establishment of the Audit Office was delayed because of preliminary measures connected with the preparation of management accounts and administrative accounts which constitute the raw materials for the Audit Office. During 2008, accounts were prepared for 2007 management. The way has now been cleared for the Audit Office to become operational. An action plan has been adopted for this purpose. In addition, following the audit of the domestic debt, the Government adopted a strategy for its clearance.

As regards anti-corruption measures, the shelving in 2005 of the proposal for the National Commission to combat Corruption and Economic Sabotage was a factor that blunted the Government's action in this area. The process is now reactivated with the adoption of the anticorruption law by Parliament and the official launch of the anti-corruption campaign. For this purpose, Parliament ratified the United Nations and African Union Conventions and the ECOWAS Protocol Against Corruption. In addition, in order to combat money laundering and terrorism financing more effectively, the National Financial Intelligence Unit has been established. 
Despite this progress in the area of government finance reforms, much remains to be done in order to: (i) reduce discrepancies between expenditure forecasts and actual expenditure, ${ }^{16}$ (ii) bring the mechanism for determining domestic payment arrears into line with the WAEMU provisions; (iii) improve budget nomenclature so that it covers analysis needs; (iv) ensure complete traceability of grant operations in the budget adopted and in the budget execution reports; (v) launch the budget preparation cycle as early as possible so as to give ministries, departments and decision-making agencies time to prepare their draft budgets; (vi) ensure complete consistency between investment budgets and medium-term expenditure forecasts; (vii) improve management of the annual cash flow plan to achieve flexible budget execution spread over time; (viii) make procurement arrangements more transparent and less centralized; (ix) improve the visibility of the units providing primary services from their budget allocations; and (x) improve, in light of the budget adopted, the content of budget execution reports. ${ }^{17}$

\subsection{Consolidation of the process of economic recovery and promotion of sustainable development}

In order to promote economic recovery, the Government has introduced several reforms designed to improve governance in State enterprises in difficulty. To this end, the Société des Phosphates $\mathrm{OTP} / \mathrm{IFG}^{18}$ was disbanded and replaced by the Société Nouvelle des Phosphates du Togo (SNPT). The Government has commenced negotiations with a view to obtaining from the partners the resources needed for equipment replacement in order to increase production and take advantage as much as possible of the favorable rates on world markets.

In the case of the Société Togolaise de Coton (SOTOCO), the audit found poor governance of the enterprise. The measures taken in the cotton sector concern clearance of the arrears owed by the enterprise to producers and to the banking system. A new enterprise ${ }^{19}$ has been created with producer participation in its capital.

As regards the banking system, the Government has taken measures to promote the recovery of distressed banks. The Banque Togolaise pour le Commerce et l'Industrie had been under provisional administration since February 2008 in order to implement a restructuring and privatization plan, in accordance with the recommendations of the WAMU Banking Commission. In addition, after the withdrawal of the Belgolaise bank from the Banque Internationale pour l'Afrique (BIA-Togo), the share of this leading bank was transferred to the State for the symbolic sum of one franc and a new management was put in place to implement a restructuring and privatization plan. In addition, a process of securitization of the banking system's non-performing loans has been initiated. It consists in issuing by Government bonds to replace non-performing loans owed to State banks and private banks by public enterprises. These bonds will be reimbursed by the State over a period of seven years. So that these bonds do not overburden the banks' portfolios, authorization for their refinancing was obtained from the Board of Governors of the Central Bank of West African States.

Efforts have been made to make the Autonomous Port of Lomé more competitive. After handling operations were transferred to private operators, the customs authorities installed a scanner to facilitate goods clearance operations. In addition, there are projects for the construction of a third dock and a basin. Agreements have been signed with partners for the implementation of these projects.

Lastly, in order to reduce the effects of the energy crisis on economic activity, the Government has granted subsidies to the Compagnie Energie Electrique du Togo (CEET) in order to enable it, firstly, to repay some of the arrears owed to the Communauté Electrique du Bénin (CEB) and, secondly, to

\footnotetext{
${ }^{16}$ Over the period 2006-2008, such discrepancies amounted to over 10 percent.

17 The data are available but the practice of supporting them with detailed and dynamic comments according to PEFA criteria has not been introduced or re-introduced.

${ }^{18}$ Office Togolais des Phosphates/International Fertilizer Group

${ }^{19}$ Nouvelle Société Cotonnière du Togo
} 
purchase electric generators. In addition, the Government has commenced construction of a new thermal power plant in the port zone (ContourGlobal project). This plant will initially run on diesel fuel and will eventually use gas to produce electricity.

Considerable efforts have been made to improve food security, including formulation and validation of the National Food Security Program (PNSA), to be implemented over the period 2008-2015. One of the goals of the PNSA measures is to promote the right to food by combating hunger.

As far as budget execution is concerned in the sectors of agriculture, transport and energy, operating expenditure execution rates have generally been satisfactory. On the other hand, execution rates for investment expenditure have been low, creating concern regarding achievement of the MDGs. The investment execution rate is 17 percent for the transport sector and only 2 percent for the energy sector. The agriculture sector had a high rate of 85 percent, but this is partly due to the small amount of resources ( 3 percent) allocated to this sector. Efforts must therefore be redoubled in the area of execution of investment expenditure, since at the existing rate chances of achieving the MDGs may be completely jeopardized.

In the area of sustainable development, the Framework Law on the Environment, establishing principles and provisions for the enhancement of sustainable development in Togo, was adopted in May 2008. This Law created the National Sustainable Development Commission and provides for the establishment of local sustainable development commissions. In order to implement the policy established by the Framework Law, a National Environmental Management Agency and a National Environment Fund were created to develop a sector financing strategy and mobilize resources. In addition, the Government has continued to engage in sustainable environmental management by implementing National Capacity-Building Self-Assessment (ANCR) projects to manage the environment and the National Action Program for Adaptation to Climate Change and by issuing the second national communication on climate change. In addition, in the context of implementation of the Hyogo Framework for Action, the national platform for disaster prevention and management was created.

\subsection{Development of social sectors, human resources and employment}

The main areas of intervention for this strategic objective are: promotion of the educational and training system; development of the health system and health care; improvement of the nutritional status of the population; improved access to safe drinking water and sanitation infrastructure; and promotion of gender equity and equality, employment, social protection and community development.

As regards education, the Government is engaged in finalizing a sectoral strategy paper for the period 2010-2020, with the priority objective of achieving Millennium Development Goal 2. With 66.1 percent of pupils completing the primary cycle and a gender parity index of 0.93 , Togo is in a better position than many countries of the subregion, but further efforts are needed. In order to improve the performance of the education system at the primary level, the Government rebuilt most of the schools destroyed by flooding in 2007 and 2008, gave 1,374 substitute teachers civil servant status, and recruited 2,015 new teachers for primary and secondary schools in 2008. In addition, starting in the academic year 2008-2009, schooling is entirely free of charge at public pre-schools and primary schools. The Government has also resumed initial teacher training with the re-opening of the Notsé Teacher Training School where 1,600 new teachers will be trained starting in 2009. A subsidy of over 200 million CFA francs for Local Initiative Schools (EDIL) supports training within under-privileged communities. As regards budget execution, the education sector had an execution rate of 106 percent in 2008. The execution rate for operating expenditure was 108 percent, but only 70 percent for investment expenditure. In order to achieve the MDGs for which the contribution of the education sector is important, there must be a quantitative and qualitative improvement in the execution of public investments in the sector. 
With regard to health, the National Health Development Plan (PNDS) for the period 2002-2006 and the new Plan for the period 2009-2013 provide for short-, medium- and long-term measures to upgrade the health system, improve maternal and child health and combat the diseases of poverty. The Government is committed to improving reproductive health and reducing mortality among children under five years of age, by improving the delivery of quality reproductive health services and improving reproductive health information and making it more available to the people concerned. These measures have resulted in a definite improvement in maternal and child health, thus setting Togo on a path to attain MDG 5 concerning the improvement of maternal health, even if the goal of child mortality reduction seems to be out of reach in view of the current situation in Togo. As regards budget execution, the execution rates for the 2008 budget for the health sector were 66 per cent and 96 percent respectively for investment expenditure and operating expenditure. The sector thus had an overall execution rate of 78 percent. In future, execution of investment expenditure must be truly improved in order to enable the country to reduce poverty and achieve the MDGs.

Subsequently, in order effectively to combat HIV/AIDS, leprosy and tuberculosis, Togo set up national programs (with five-year strategic frameworks) to combat those three diseases. Nationwide there has been a decrease in new HIV infections, particularly in the 15 to 24 age group, from 3.38 percent in 2006 to 2.80 percent in 2008. If these efforts are maintained, Togo could continue to reverse the trend and halt the spread of HIV by 2015.

With the goal of combating malnutrition, the Government has adopted measures to monitor the growth of children under five years of age, provide nutritional care, prepare a package of activities on good practices relating to child survival and development (feeding of infants and young children, good hygiene) and provision of micronutrient supplements. However, these efforts are insufficient and must be upgraded and extended to all regions, with special emphasis on a communities approach in order to reach as many people as possible.

For the water and sanitation sector, the investment expenditure execution rate was 61 percent in 2008. Efforts will need to be redoubled in order to remain on track to meet the MDG targets for the sector. Accordingly, budget execution should be a major concern, as regards both financial and physical execution.

With regard to employment, in March 2008 the Government recruited 704 health workers and in December the same year 4,000 new civil servants, including 35 persons with disabilities. It also approximately doubled the minimum wage, from CFAF13,757 to CFAF28,000.

As regards promotion of gender equity and equality, since the adoption of the national strategy for mainstreaming gender in the development sectors, the efforts made in 2008 resulted in: (i) validation of the national policy for gender equity and gender equality; (ii) the creation by decree of gender focal points in nine (9) key development sectors; and (iii) the training of senior officials and members of Parliament in gender-based planning and budgeting.

For the protection of children, the most noteworthy Government efforts were: (i) the adoption of Law No. 2007-017 of July 6 promulgating the Children's Code in accordance with the national legislation and the international conventions ratified; (ii) the holding of a nation-wide assembly on strategies for combating human trafficking, particularly trafficking of women and children; (iii) creation of a telephone hot line ${ }^{20}$ for child protection; (iv) ratification of the Hague Convention on Intercountry Adoption, which was added recently to the legal arsenal for the protection of children. Lastly, the Ministry for Social Action, Promotion of Women and Protection of Children and Elderly Persons has formulated a policy and strategic plan for the protection of children.

\footnotetext{
${ }^{20}$ Toll-free number 111, which users can call to request information or report children in difficulty.
} 
For the promotion of persons with disabilities, important progress has been made, including the ratification in 2008 of the Convention on the Rights of Persons with Disabilities.

As far as young people are concerned, the Government adopted a national policy on youth for the period 2008-2012 and has established a national platform, the National Youth Council.

\subsection{Implementation, monitoring and assessment mechanism}

The Interim PRSP specified that the institutional framework for implementing and monitoring the PRSP would include at the national level: (i) the National Council on Development Policy and Poverty Reduction (Conseil national des politiques de développement et de lutte contre la pauvreté); (ii) the Interministerial Committee Responsible for Poverty Reduction Strategies (Comité Interministériel chargé des stratégies de lutte contre la pauvreté, CISLP); (iii) a PRSP Technical Steering Committee (Comité Technique de pilotage du DSRP); and (iv) Sectoral PRSP Committees. In addition, there are to be two separate local levels: (i) Regional Participatory Monitoring Committees (Comités régionaux de suivi participatif); and (ii) Local Participatory Monitoring Committees (Comités locaux de suivi participatif).

These will all be assisted by a Permanent Technical Secretariat filling the need for a standing body equipped with substantial permanent expertise and capable of providing day-to-day coordination of all technical activities associated with the implementation, monitoring and assessment of the PRSP.

None of these bodies have yet been set up and the PRSP monitoring and assessment plan has not been formulated, although studies have been made on the process for making this arrangement operational. This is the main reason for the delay in preparing the report monitoring implementation of the Interim PRSP in 2008. Because of the failure to set up the sectoral committees in 2008, it was not possible correctly to monitor implementation of the priority measures of the Interim PRSP in the various sectors so as to draw the attention of those responsible to the risks and accurately calculate the values for indicators and analyze them appropriately. It should be noted that the lack of skilled personnel was largely responsible for the delay in implementing this institutional framework. In addition, the authorities have not really mastered modern instruments of planning, programming, budgeting and monitoring and assessment, so that the stakes involved in the establishment of the PRSP institutional framework are not always correctly perceived in the existing situation. 


\section{CHAPTER 3: THE DIMENSIONS OF POVERTY IN TOGO}

There are many dimensions to the phenomenon of poverty, and it does not lend itself to any single definition. In Togo, therefore, the measurement and study of poverty are based on three approaches: a monetary approach, a non-monetary approach and an approach based on people's perception of poverty.

The poverty diagnosis followed the same methodology as was used in the Interim PRSP. In the absence of new data from recent surveys, the approach followed was to refine the regional mapping of poverty by disaggregating it to the prefecture level in each region of the country. The poorest areas were targeted, taking into account the monetary and non-monetary aspects of poverty.

\section{The Monetary Approach to Poverty}

The results from the QUIBB survey conducted in 2006 do not really reflect the existing poverty situation because of the exogenous shocks affecting the country, in particular the rise in food prices in 2008 and the flooding of 2007 and 2008. This probably caused an increase in monetary poverty in general. The sharp price rises in 2008 (over 8.4 percent on average) undoubtedly caused poverty thresholds to rise in the regions. In addition, growth was not strong enough to increase households' revenue and offset the price increases. Consequently, per capita GDP fell by 1.4 percent in 2007 and by 0.8 percent in 2008 , causing the economic situation of households to become even worse.

Monetary poverty is reflected in consumption below a threshold considered to be the minimum for meeting basic needs. In Togo, poverty thresholds were calculated on the basis of the 2006 QUIBB survey for the five regions of the country and for the capital, Lomé, using methods based on food needs $(2,400 \mathrm{Kcal}$ per adult equivalent per day) and nonfood needs. These thresholds vary between CFAF154,853 and 179,813 per adult equivalent per year for the administrative regions, compared to CFAF242,094 in Lomé and its outskirts

Table 1: Poverty thresholds by region

\begin{tabular}{|l|c|c|c|c|c|c|c|}
\hline & Lomé & Maritime $^{21}$ & Plateaux & Centrale & Kara & Savanes & National $^{22}$ \\
\hline $\begin{array}{l}\text { Poverty threshold per adult equivalent } \\
\text { per year in CFAF }\end{array}$ & 242094 & 156115 & 154853 & 179813 & 155026 & 157294 & 242094 \\
\hline
\end{tabular}

Source: DGSCN, Poverty Profile 2006, based on the QUIBB survey

Regional price disparities explain the poverty threshold discrepancies between regions.

\subsection{The profile of monetary poverty nationwide}

On the basis of the poverty thresholds given above, the incidence of poverty is estimated at 61.7 percent of the population, or 3,242,257 individuals distributed among 545,486 households. Poverty is essentially rural: in the countryside, the incidence is 74.3 percent, accounting for 79.9 percent of the total poor population. In urban areas, the incidence of poverty is 36.7 percent, representing 20.1 percent of the total poor population. Generally speaking, the Savanes region is the poorest in the country, with an incidence of 90.5 percent, followed by the Centrale region (77.7 percent), Kara (75.0 percent), Maritime (69.4 percent), Plateaux (56.2 percent) and finally Lomé ( 24.5 percent).

\footnotetext{
${ }^{21}$ Maritime Region excluding Lomé-Golfe.

${ }^{22}$ The Lomé threshold is taken as the national poverty threshold. However, the incidence of poverty nationwide is not based directly on this threshold, but on the regional thresholds, determining the number of poor people in each region and, by aggregation, the number of poor people nationwide, which is then compared with the total population.
} 
It should be noted that, given their demographic weight, the Maritime and Plateaux regions alone account for 44.6 percent of the poor population.

Table 2: Incidence of monetary poverty by locality ( percent)

\begin{tabular}{|l|l|c|c|c|c|c|c|c|}
\hline \multicolumn{2}{|l|}{} & Lomé & Maritime & Plateaux & Centrale & Kara & Savanes & National \\
\hline \multirow{2}{*}{$\%$ of population } & 19.9 & 21.0 & 23.0 & 10.3 & 13.3 & 12.5 & 100 \\
\hline \multirow{2}{*}{$\begin{array}{l}\text { Incidence of } \\
\text { poverty ( \%) }\end{array}$} & Urban & 24.5 & 54.3 & 36.5 & 60.2 & 60.9 & 76.8 & 36.7 \\
\cline { 2 - 9 } & Rural & - & 71.1 & 60.2 & 84.0 & 80.0 & 92.4 & 74.3 \\
\hline & Overall & $\mathbf{2 4 . 5}$ & $\mathbf{6 9 . 4}$ & $\mathbf{5 6 . 2}$ & $\mathbf{7 7 . 7 7}$ & $\mathbf{7 5 . 0}$ & $\mathbf{9 0 . 5}$ & $\mathbf{6 1 . 7}$ \\
\hline \multicolumn{2}{|l|}{ Contribution to poverty } & 7.9 & 23.7 & 20.9 & 12.9 & 16.2 & 18.4 & 100 \\
\hline
\end{tabular}

Source: DGSCN, Poverty profile 2006, based on the QUIBB survey

Rural poverty is very pronounced in the Savanes, Centrale and Kara regions, where the incidences are 92.4 percent, 84.0 percent and 80.0 percent, respectively. It is relatively moderate in the Plateaux region, with an incidence of 60.2 percent, and in the Maritime region, where 71.1 percent of the rural population is poor.

Urban poverty follows almost the same trends as rural poverty in the various regions. It is much less severe in Lomé, where the incidence is 24.5 percent and in the Plateaux region (36.5 percent). The city of Lomé and the Plateaux region stand out in contrast to the other regions, where at least 50 percent of the urban population is poor, and particularly the Savanes region, where 76.8 percent of the urban population is poor. 
Chart 1: Incidence of poverty in Togo

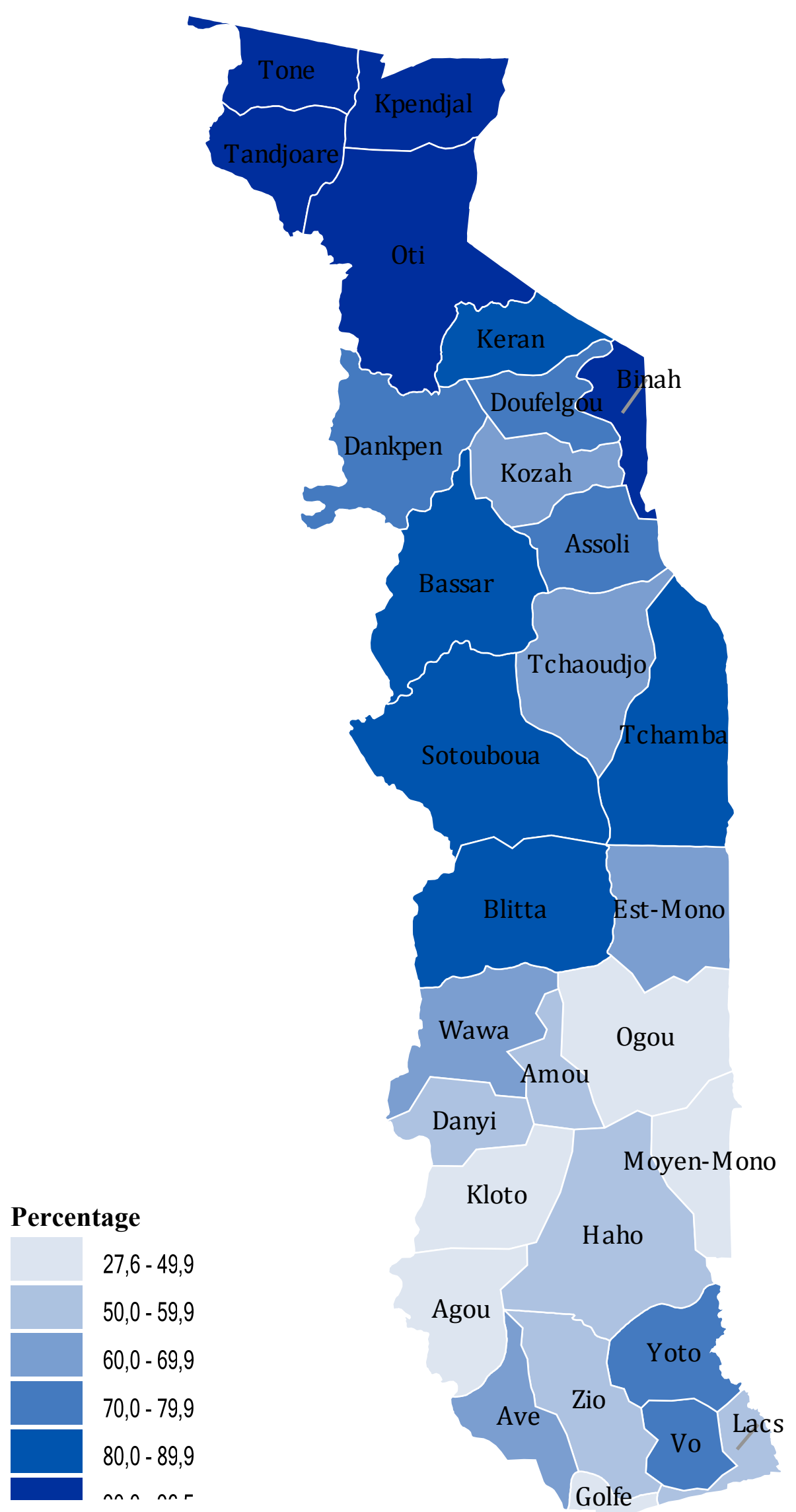




\subsection{Monetary poverty profile by region}

Monetary poverty in Lomé and its outskirts. Poverty affects 27.6 percent of the population of Lomé and its outskirts. This poverty is more marked on the outskirts of Lomé (Golfe prefecture), where the incidence of poverty is 39.3 percent, than in Lomé commune, where poverty affects 22.5 percent of individuals. The incidences of poverty in Lomé and its outskirts are well below the national average.

Monetary poverty in the Maritime region. The prefecture of Vo is the poorest prefecture in the Maritime region. Poverty there affects 76.3 percent of the inhabitants. Next come the prefectures of Yoto with an incidence of 74.8 percent, Avé (73.0 percent) and Zio (65.1 percent). The Lacs prefecture, with an incidence of 63.4 percent, is the least poor prefecture in the Maritime region.

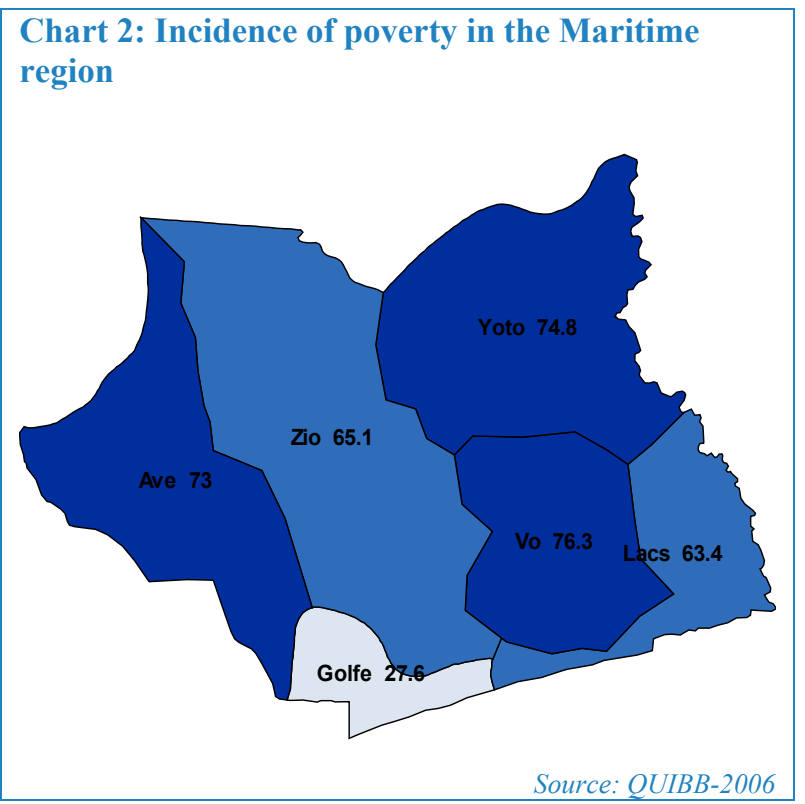

These incidences of poverty, combined with the demographic weight of the prefectures, show that it is also the prefecture of Vo that has the largest number of poor, since 26.8 percent of the region's poor are concentrated solely in this prefecture. On the other hand, the prefecture of Avé has the smallest number of poor, with 10.7 percent of the region's poverty.

Monetary poverty in the Plateaux region. Poverty affects 56.2 percent of the population of the Plateaux region, which is the least poor region after Lomé-Golfe. The prefecture of Wawa is the poorest in this region, with an incidence of 72.3 percent. It is followed by the prefectures of Est Mono (68.2 percent) and Amou $(60.0$ percent). Next come the prefectures of Haho with an incidence of 59.0 percent, Danya (58.5 percent), Moyen Mono (55.7 percent), and Ogou (51.4 percent). The prefectures of Agou and Kloto, with respective incidences of 49.5 percent and 42.1 percent, are the poorest prefectures in the Plateaux region.

\section{Chart 3: Incidence of poverty in the Plateaux region}

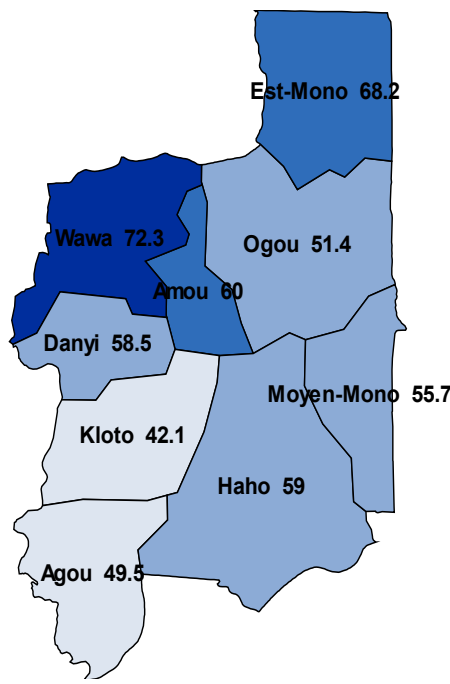

Source: $Q U I B B-2006$

In addition, considering the size of its population, the prefecture of Haho has the largest number of poor, accounting for 20 percent of the region's poverty. On the other hand the prefecture of Danyi, accounting for 3.7 percent of the region's poverty, is the prefecture with the smallest number of poor in the region.

Monetary poverty in the Centrale region. The Central region is the second poorest region in Togo, after the Savanes region.

The prefecture of Sotouboua, were poverty affects 85.2 percent of the inhabitants, is the poorest prefecture of the region. Next come the prefecture of Tchamba, with an incidence of 80.2 percent, and the prefecture of Blitta, with an incidence of 79.1 percent. Tchaoudjo 
is the least poor prefecture of the region, with an incidence of 69.2 percent.

Chart 4: Incidence of poverty in the Centrale region

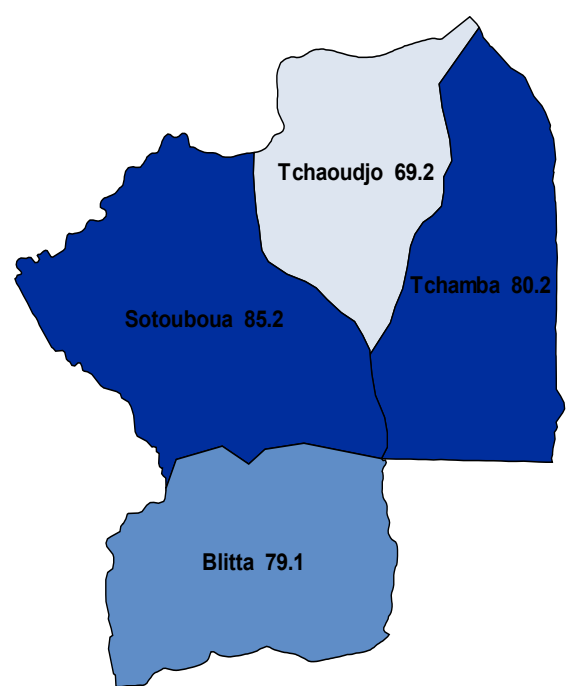

Source: QUIBB-2006

The prefectures of Tchaoudjo and Sotouboua, taking into account their demographic weight, are the ones which account for the most poverty in the Centrale region, each with almost 29 percent. The prefecture of Tchamba, accounting for 18.1 percent, is the prefecture with the smallest number of poor.

\section{Monetary poverty in the la Kara region.} The Kara region is the third poorest in Togo, after the Savanes and Centrale regions. The prefecture of Binah is by far the poorest prefecture in this region, with poverty affecting 87.1 percent of individuals. It is followed by the prefectures of Bassar, with an incidence of 81.3 percent, and Kéran, with an incidence of 80.5 percent. Next come the prefectures of Doufelgou (76.7 percent) and Dankpen (76.2 percent). The prefecture of Assoli, with an incidence of 73.4 percent, and the prefecture of Kozah, with an incidence of 65.9 percent, are the poorest prefectures of the region.

However, the largest number of poor is found in the prefecture of Kozah, considering the size of its population. This prefecture accounts for 27.8 percent of the poor of the region.
Chart 5: Incidence of poverty in the la Kara region

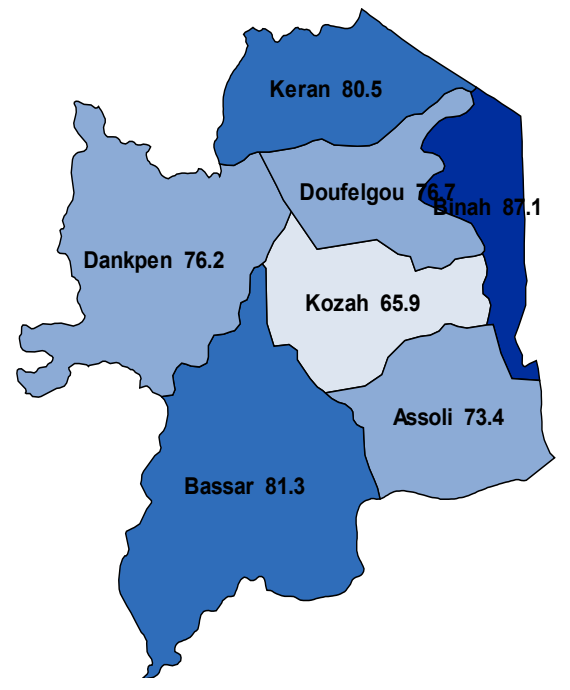

Source: QUIBB-2006

The prefecture of Assoli, accounting for 8.9 percent of the region's poverty, is the prefecture with the smallest number of poor.

Monetary poverty in the Savanes region. The Savanes region is by far the poorest region in the country, with an incidence of poverty estimated at over 90 percent. The prefecture of Kpendjal is the area with the most poverty in the region and in Togo, affecting 96.5 percent of the population. Next come the prefecture of Tandjoaré, with an incidence of 90.3 percent, and the prefecture of Oti, with an incidence of 89.3 percent. The prefecture of Tône is the least poor in the region, with an incidence of 88.4 percent.

In addition, considering its demographic weight, this prefecture has the largest number of poor in the region, accounting for 43.2 percent of the region's poverty; the smallest contribution to the region's poverty is made by the prefecture of Tandjaoré (13.9 percent). 
Chart 6: Incidence of poverty in the Savanes region

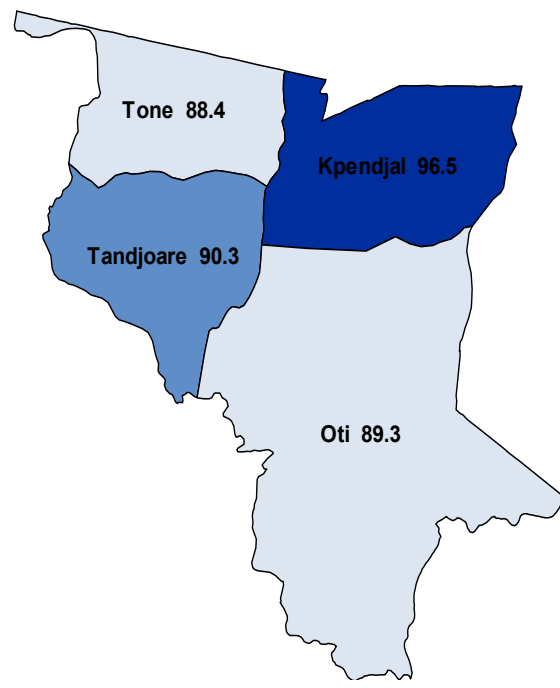

Source: QUIBB-2006

\subsection{Poverty and inequality}

Monetary inequality. The Gini inequality coefficient, ${ }^{23}$, calculated for Togo on the basis of the findings of the QUIBB survey, was 33.5 percent in 2006. Inequalities are nearly the same in urban and rural areas: the Gini indices are respectively 31.1 percent and 29.8 percent. However, inequalities between urban and rural areas are fairly high, and account for more than 53 percent of inequality at the national level. Inequality does not differ greatly from one region to another.

Inequality of access to basic services. As regards access to education, the distribution of public subsidies is not pro-poor. The poorest 20 percent receives the equivalent of CFAF5,607 in education subsidies per capita, while the wealthiest 20 percent receive CFAF10,376, or roughly double that amount, per capita.

Similarly, the distribution of public health subsidies is not pro-poor. The poorest 50 percent of the Togolese population receives only 20 percent of the public subsidies to teaching hospitals and 30 percent of the subsidies to hospitals and health centers. In

\footnotetext{
${ }^{23}$ Showing the extent of inequality within a population. It ranges from 0 to 100 percent. The higher the coefficient, the more inequality
}

rural areas, where about 80 percent of the poor population lives, health services are provided at clinics or health huts, which receive very few government subsidies.

An analysis of electricity services in Togo shows that the poor have very little access. Only 11.1 percent of poor people have access to electricity, compared with 42.9 percent of nonpoor. With regard to access to safe drinking water, the gap between poor and nonpoor is relatively smaller: 41.0 percent of the poor have access to safe drinking water, compared with 54.3 percent of the nonpoor.

\subsection{Poverty and vulnerability}

The analysis of the poverty profile reflects the situation at the time of the survey and cannot be used to forecast poverty trends in the medium and long term. The concept of vulnerability on which the analysis is based is defined as the present probability of remaining poor or of becoming poor in the future, regardless of the current situation. The simultaneous analysis of poverty and vulnerability can be used to distinguish the long-term poor, the short-term poor, the vulnerable nonpoor and the nonvulnerable nonpoor.

Using this classification, the vulnerability rate emerging from the findings of the QUIBB survey is 81.8 percent, distributed among the long-term poor (39.6 percent), the short-term poor (22.0 percent) and the vulnerable nonpoor (20.2 percent). This implies that, if no action is taken to improve living conditions in Togo, the poverty incidence could reach 81.8 percent.

The vulnerability rate is higher in rural areas (87.4 percent) than in the cities (71.0 percent). However, it is the urban nonpoor who are most vulnerable, with a rate of 34.2 percent compared with only 13.0 percent in the countryside. The low rate of urban poverty must be viewed in light of this greater vulnerability among the urban nonpoor.

The population group most vulnerable to poverty is children, who account for almost half of the population of Togo (48.2 percent). According to MICS 3, over half of these children are in difficulty because they live in poor households. The vulnerability of 
Togolese children is exacerbated by their lack of access to basic social services (health and education), as well as by practices such as migration or child trafficking and child labor resulting from households' strategic survival choices. Child labor is one of the most decisive factors in their vulnerability to poverty. In Togo, about 32 of every 100 children work, and the figure is naturally higher for children from poor households (36.3 percent compared with 17 percent for children from nonpoor households. The proportion of child workers is also higher in rural areas (36.9 percent) than in the cities (14.7 percent). However, the phenomenon is equally widespread among boys and girls.

Moreover, two important factors contributing to an increased rate of vulnerability to poverty must be taken into account. These are the prevalence of HIV/AIDS and natural disasters. Poverty is a decisive factor in behaviors that expose individuals to the risk of HIV infection, which in turn affects their productivity and causes and/or deepens poverty. In addition to HIV/AIDS, certain diseases such as leprosy and tuberculosis substantially increase vulnerability to poverty in Togo.

In addition, in the light of the experience of the last two years, analysis of the emergencies in Togo reveals the increasingly recurrent nature of certain disasters which, combined with the adverse effects of poverty, are creating an increasingly complex and alarming humanitarian problem. These disasters undermine the efforts made and cause the destruction of resources, sometimes acquired with difficulty. They are thus an important element of household vulnerability and a serious obstacle to the achievement of the Millennium Development Goals, particularly those concerning the elimination of extreme poverty and hunger.

\subsection{Determining factors of poverty}

The main determining factors of household poverty are place of residence, household size, health of the members and the household's factors of production. In addition, the education level, occupational category, sex, age and marital status of the head of household also influence households' poverty status.
Poverty is more widespread in rural than in urban areas and affects large households to a much greater degree. More than 90 percent of the poor are in households comprising at least ten persons, compared with only 24.5 percent in households with not more than three members.

The health or disability of household members, particularly the head of household, influences poverty status. In Lomé, a household with a disabled head is 17.2 percent more likely to be poor than a household with an able-bodied head.

Households' production factors, such as the amount of land and the number of cattle owned ,significantly affect the incidence of poverty in rural areas.

Access to education, health and transport infrastructure, as well as access to markets for agricultural products, have a definite influence on the poverty status of households, especially in rural areas.

The education level of heads of household, particularly female heads of household, has a positive impact on the household's standard of living. 63.9 percent of households where the head has no schooling are poor. On the other hand, the incidence of poverty is 44.9 percent for households where the head has completed primary school, 20.5 percent where the head has completed secondary school, and only 8.5 percent where the head has pursued postsecondary studies. In addition, the effect of education on households' poverty status is greater in rural than in urban areas. For example, a rural household where the head has completed primary school is 50 percent less likely to be poor than an urban household where the head has the same schooling.

An analysis of poverty by occupational category shows that people living in households headed by independent farmers are more affected by poverty, with an incidence of 78.8 percent, followed by people living in households where the head is "inactive or unemployed", with a poverty incidence of 55.2 percent. The persons least likely to be poor are wage-earning or salaried employees in the public and private sectors, in which categories the poverty rates are 38 percent and 37 percent respectively. 
The poverty incidence is higher among households headed by men than among those headed by women: 51 percent of the former are poor, compared to 34.8 percent of the latter. Households with younger heads are relatively less likely to be poor than those headed by older persons. For example, the poverty incidence is 27.7 percent among households where the head is 15-30 years of age, compared with 49.8 percent and 56.6 percent, respectively, when the head is in the 31-55 age bracket and is over 55. Lastly, households where the head is polygamous have a higher poverty rate (63.9 percent) than monogamous households (49.9 percent); households headed by a widow or widower have an incidence of 42.2 percent, whereas households headed by a separated or divorced person and those where the head has never married have a lower poverty incidence (23.4 percent and 12.6 percent respectively).

\section{The Non-Monetary Approach to Poverty}

Non-monetary poverty refers to households' living conditions and wealth. In view of the data available, only aspects related to education, health, water and sanitation are considered. For each of these aspects, a regional comparison is first made. The disparities within each region are then highlighted.

\subsection{Education}

Education is a determining factor of poverty. The analysis of school enrollment is based on the gross enrollment ratio and the gender parity index. The former measures the capacity of an education system to educate school-age children and the latter reflects girls' enrollment compared with that of boys.

\section{Nationwide}

The gross enrollment ratio nationwide is 112 percent and the parity index is 0.92 . This shows, firstly, that the existing education system has the capacity to enroll all school-age children and, secondly, that slightly fewer girls are enrolled than boys.

An analysis of enrollment indicators for the academic year 2006-2007 shows that the highest gross enrollment ratio at the primary level is found in the Centrale region (125 percent). On the other hand, the Savanes region has the lowest rate (96 percent).

The Maritime region has the highest gender parity index (1.06). The Savanes region has the most serious female enrollment problem, with the lowest parity index (0.77).

Table 3: Gross enrollment ratio by region

\begin{tabular}{|l|c|c|c|c|}
\hline \multirow{2}{*}{ Region } & \multicolumn{3}{|c|}{ Gross enrollment ratio (\%) } & \multirow{2}{*}{$\begin{array}{c}\text { Parity } \\
\text { index }\end{array}$} \\
\cline { 2 - 4 } & Girls & Boys & Total & \\
\hline Lomé - Golfe & 104 & 127 & 114 & 0.82 \\
\hline Maritime & 126 & 119 & 122 & 1.06 \\
\hline Plateaux & 103 & 106 & 105 & 0.97 \\
\hline Centrale & 122 & 128 & 125 & 0.95 \\
\hline Kara & 104 & 115 & 110 & 0.90 \\
\hline Savanes & 83 & 107 & 96 & 0.77 \\
\hline Nationwide & $\mathbf{1 0 7}$ & $\mathbf{1 1 6}$ & $\mathbf{1 1 2}$ & $\mathbf{0 . 9 2}$ \\
\hline
\end{tabular}

Source: Annuaire des statistiques scolaires 2006-2007

\section{Regional}

The available data do not allow analyses disaggregated between the commune of Lomé and the Golfe prefecture.

Maritime region. The prefecture of Yoto has the highest gross enrollment ratio (129 percent). Next come the prefectures of Zio (123 percent) and Vo (122 percent). The lowest gross enrollment ratios are found in the Lacs (120 percent) and Avé (114 percent) prefectures.

On the other hand, in the prefecture of Avé girls' enrollment is relatively higher (gender index of 1.16), while the lowest parity index is found in the prefecture of Yoto (about 1.00). 
Chart 7: Gross enrollment ratios in the Maritime region

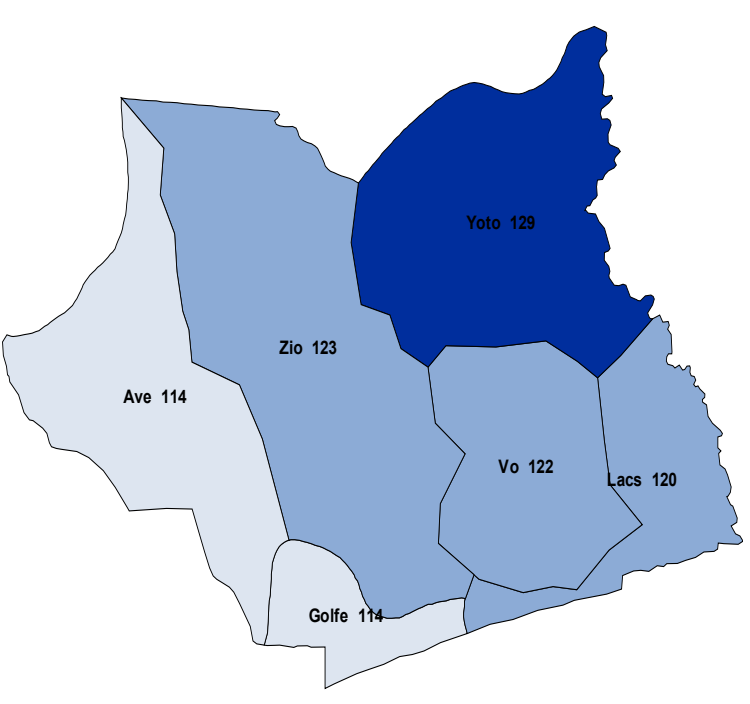

Source: Annuaire des statistiques scolaires 2006-2007

Plateaux region. The highest gross enrollment ratios in the region are found in the prefectures of Est Mono (136 percent) and Kloto (120 percent), while the lowest rates are in the prefectures of Ogou (91 percent) and Moyen Mono (90 percent).

The prefectures of Amou, Wawa, Danyi, Haho and Agou have rates of 112 percent, 112 percent, 104 percent, 96 percent and 94 percent respectively.

The prefectures of Kloto and Amou have the highest parity index (1.06). The prefecture of Moyen Mono is the prefecture in which girls have the most difficulty regarding access to school, with the lowest parity index of 0.76 .
Chart 8: Gross enrollment ratios in the Plateaux region

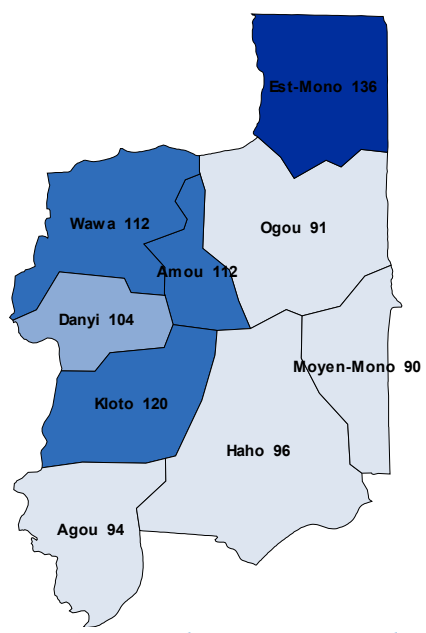

Source: Annuaire des statistiques scolaires 2006-2007

Centrale region. The prefecture of Tchamba has the highest gross enrollment ratio (148 percent). The prefectures of Blitta and Sotouboua are next, with respective rates of 129 percent and 120 percent. The prefecture of Tchaoudjo has the lowest rate (116 percent)

On the other hand, the lowest parity index is found in the prefecture of Tchamba (0.88) and the highest is in the prefectures of Tchaoudjo and Blitta (0.97).

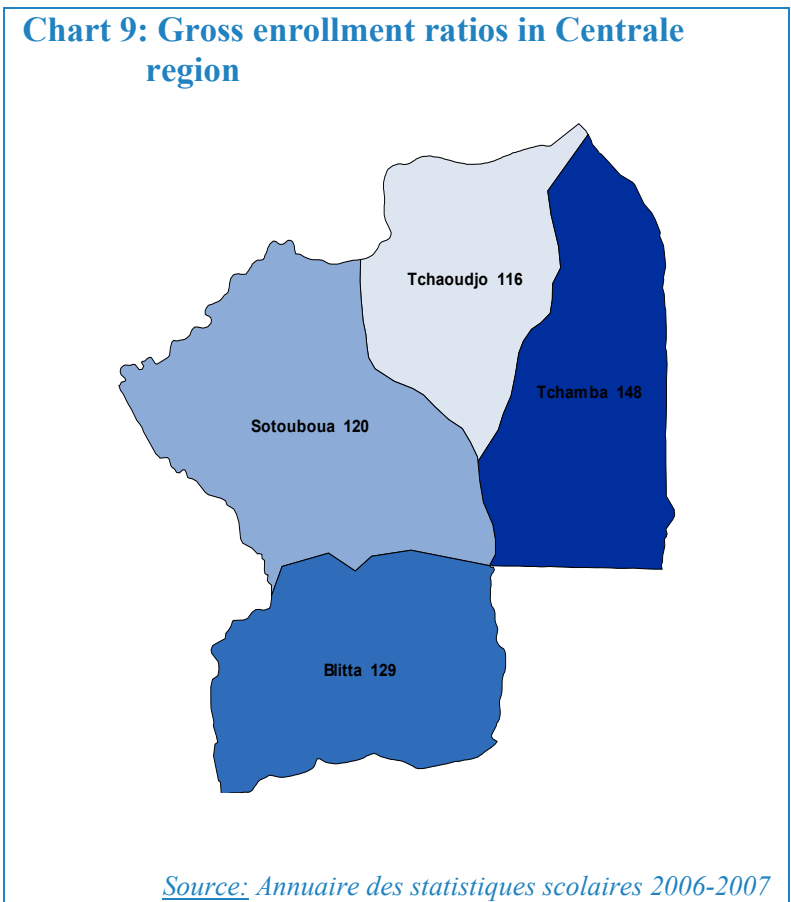


La Kara region. The prefecture of la Binah has the highest gross enrollment ratio for both sexes (124 percent) in the la Kara region. Next come the prefectures of Assoli (112 percent), la Kozah (112 percent), la Kéran (111 percent) and Doufelgou (110 percent).

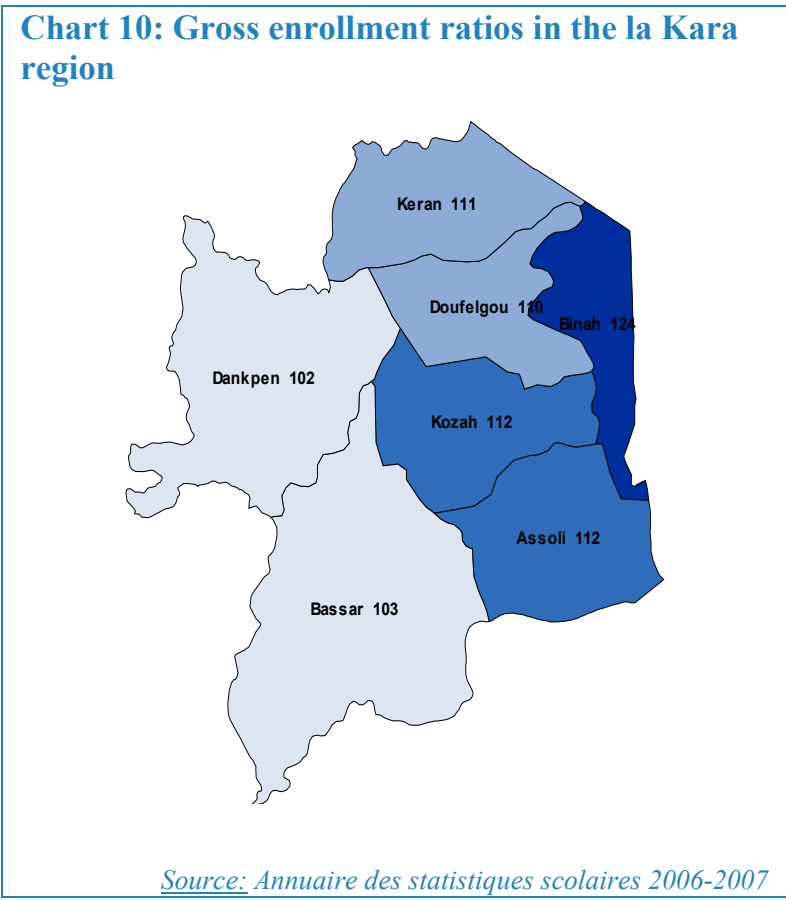

The prefectures of Dankpen and Bassar have the lowest gross rates (102 percent and 103 percent respectively). The prefecture of la Kozah is the prefecture in which girls have relatively greater access to education (parity index of 1.08). On the other hand, the prefecture of la Kéran has the lowest parity index (about 0.71).

Savanes region. In the Savanes region, the highest gross enrollment ratios are found in the prefectures of Tandjoaré (126 percent) and Tône (106 percent), while the lowest rates are in the prefectures of Oti ( 81 percent) and Kpendjal (66 percent).

The prefecture of Tandjoare has the highest parity index (0.83), while the lowest index is found in the prefecture of Kpendjal (0.66). Indeed, this is the prefecture where there are the most problems in the country as regards girls' enrollment.

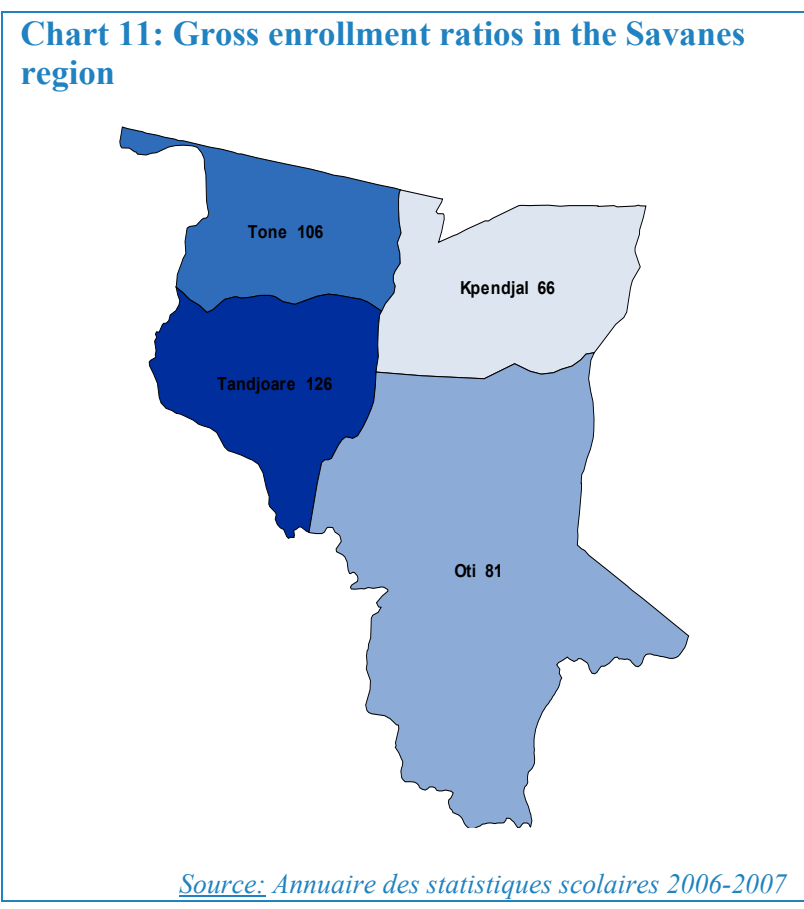

\section{$2.2 \quad$ Health}

In the context of the commitments made by Togo regarding health, particularly universal access and integration of reproductive health, coverage of health infrastructures, proportion of births assisted by skilled medical personnel, vaccination coverage, morbidity due to leprosy and HIV/AIDS prevalence are the main indicators used for targeting health services.

\section{Nationwide}

An analysis of the percentage of births assisted by skilled medical personnel shows that the percentages are higher in Lomé-Golfe (97.3 percent and in the Maritime (71.4 percent) and Plateaux (56.9 percent) regions than in the poorer Centrale (54.4 percent), la Kara (53.4 percent) and Savanes (38.9 percent) regions. The same trend is found for the proportion of fully vaccinated children, except in Centrale region. However, the findings of the MICS 3 survey (2006) show that in the Centrale, la Kara and Savanes regions more pregnant women use treated mosquito nets than in the other regions.

In addition, access to health services is more difficult in the Centrale, la Kara and Savanes regions than in the Maritime and Plateaux regions. In the latter two regions, over 70 percent of households live less than three kilometers from the nearest health center, 
while for the other regions the figure is at most 67.3 percent. The fact that there are fewer health units per 10,000 inhabitants in the Maritime and Plateaux regions is partly due to the heavy concentration of population in these regions.
HIV prevalence in the general population was estimated at 3.2 percent in 2006 . This rate conceals regional disparities but is lower in the more northern areas.

Table 4: Health indicators for the various regions

\begin{tabular}{|c|c|c|c|c|c|c|c|}
\hline \multirow[t]{2}{*}{ Region } & \multirow[t]{2}{*}{$\begin{array}{c}\% \\
\text { Prevalence of } \\
\text { HIV-HIV/AIDS* }\end{array}$} & \multirow{2}{*}{$\begin{array}{c}\% \text { of births } \\
\text { attended by } \\
\text { skilled medical } \\
\text { personnel }\end{array}$} & \multirow[t]{2}{*}{$\begin{array}{l}\% \text { of fully } \\
\text { vaccinated } \\
\text { children }\end{array}$} & \multirow{2}{*}{$\begin{array}{c}\text { \% of pregnant } \\
\text { women using an } \\
\text { insecticide- } \\
\text { treated mosquito } \\
\text { net }\end{array}$} & \multirow{2}{*}{$\begin{array}{c}\text { \% of households } \\
\text { living less than } 3 \\
\text { km from the } \\
\text { nearest health } \\
\text { center }\end{array}$} & \multicolumn{2}{|c|}{$\begin{array}{c}\text { Number of health units } \\
\text { per } 10,000 \\
\text { inhabitants } * *\end{array}$} \\
\hline & & & & & & $\begin{array}{c}\text { Rural } \\
\text { areas }\end{array}$ & $\begin{array}{c}\text { Urban } \\
\text { areas }\end{array}$ \\
\hline Lomé and Golfe & 6.3 & 97.3 & 65.7 & 21.2 & 84.3 & - & 0.6 \\
\hline Maritime & 4.5 & 71.4 & 62.9 & 31.5 & 79.9 & 1.0 & 1.2 \\
\hline Plateaux & 3.5 & 56.9 & 66.2 & 33.6 & 71.0 & 1.5 & 1.6 \\
\hline Centrale & 3.8 & 54.4 & 69.8 & 32.2 & 64.8 & 1.8 & 1.5 \\
\hline Kara & 2.5 & 53.4 & 53.2 & 33.7 & 67.3 & 1.8 & 1.7 \\
\hline Savanes & 1.4 & 38.9 & 62.7 & 42.7 & 45.0 & 1.1 & 1.1 \\
\hline Nationwide & 3.2 & 63.3 & 63.8 & 30.7 & 71.2 & 2.7 & 2.3 \\
\hline
\end{tabular}

Source: QUIBB, 2006; *CNLS, 2006; **Ministry of health, 2008

\section{Regional}

Lomé and its outskirts (Golfe prefecture). All health indicators are better in Lomé commune than in the Golfe prefecture, with the exception of the proportion of women sleeping under a treated mosquito net. These respective rates are 20.4 percent and 22.3 percent for the morbidity rate, 64.5 percent and 66.0 percent for prevalence of malaria, 7.8 percent and 10.9 percent for prevalence of diarrhea, 98.1 percent and 94.4 percent for the proportion of births assisted by skilled medical personnel, and 67.0 percent and 62.7 percent for the proportion of fully vaccinated children under the Expanded Programme on Immunization (EPI).

Health coverage is also much better in the commune of Lomé than in the outskirts. For example, 84.8 percent of households live less than 3 kilometers from the nearest health center in Lomé compared with 76.7 in the Golfe prefecture. Similarly, there are 0.7 health units per 10,000 inhabitants in the commune of Lomé compared with 0.4 units for the outskirts of Lomé. The prevalence of HIV/AIDS was 6.3 percent in 2008 in Lomé and its outskirts.

Maritime region. An analysis of health indicators in the Maritime region shows that the three poorest prefectures (Vo, Yoto and
Zio) are in the worst situation. The proportion of births assisted by skilled medical personnel is 60.5 percent, 60.6 percent and 71.9 percent respectively in the prefectures of Vo, Zio and Yoto, compared with 76.0 percent in Avé and 84.6 percent in Lacs.

Chart 12: Proportion of births assisted by skilled medical personnel in the Maritime region

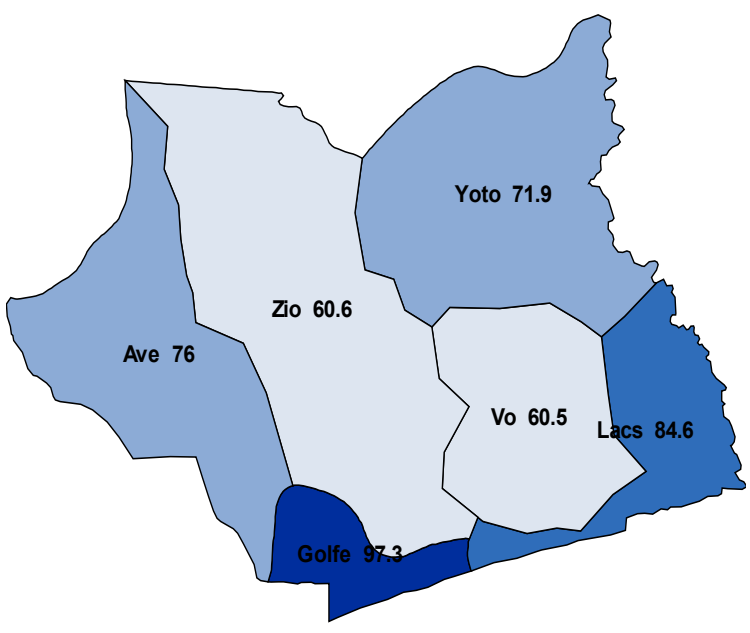

Source: QUIBB-2006

In addition, these three prefectures are in the worst position as regards access to health services. The percentage of households living less than 3 kilometers from the nearest health center is 77.9 percent in the prefecture of $\mathrm{Vo}$, 
83.3 percent in the prefecture of Yoto, 75.5 percent in the prefecture of Zio, 77.5 percent in the prefecture of Avé and 93.0 percent in the prefecture of Lacs. The prevalence of HIV/AIDS in the Maritime region was 4.5 percent in 2008.

Plateaux region. An analysis of health indicators shows that the prefectures of Est Mono, Haho and Amou have the smallest percentage of births assisted by skilled medical personnel.

Chart 13: Proportion of births assisted by skilled medical personnel in the Plateaux region

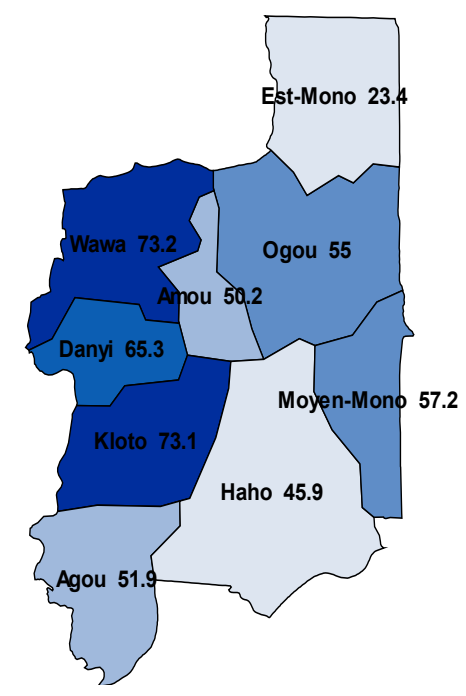

Source: QUIBB-2006

The proportion of births assisted by skilled medical personnel is 23.4 percent in the prefecture of Est Mono, 45.9 percent in Haho and 50.2 percent in Amou, compared with the regional average of 56.9 percent.

The prefectures of Est Mono and Haho are in the worst position as regards access to health services. For example, 39 percent of households in the prefecture of Est Mono and 62.4 percent of households in the prefecture of Haho live less than 3 kilometers from the nearest health center, compared with an average of 71.0 percent in the region. The prevalence of HIV/AIDS was 3.5 percent in 2008.

Centrale region. The highest proportion of births assisted by skilled medical personnel in the region is found in the prefecture of Tchaoudjo, with a rate of 67.0 percent, followed by the prefecture of Tchamba with a rate of 57.6 percent. The prefectures of Blitta, with a rate of 50.5 percent and Sotouboua, with a rate of 41.9 percent have the lowest rates of births assisted by skilled medical personnel in the region.

Chart 14: Proportion of births assisted by skilled medical personnel in Centrale region

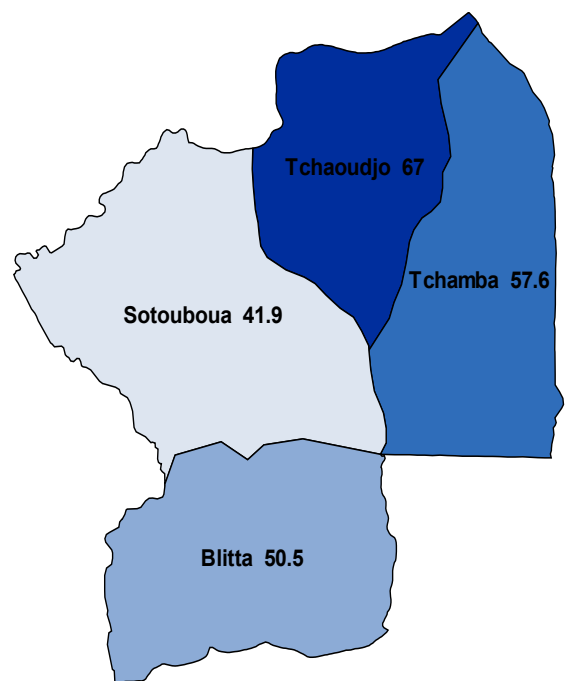

Source: $O U I B B-2006$

Similarly, households are further away from health centers in the prefectures of Blitta and Sotouboua. For example, 55.3 percent of households in the prefecture of Blitta and 61.6 percent of households in the prefecture of Sotouboua live less than three kilometers from a health center, compared with 68.5 percent in the prefecture of Tchaoudjo and 75.1 percent in the prefecture of Tchamba. The prevalence of HIV/AIDS is 3.8 percent in Centrale region.

La Kara region. An analysis of health indicators in the Kara region also yields widely differing results. In general, the four poorest prefectures (Binah, Bassar, Kéran and Dankpen) have the lowest proportion of births assisted by skilled medical personnel, with respective rates of 50.0 percent, 29.8 percent, 30.3 percent and 44.8 percent. The rates are estimated at 64.7 percent in the prefecture of Doufelgou, 77.4 percent in the prefecture of Assoli and 75.5 percent in the prefecture of la Kozah.

The conditions of access to health confirm this finding. 
Chart 15: Proportion of births assisted by skilled medical personnel in the la Kara region

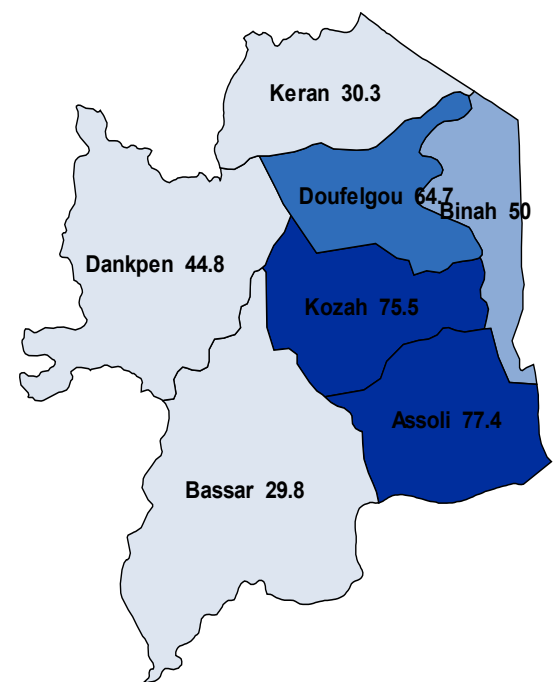

Source: QUIBB-2006

61.6 percent of households in the prefecture of la Binah, 36.1 percent in the prefecture of Bassar, 51.3 percent in the prefecture of la Kéran and 65.5 percent in the prefecture of Dankpen live less than three kilometers from the nearest health center, compared with 87.,9 percent for the prefecture of Doufelgou, 94.5 percent for the prefecture of Assoli and 77.4 percent for the prefecture of la Kozah. In the la Kara region, the prevalence of HIV/AIDS in 2008 was 2.5 percent.

Savanes region. The prefectures of Kpendjal, Tandjoare and Oti, which are the poorest in the Savanes region in monetary terms, are also in the worst position as regards access to health. In these prefectures, the percentages of births assisted by skilled medical personnel are respectively 41.2 percent, 34.9 percent and 32.7 percent, compared with 42.0 percent for the prefecture of Tône. In addition, only 63.7 percent of children in the prefecture of Kpendjal, 59.6 percent in Tandjoaré and 50.5 percent in Oti are fully vaccinated under the Expanded Programme of Immunization, compared with 69.3 percent in the prefecture of Tône.

In these prefectures also, the conditions of access to health are the most difficult. For example, 50.4 percent of households in the prefecture of Kpendjal, 45.5 percent in the prefecture of Tandjoaré and 33.8 percent in the prefecture of Oti live less than three kilometers from the nearest health center. The prevalence of HIV/AIDS in the Savanes region (1.4 percent in 2008) is the lowest of all the regions of the country.

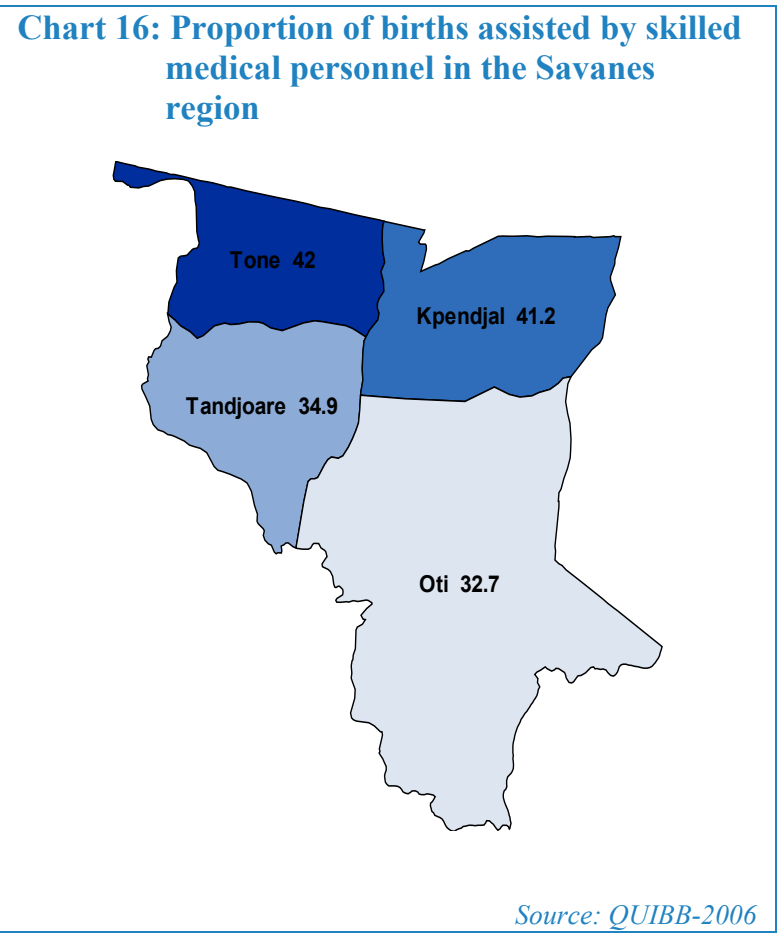

\subsection{Water}

Two types of indicator are used to target assistance in the area of water. The first is access to safe drinking water, calculated on the basis of the QUIBB survey. In calculating this indicator, all categories of water from faucets, protected wells and bore wells are considered to be safe drinking water. In addition, access considers only the fact that a household uses these categories of water for drinking, but does not take into account conditions of access, such as distance from the water source. The second indictor is the population supplied with safe drinking water. This indicator is calculated by the Directorate General of Water and Sanitation. It compares the population supplied and the safe drinking water potential at a given location. The potential is expressed as a WPE (Water Point Equivalent), ${ }^{24}$ corresponding to a source of safe drinking water able to supply a population of 250 persons in satisfactory conditions.

\footnotetext{
24 A hand-pumped bore well counts as one WPE, a separate water point four WPE and a public standpipe two WPE.
} 
To a certain degree there is a correlation between the two indicators, because the regions with the lowest rates of access to safe drinking water are generally those where the population supplied is small. The preferred indicator for further analysis is the population supplied with safe drinking water.

\section{Nationwide}

The Centrale and la Kara regions have the largest potential population supplied with safe drinking water (45 percent and 43 percent respectively). Next come the Maritime region (including the Golfe prefecture) and the Plateaux region, with 33 percent and 29 percent respectively. The Savanes region, with a potential population supplied with safe drinking water of 26 percent, is in the worst position.

Table 5: Indicators of access to safe drinking water in the different regions

\begin{tabular}{|l|c|c|}
\hline Region & $\begin{array}{c}\text { Access to safe } \\
\text { drinking water (\%) }\end{array}$ & $\begin{array}{c}\text { Potential } \\
\text { population } \\
\text { supplied with safe } \\
\text { drinking water } \\
\text { ( \%) }\end{array}$ \\
\hline Maritime & 35.6 & 33 \\
\hline Plateaux & 26.6 & 29 \\
\hline Centrale & 57.1 & 45 \\
\hline Kara & 56.6 & 43 \\
\hline Savanes & 38.4 & 26 \\
\hline Nationwide & $\mathbf{3 9 . 0}$ & $\mathbf{3 4}$ \\
\hline
\end{tabular}

Source: Directorate General of Water and Sanitation2007

\section{Regions}

Since the method of calculation differs from one area to another, the population supplied with safe drinking water within each region is broken down into rural areas, semi-urban areas and urban areas.

Maritime region. In rural areas, the prefectures of Avé and Yoto are in the best position, with potential supplied populations of 52 percent and 45 percent respectively. Next come the prefectures of Golfe (18 percent) and Yoto (17 percent). Les prefectures of Vo and Lacs are in the worst position, with respective rates of 7 percent and 7.5 percent.
In semi-urban areas, the prefecture of Avé is in the best position, with a rate of 55 percent. However, the prefectures of Yoto and Lacs are in the worst position, with respective rates of 2 percent and 3.3 percent.

In urban areas, the prefectures of Zio and Golfe are in the best position, with respective rates of 50 percent and 44 percent. The prefectures of Yoto and Lacs are in the worst position, with respective rates of 25 percent and 26 percent.

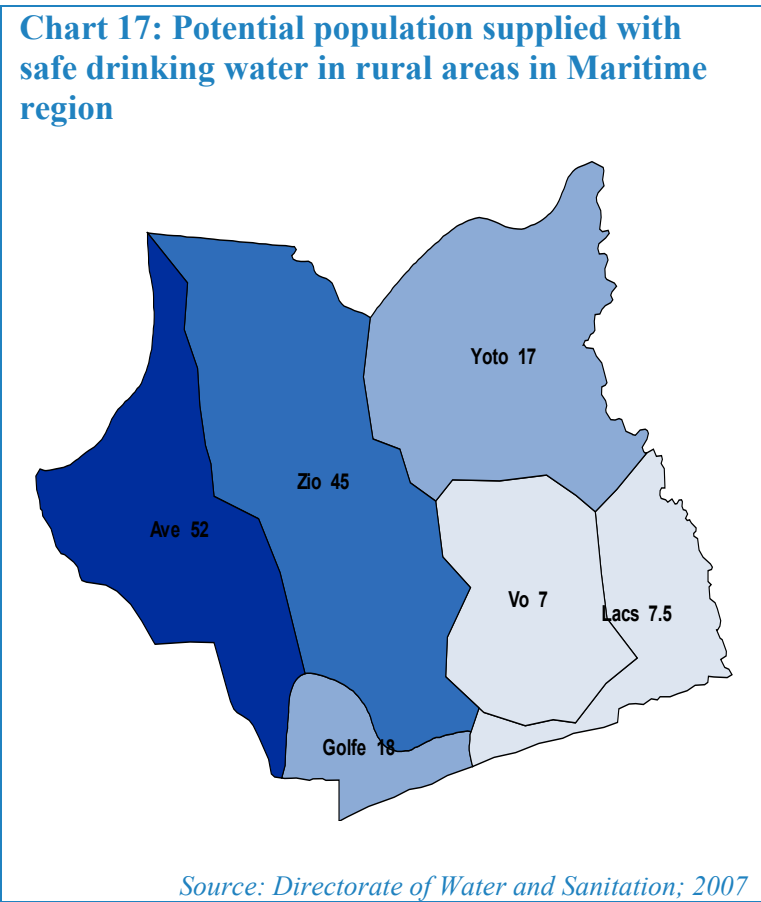

On the other hand, as regards access to safe drinking water, the prefecture of Yoto has the highest rate. This means that, in this prefecture, despite the low safe drinking water potential, the inhabitants manage to have greater access to safe drinking water by making greater efforts.

Plateaux region. In rural areas, the prefecture of Est Mono, with a potential supplied population of 44 percent, stands out from the other prefectures. Far behind, in order of magnitude, come the prefectures of Ogou (34 percent), Agou (30 percent), Haho (28 percent), Amou (27 percent), Kloto (26 percent), Danyi (22,4 percent) and Moyen Mono (22 percent). The prefecture of Wawa is in the worst position, with a rate of 14.4 percent. 
In semi-urban areas, the prefecture of Amou is in the best position, with a rate of 54 percent. The prefecture of Haho is in the worst position, with a rate of 13 percent.

In urban areas, unlike the semi-urban areas, the prefecture of Haho is in the best position, with a rate of 68 percent, and the prefecture of Amou is in the worst position, with a rate of 5 percent.

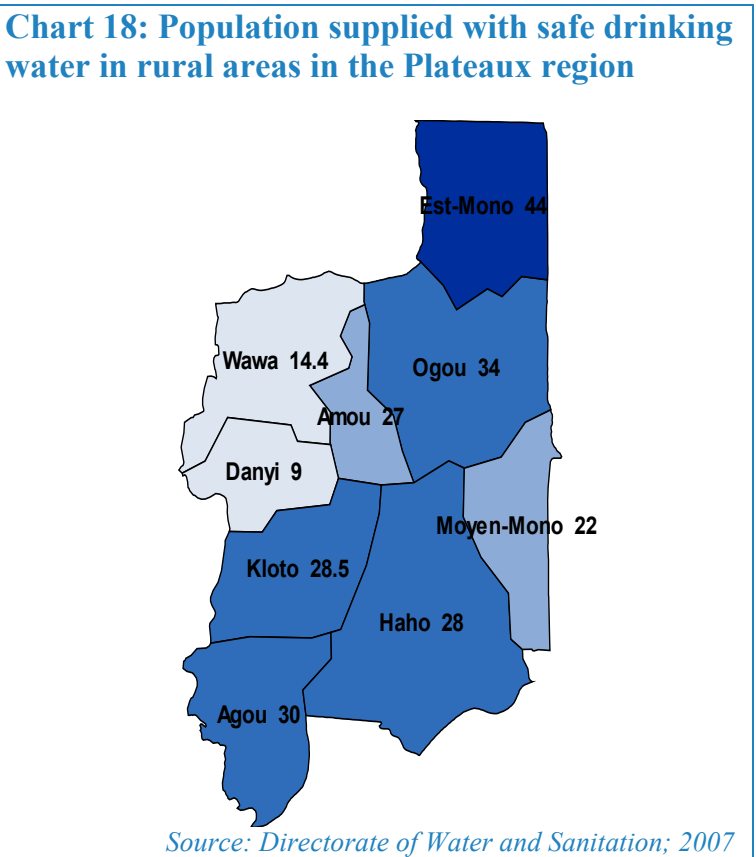

Centrale region. In rural areas, the prefecture of Sotouboua is in the best position, with a potential supplied population of 62 percent. Next come the prefecture of Tchamba (47 percent) and the prefecture of Blitta (45 percent). The prefecture of Tchaoudjo is in the worst position, with a rate of 31 percent.

In semi-urban areas, the prefectures of Tchamba, Sotouboua, Tchaoudjo and Blitta have rates of 86 percent, 68 percent, 53 percent and 45 percent respectively.

In urban areas, the prefecture of Tchamba is in the best position, with a rate of 35 percent. The prefecture of Sotouboua is in the worst position, with a rate of 16 percent.
Chart 19: Population supplied with safe drinking water in rural areas in the Central region

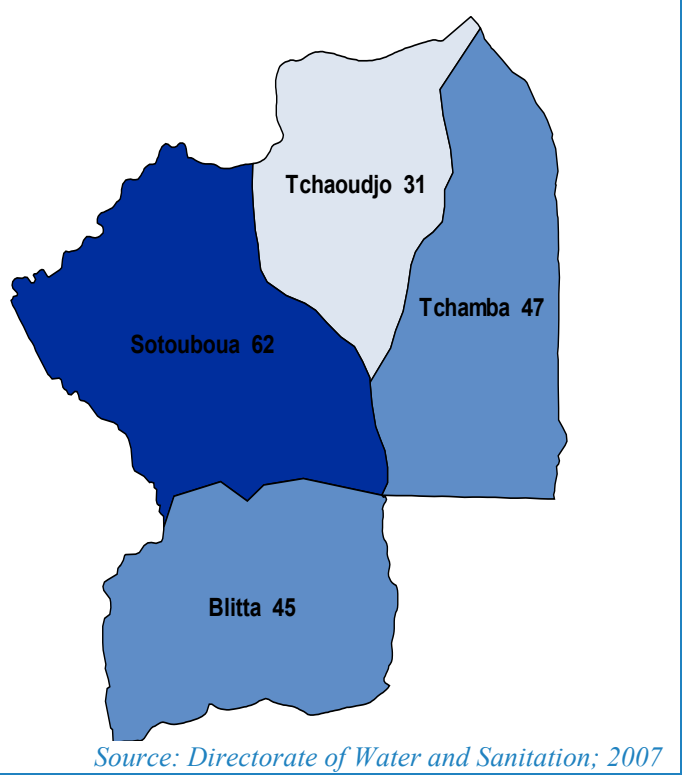

La Kara region. In rural areas, the prefecture of Dankpen is in the best position, with a potential supplied population of 65 percent. Next come, in order, the prefectures of Bassar, la Kéran, la Kozah, Doufelgou, and Assoli, with respective rates of 53 percent, 38 percent, 32 percent, 30 percent and 30 percent. The prefecture of la Binah is in the worst position, with a rate of 26 percent.

Chart 20: Population supplied with safe drinking water in rural areas in the La Kara region

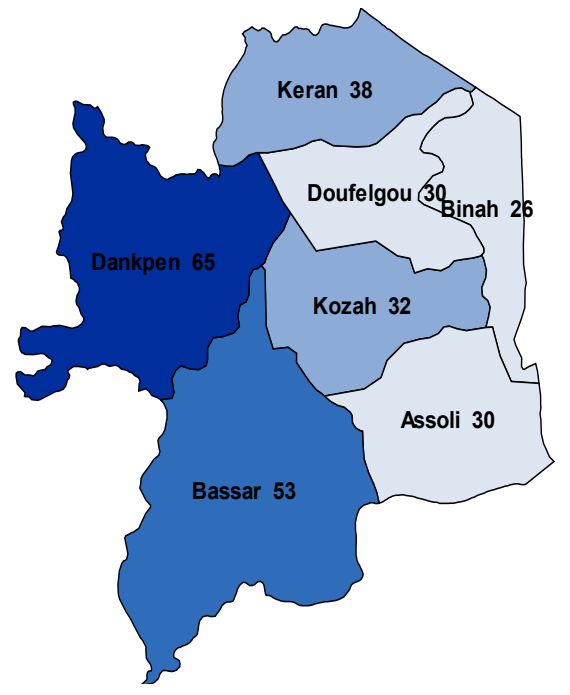

Source: Directorate of Water and Sanitation; 2007 
In semi-urban areas, the prefectures of Assoli and Bassar, with respective rates of 79 percent and 77 percent, are in the best position. As in rural areas, the prefecture of la Binah is in the worst position, with a rate of 14 percent.

In urban areas, the prefecture of Doufelgou is the best supplied, with a rate of 57 percent. The prefecture of la Binah remains, with the prefecture of la Kéran, the worst supplied, each with a rate of 26 percent.

Savanes region. In rural areas, the prefecture of Oti, with a potential supplied population of 46 percent, stands out from the others. The other rates are 26 percent for Tône, 22 percent for Tandjoaré and 20 percent for Kpendjal.

\section{Chart 21: Population supplied with safe drinking} water in rural areas in the Savanes region

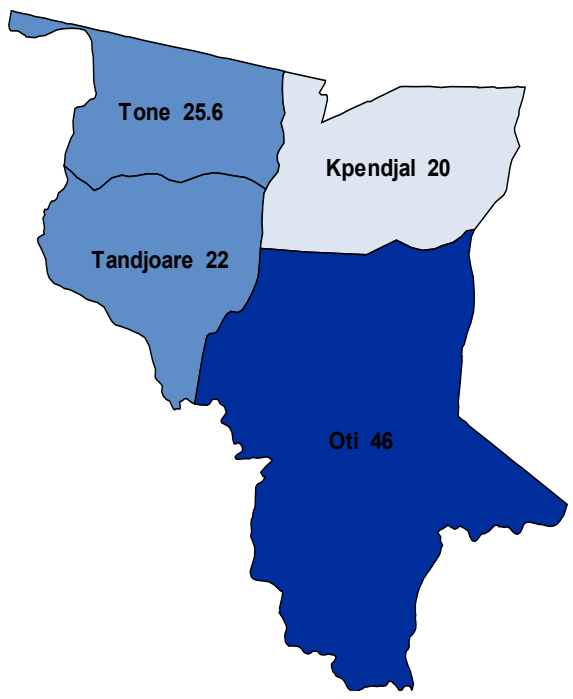

Source: Directorate General of Water and Sanitation, 2007

In semi-urban areas, the prefectures of Oti and Tandjoaré are in the best position, with potential supplied populations of 23 percent and 24 percent respectively. The prefectures of Tône and Kpendjal are in the worst position, with respective rates of 10 percent and 13 percent.

In urban areas, the prefecture of Oti is in the best position, with a rate of 54 percent. The prefecture of Tandjoare is in the worst position, with a potential rate of supply of practically zero.

\subsection{Sanitation}

The targeting of efforts in the area of sanitation is mainly based on the proportion of the population using latrines (including pour-flush latrines with sewage systems or septic tanks and covered or improved open-air latrines). Another indicator is the percentage of school and health structures equipped with latrines and modern water points.

\section{Nationwide}

The largest number of users of latrines is in Lomé and its outskirts, where the rate is 78.2 percent. It is followed, far behind, by Maritime region, with a rate of 21.2 percent and Centrale region, with a rate of 20.5 percent. The proportion of persons using latrines is 15.6 percent in the Plateaux region and 11.6 percent in the La Kara region. The lowest percentage $(8.5$ percent $)$ is found in the Savanes region.

Table 6: Sanitation indicators in the various regions

\begin{tabular}{|l|c|c|c|}
\hline \multicolumn{1}{|c|}{ Region } & $\begin{array}{c}\text { \%of the } \\
\text { population } \\
\text { using } \\
\text { latrines }\end{array}$ & $\begin{array}{c}\text { \%o of school } \\
\text { infrastructures } \\
\text { equipped with } \\
\text { latrines and } \\
\text { modern water } \\
\text { points }\end{array}$ & $\begin{array}{c}\text { \% of health } \\
\text { facilities } \\
\text { equipped } \\
\text { with latrines } \\
\text { and modern } \\
\text { water points }\end{array}$ \\
\hline $\begin{array}{l}\text { Lomé and } \\
\text { outskirts }\end{array}$ & 78.2 & 4.0 & - \\
\hline Maritime & 21.2 & 4.0 & 15.0 \\
\hline Plateaux & 15.6 & 2.0 & 50.0 \\
\hline Centrale & 20.5 & 1.0 & 9.0 \\
\hline Kara & 11.6 & 15.0 & 25.0 \\
\hline Savanes & 8.5 & & \\
\hline Source: Directorate General of Water and Sanitation - & \\
\hline 2007 & & & \\
\hline
\end{tabular}

In addition, in view of the proportion of school infrastructures equipped with latrines and modern water points, there is a supply problem in the Maritime region, the Plateaux region and, to a lesser extent, the La Kara region. Only 4 percent of school infrastructures are equipped with latrines and modern water points in the Maritime and Plateaux regions, compared with 12 percent for the La Kara region, 15 percent for the Savanes region and 26 percent for the Centrale region. 
These three regions are also in a bad position as regards the proportion of health facilities equipped with latrines and modern water points, but the situation is more critical in the La Kara region. Only 9 percent of health facilities in the La Kara region, 12 percent in the Plateaux region and 15 percent in the Maritime region are equipped with latrines and modern water points, compared with 25 percent for the Savanes region and 50 percent in the Centrale region.

\section{Regions}

Lomé-Golfe. As far as use of latrines is concerned, the outskirts of Lomé (Golfe prefecture) are in a worse position than Lomé commune, with a rate of 56.3 percent compared with 81.4 percent. However, the rate of latrine use in the Golfe prefecture is considerably higher than the rates found in the other prefectures. This performance should not obscure the fact that the uncontrolled release of sewage sludge in Lomé and its outskirts results in pollution of surface and ground water, exposing the population to diseases.

Maritime region. In the Maritime region, the prefecture where the inhabitants made the least use of latrines is the prefecture of Avé, with a rate of 7.6 percent.

The other prefectures with low rates of latrine use are the prefectures of Vo (16.5 percent), Zio (18.8 percent), and Yoto (19.0 percent). The prefecture of Lacs, with a rate of 36.4 percent, has the highest latrine use in the Maritime region.

As regards the proportion of school infrastructures equipped with latrines and modern water points, the prefectures of Yoto and Zio are in the worst position, with respective rates of 1 percent and 2 percent compared with a regional average of 4 percent.
Chart 22: Percentage of inhabitants using latrines in the Maritime region

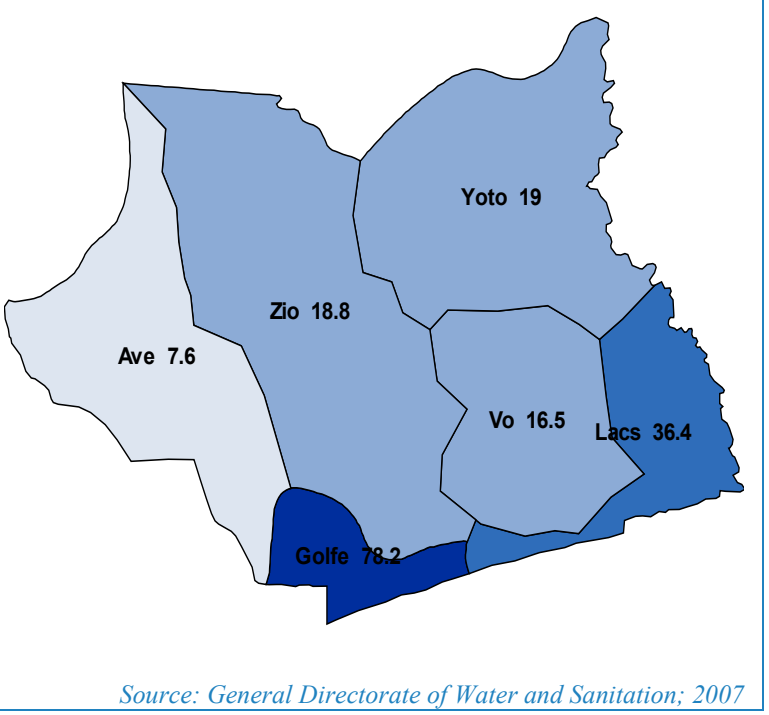

With regard to the proportion of health facilities equipped with latrines and modern water points, the prefecture of Zio is in the worst position, with a rate of 8 percent, less than the regional average of 15 percent.

Plateaux region. In the Plateaux region, the areas with the lowest latrine use are the prefectures of Est Mono, with a rate of almost zero, Moyen Mono (3.4 percent) and Danyi (5.0 percent). The prefecture of Kloto (39.4 percent) has the highest latrine use in the Plateaux region.

Chart 23: Percentage of inhabitants using latrines in the Plateaux region

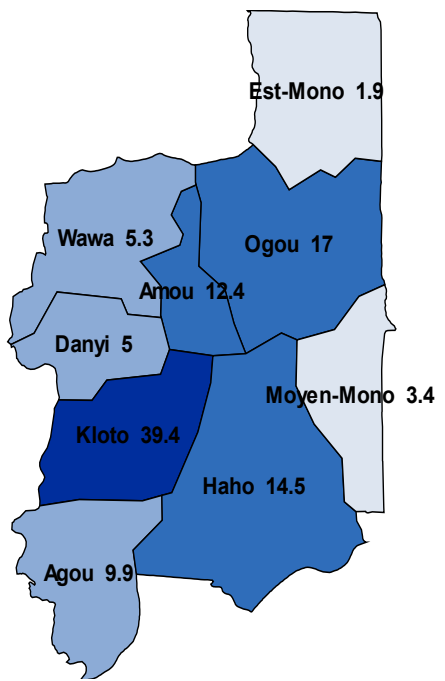

Source: General Directorate of Water and Sanitation; 2007 
As regards the proportion of school infrastructures equipped with latrines and modern water points, the prefectures of Moyen Mono, Danyi, Ogou and Wawa are in the worst position, with respective rates of 1 percent, 2 percent, 2 percent and 3 percent, compared with a regional average of 4 percent.

The prefectures of Wawa and Haho are in the worst position as regards health facilities equipped with latrines and modern water points, with rates (6 percent in both cases) that are below the regional level (15 percent).

Centrale region. In the Centrale region, the prefectures of Sotouboua and Blitta have very low rates of latrine use (6.7 percent and 7.0 percent respectively. The prefectures of Tchaoudjo and Tchamba, with respective rates of 34.3 percent and 33.3 percent, have rates considerably higher than the regional average.

With regard to the proportion of school infrastructures equipped with latrines and modern water points, the prefectures of Blitta and Sotouboua are in the worst position, with respective rates of 13 percent and 25 percent, compared with a regional average of 26 percent.

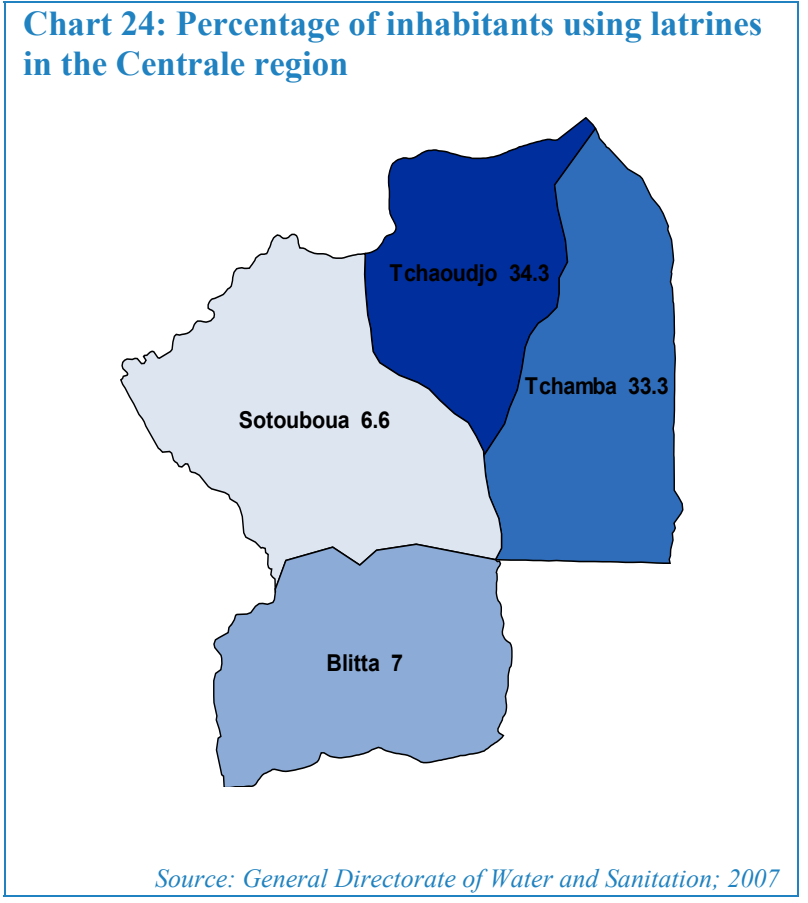

As regards health facilities equipped with latrines and modern water points, the prefecture of Blitta and the prefecture of
Tchaoudjo are in the worst position, each with rates of 42 percent, which are below the regional average of 50 percent.

La Kara region. With the exception of the prefectures of Assoli (24.6 percent) and la Kozah (21.0 percent), latrine use rarely exceeds 8 percent in the other prefectures of the La Kara region, where the average is very low (11.6 percent). The prefectures of Bassar (1.9 percent), Dankpen (4.0 percent), Doufelgou (4.5 percent) and la Kéran (8.0 percent) are in a much worse position that the prefectures of Assoli and la Kozah.

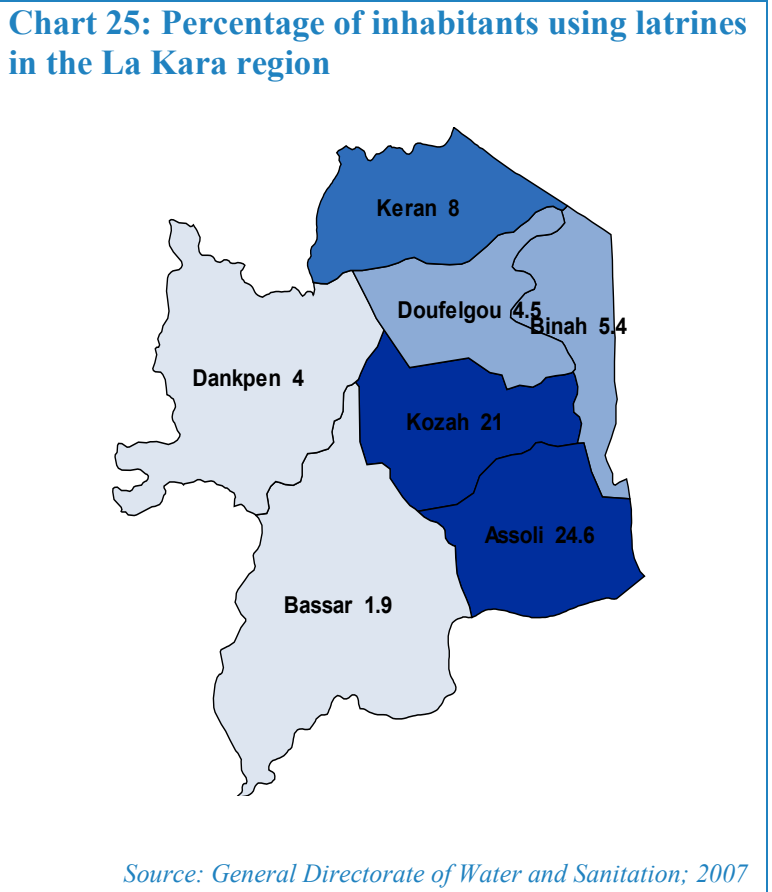

With regard to the proportion of school infrastructures equipped with latrines and modern water points, the prefectures of Bassar, Assoli and Dankpen are in the worst position, with respective rates of 3 percent, 4 percent and 9 percent, compared with a regional average of 12 percent.

The prefectures of Bassar and Dankpen, with the prefecture of la Kozah, are in the worst position as regards health facilities equipped with latrines and modern water points, with rates (respectively 7 percent, 4 percent and 4 percent) below the regional average (9 percent). 
Savanes region. The Savanes region has the lowest rate of latrine use in the country. The three poorest prefectures have the lowest rates: Oti (3.8 percent), Kpendjal (4.9 percent) and Tandjoaré $(5.7$ percent). The prefecture of Tône has a slightly higher rate of latrine use (13.3 percent).

As regards the proportion of school infrastructures equipped with latrines and modern water points, the prefectures of Oti and Tandjoaré are in the worst position, with an identical rate of 8 percent, compared with a regional average of 12 percent. As for health facilities equipped with latrines and modern water points, the prefectures of Oti and Tandjoaré are in the worst position, with respective rates of 16 percent and 11 percent, which are far below the regional average of 25 percent.

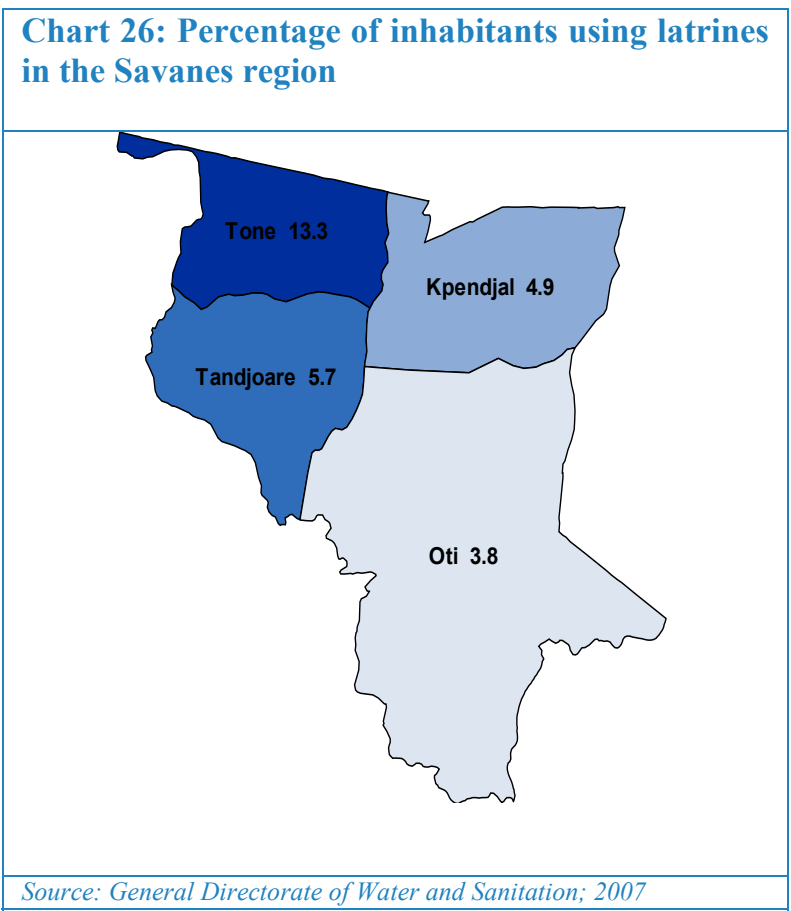

\section{Approach Based on The Perception of Poverty by Households}

The monetary and non-monetary approaches to poverty to not fully take into account the multiple dimensions of a complex phenomenon that is difficult to grasp. The perception of poverty by the public, the causes of poverty and the priority needs to be met for the various population groups elucidate the various aspects of poverty and make it easier to understand the phenomenon. This analysis is the result of the qualitative survey conducted in December 2006, covering a representative population sample. ${ }^{25}$

\subsection{People's perception of poverty}

It emerges from the individual interviews that 74.6 percent of respondents consider themselves poor, and that they have their own definition of poverty. Generally speaking, the meaning of poverty is defined in a contextual framework (condition of dwelling, size of fields), but there is in all these perceptions, group and individual alike, a common denominator: the lack of basic necessities.

The people interviewed were virtually unanimous in considering themselves poor, because they could not meet very specific needs, such as schooling for their children, health care, clothing, housing and food. As these people put it, «You can tell a poor person, first by his looks: he's not dressed well, he has nothing to eat, his children are hungry, and they cry all the time because they have no food. A poor man always looks pensive. When he is sick, he can't work in the fields, and he has no money». A poor person is one "who must live off other people, and has lost his self-esteem ». Many people felt that their lives had deteriorated a great deal between 2000 and 2006.

The perception of poverty that emerges from the interviews, then, can be summarized as follows: "Poverty is the inability of people to meet their essential needs for food, health, education, water, clothing and housing. In collective terms, poverty is defined by such factors as lack of basic infrastructure (schools, clinics, safe drinking water, a market) and poor transportation facilities ».

\footnotetext{
${ }^{25}$ The qualitative survey was conducted by the Population Research Unit (URD), with World Bank funding.
} 
The people interviewed gave several reasons for the deterioration in living conditions, including low incomes from farming, lack of goodwill, inadequate and irregular wages, unemployment among school graduates, social and political unrest and lack of access to water.

\subsection{People's expectations}

People very clearly identified the causes of poverty, and had many suggestions for improving their lives. Their expectations can be summarized under three headings:

Social support (education, health, safe drinking water, basic goods). For rural people, reducing poverty means providing safe drinking water and access to basic goods. In the towns, people mentioned (in addition to safe drinking water) the importance of building schools and health centers as a way to help them to reduce poverty.

Employment (jobs for young people, income-generating activities, access to credit). Urban households emphasized in particular the problem of youth unemployment, while rural people were more likely to stress the need for income-generating activities.

Good governance. People defined this as the guarantee that everyone will be fairly rewarded for their efforts. Good government means a calmer political situation, more justice, and less corruption.

\section{Togo's MDG StATUS ANd Challenges to 2015}

Table 7 summarizes the status of certain indicators included in the targets of the Millennium Development Goals. It thus shows the main indicators and targets to be reached by 2015 .

\subsection{Togo's MDG status}

At the United Nations General Assembly session in September 2005, devoted to tracking progress in relation to the MDGs, the Togolese authorities reaffirmed their commitment to implementing the public policies needed to combat poverty and hunger, illiteracy, discrimination against women, HIV/AIDS and other diseases, as well as degradation of the environment. This commitment is of great importance, as Togo's current socio-economic situation suggests that at the current rate of progress the country is unlikely to achieve the MDGs by 2015.

The conclusions of the second national MDG monitoring report approved in December 2008 showed that, at the current pace of progress with the indicators, and by means of sustained efforts, only MDGs 2 and 6 («Achieve universal primary education» and «Combat HIV/AIDS ») could be achieved by 2015. The country is unlikely to achieve the following goals by 2015: "Eradicate extreme poverty », « Promote gender equality», "Reduce child mortality», «Improve maternal health» and «Ensure environmental sustainability ». However, there is hope that these goals can be achieved at a later date.

Table 7: Togo's MDG status and targets of the indicators

\begin{tabular}{|c|c|c|c|c|}
\hline Goals & Targets used for the analysis & Indicators used in Togo & $\begin{array}{l}2006 \text { current } \\
\text { value of the } \\
\text { indicator }\end{array}$ & $\begin{array}{l}\text { MDG target } \\
\text { value for } \\
2015\end{array}$ \\
\hline \multirow[t]{2}{*}{$\begin{array}{l}\text { 1. Eradicate extreme poverty } \\
\text { and hunger }\end{array}$} & $\begin{array}{l}\text { 1. Between } 1990 \text { and } 2015 \text {, reduce by half } \\
\text { the proportion of the Togolese population } \\
\text { living below the poverty threshold, by } \\
\text { reducing the poverty index to } 15 \% \text { by } \\
2015\end{array}$ & 2. Monetary poverty index & $61.7 \%$ & $30.9 \%$ \\
\hline & $\begin{array}{l}\text { 2. Between } 1990 \text { and } 2015 \text {, reduce by half } \\
\text { the number of persons suffering from } \\
\text { malnutrition }\end{array}$ & 4. Proportion of underweight children & 26.05 & $12.3 \%$ \\
\hline $\begin{array}{l}\text { 2. Achieve universal primary } \\
\text { education }\end{array}$ & $\begin{array}{l}\text { 3. By 2015, ensure that children } \\
\text { everywhere, boys and girls alike, will be }\end{array}$ & $\begin{array}{l}\text { 6. Net enrolment rate in primary } \\
\text { education }\end{array}$ & $74.6 \%$ & $100 \%$ \\
\hline
\end{tabular}




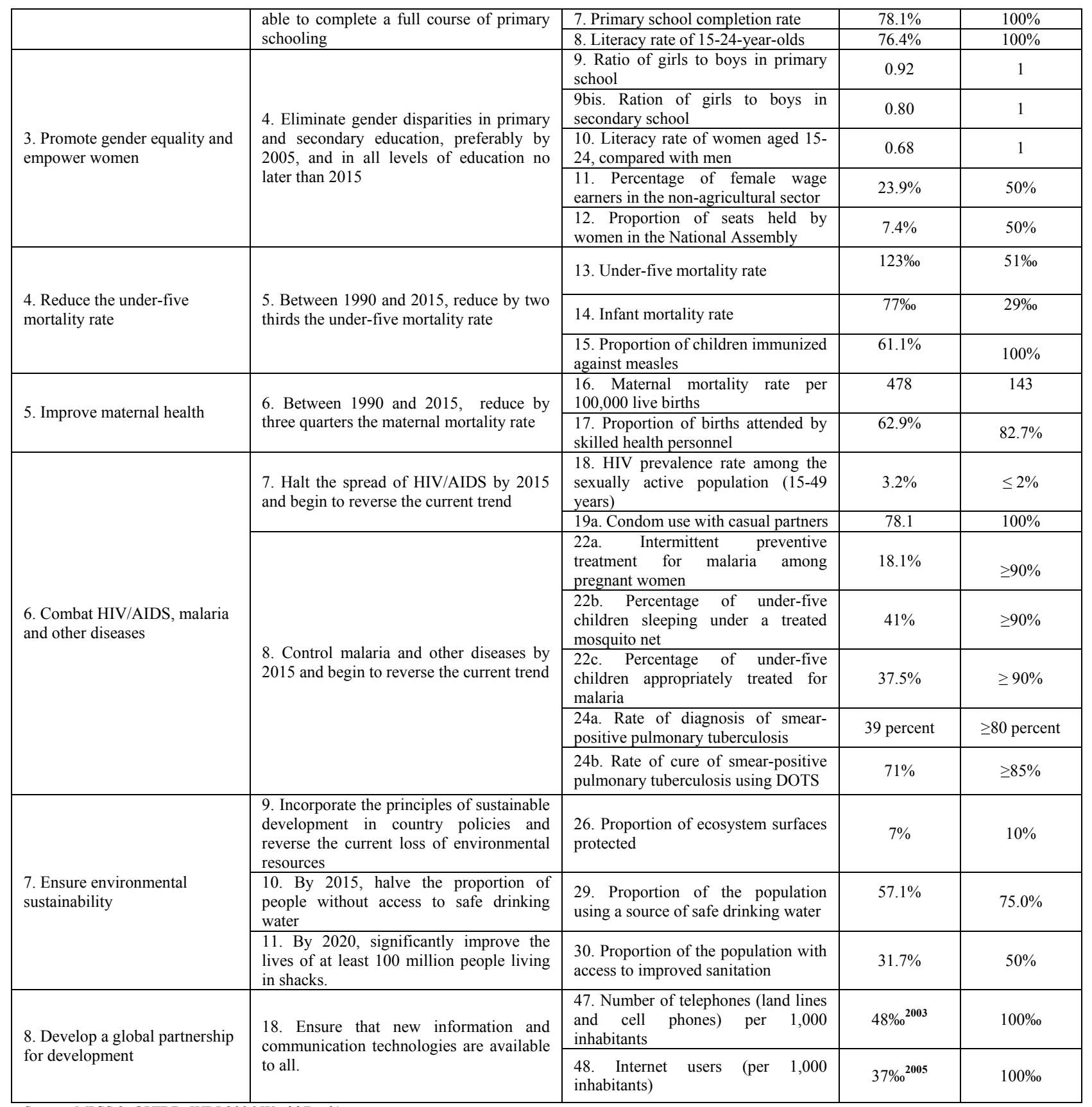

Source: MICS 3; QUIBB; WDI 2006 World Bank)

From: * 1998 Demographic and Health Survey in Togo

\subsection{Challenges to achieving the MDGs in Togo}

Despite considerable efforts in certain areas such as education, maternal health and HIV/AIDS, the achievement of the MDGs will depend on the ability of the authorities and national development actors to meet the following challenges, with the support of all the national and international partners: (i) consolidation of political dialogue and consensus on national development priorities; (ii) mobilization of the resources required to implement the development programs on which achievement of the MDGs depends; (iii) efficiency of public spending; and (iv) rapid creation of the essential institutional and human capacity to manage the key functions of public administration.

Consolidation of political dialogue and national consensus is one of the essential foundations of political stability, which is a prerequisite for achievement of the MDGs. It is essential to continue the process of consolidation of political dialogue and of reforms to strengthen social cohesion, in order to create a political and social climate conducive to the pursuit of policies of growth and poverty 
reduction and progress towards achievement of the MDGs. National consensus will not only be based on a functioning pluralist political and institutional system, on rule of law respectful of human rights and on counter-powers (press, civil society) with the necessary capacities. It also presupposes a level of economic governance that rehabilitates the Government, politicians and public administration, based on effectiveness, competence, efficiency, transparency and accountability. Another factor essential to achievement of the MDGs is social mobilization, with promotion of participation by citizens in decision-making of concern to them; it must be effective at all levels, from design to execution of development programs (for instance in the areas of health, education and water resource management) and must, in particular, result in strong involvement of civil society as regards both preparation of the various sectoral strategies and through capacity-building.

Mobilization of domestic and external resources. After the essential continuation of efforts to consolidate consensus on political issues and restore confidence in government, the most important challenge facing Togo in achieving the MDGs is resource mobilization. This challenge mainly relates to growth and its distribution. Simulations show that average economic growth of 7 percent over a long period would, all other things being equal, make it possible to achieve the poverty reduction goal of the MDGs by 2015. A considerable growth spurt is therefore needed if the MDGs are to be achieved, but it will have to be poverty-reducing growth - in other words, job-creating growth especially for the most under-privileged groups. In addition, emphasis must be placed on the need to promote equitably distributed growth that mainly helps the poorest people. Lastly, the allocation of resources, particularly those included in the budgets of central government and local authorities, must reflect the priorities required for achievement of the MDGs: the allocation of public expenditure must promote achievement of the MDGs.

On the domestic front, the Government faces the problem of expanding the tax base in a situation where a significant portion of the economy (agriculture, accounting for around 30 percent of GDP) is not taxed, and where the informal economy has rapidly acquired more importance in recent years. In addition, tax evasion as well as tax and customs exemptions constrain the performance of the revenue system. This situation is accentuated by the ineffectiveness of tax audits, due primarily to human resource problems in tax administration and the inadequacy of measures to encourage tax compliance. Consequently, the average tax pressure rate of recent years has been 14 percent, compared to a minimum of 17 percent called for in the WAEMU context, and this is not producing the revenues needed to meet priority needs. However, the measures adopted during 2008 succeeded in raising this rate to 16.4 percent. This illustrates the importance of the measures designed to improve tax assessment and to improve the capacity of the collection agencies. The technical and financial support of Togo's partners will be crucial in order to eliminate the various obstacles to increased tax revenue.

On the external front, cooperation with the country's main partners was frozen for more than a decade, greatly reducing external financial assistance. Traditionally, nearly 80 percent of government capital spending was financed by external resources, and the drying up of those resources has jeopardized achievement of the MDGs. Thus the achievement of the MDGs in Togo depends on substantial external aid on highly concessional terms which can be rapidly mobilized. In this context, it will be important to establish a strategic mechanism for effective coordination of aid and to follow up the conclusions and recommendations of the Brussels meeting in September 2008 by capacity-building in the Ministry responsible for cooperation. For this purpose, the initiative of the Secretary-General of the United Nations concerning the scaling up of investments to accelerate achievement of the MDGs, under the «Gleneagles Scenario », provides an opportunity for the country to mobilize the additional external resources essential for its development.

Efficiency of public spending. The 2006 PEMFAR review showed that a great many operations are performed using exceptional procedures, thereby increasing the risk that a significant portion of funds will be allocated to non-priority sectors (important progress was made during the fiscal year 2008 to limit the use of exceptional procedures). Moreover, the lack of transparency in procurement procedures and weaknesses in expenditure monitoring and control have meant that investments do not always produce the expected effects. The effective implementation of the action plan to improve the 
reliability of the system for managing public finance should enhance capacity over the next two or three years (automated system for management of public spending, tools for programming and monitoring public spending, procurement management, staff training, etc.). Such enhancements, which are essential for reliable management of public spending, should guarantee the efficiency of public spending. Lastly, it is essential to adopt an efficient and transparent system for monitoring public spending is essential in this context.

Institutional and human capacities. The resumption of growth and reduction of poverty are still hampered by shortcomings related to human resources and production capacities in crucial sectors. In terms of resource absorption capacity, the prolonged socio-political crisis in Togo has led to a marked deterioration in the institutional and human capacities needed to manage development properly. For the scarce financial resources available to the State, the absorption rate is very low (for example, the execution rate of the Public Investment Program for the fiscal year 2008 is 52 percent). This is primarily attributable to the shortage of material and human resources and the failure to follow donormandated procedures, mainly because officials are inadequately trained and staff who retire are not replaced. The scarcity of budgetary resources and the freeze on civil service recruitment have created considerable capacity constraints, particularly in key ministries responsible for the economy, finance, health, education and agriculture. The top priority is to reverse the observed tendency of the institutional capacities of the public administration to deteriorate, because of depletion of the ranks through retirement, breakdown of the training system, the lack of suitable reference tools (handbooks of procedures) and the lack of operational resources. In addition, private sector capacity-building is another essential element for sustained economic growth and good resource absorption (arrangements for Government/private sector consultations, one-stop shopping, market information, specialized jurisdictions), and economic and financial aspects are also important (cost of factors of production, investment credits, insurance). Similarly, the strengthening of civil society is a crucial element of capacity-building, essential for the consolidation of democracy and for efficient implementation of development programs in many sectors of importance for the MDGs. 


\section{CHAPTER 4: PILLARS OF THE FULL POVERTY REDUCTION STRATEGY}

Like the interim strategy, the full poverty reduction strategy which the Government intends to implement with the participation of all development actors and beneficiary population groups is designed ultimately to achieve effective and sustainable improvement of people's living conditions by tackling the principal causes of poverty described above. This goal reflects the vision of the highest authorities and the Government's General Policy Statement. The social project of the Head of State makes the wellbeing of the Togolese people the focus of public action. In this connection, the vision of the Head of State in the medium and long terms is to enable Togo, which is emerging from a long period of political and economic fragility, to become an emerging nation. For this purpose, social cohesion must be the cornerstone of all progress and the foundation of this emerging nation. Following this vision, the Government's General Policy Statement outlines two sets of priorities: (i) build on the results of the efforts already made so as to ensure that they have a direct effect on the daily lives of as many Togolese as possible; and (ii) continue the reforms already introduced under the Comprehensive Political Agreement, as well as the structural reforms to promote growth and sustainable development, in order to achieve the Millennium Development Goals (MDGs). This Statement, adopted by the National Assembly on September 16, 2008, is the bible on which the full poverty reduction strategy for 2009-2011 is based.

The full poverty reduction strategy is thus a continuation of the interim strategy. It builds on the achievements of the I-PRSP and embarks on new initiatives to consolidate the country's recovery. The F-PRSP thus does not break with the actions to promote peace and revitalize the national economy contained in the I-PRSP. On the contrary, it provides more signposts for the national development process with a view to achieving a considerable reduction of poverty.

Despite the efforts made by the Government to improve governance and revitalize the economy, implementation of the I-PRSP in 2008 resulted in economic growth $(1.1 \text { percent })^{26}$ that was lower than forecast $(3.0 \text { percent })^{27}$ and far below the population growth rate $(2.4$ percent). The global economic crisis, with the hike in oil and food prices, has adversely affected the performance of the Togolese economy, reducing the expected growth. As well as these crises which have affected all the countries of the planet to varying degrees, Togo is, like most countries in the West African subregion, facing an energy crisis that has slowed economic activity, particularly during 2008. In addition, the country has also suffered flooding, which has undermined national production and destabilized distribution circuits. The growth achieved, although comparable to that of previous years, must therefore be viewed in the light of the numerous shocks experienced by the Togolese economy in 2008. In order to enhance the ability of the economy to protect itself from such shocks, the Government intends, firstly, to lay the foundations for strong and sustainable economic growth and, secondly, to work towards strengthening of the newly restored peace and entrenchment of the principles of good governance.

In order to achieve this ambition, the Government intends to focus on four strategic pillars: (i) improvement of governance; (ii) consolidation of the bases of strong and sustainable growth; (iii) development of human capital; and (iv) reduction of regional imbalances and promotion of communities development. For these various pillars, it intends to integrate cross-cutting concerns related to the environment, HIV/AIDS, gender and human rights in order to make the full strategy the integrated framework for all national development activities.

\footnotetext{
${ }^{26}$ Indicators in the macroeconomic framework agreed with the IMF on February 25, 2009.

${ }^{27}$ Framework for the Interim PRSP.
} 
The interim strategy's strategic objective of improving political and economic governance led to the first strategic pillar of the F-PRSP, entitled « Strengthening of governance ». The country has made considerable progress implementing the main commitments of the Comprehensive Political Agreement and has initiated important reforms in the area of economic governance. With these results, a stronger consensus emerged among the public and politicians on the need to forge ahead with these political and economic reforms.

In the spirit of the Interim PRSP, the Government intends to pursue the promotion of good political and economic governance that commenced in 2005. For this purpose, four priority areas of intervention have been adopted for the next three years: (i) strengthening of political governance; (ii) promotion of institutional governance; (iii) implementation of administrative reform; and (iv) strengthening of economic governance.

\subsection{Strengthening of political governance}

The political calm which followed the Comprehensive Political Agreement is tangible proof that efforts to achieve peace, stability and security, through dialogue and consensus-building, are essential for Togo's recovery. Since the signature of the Agreement, Togo has embarked on a new political era market by the organization of legislative elections found to be transparent, fair and democratic, which resulted in the installation of a multipartite National Assembly. This was followed by a series of regulatory and institutional reforms needed for the consolidation of democracy, the rule of law and good governance. This was the context in which the Permanent Framework for Dialogue and Consensus-Building, the national dialogue on good governance, and the National Council for Social Dialogue were created. All these efforts can consolidate the factors that allowed the country to end the social and political unrest which formerly exacerbated people's poverty.

\section{Box 2: Comprehensive Political Agreement}

With the aim of consolidating national reconciliation and social peace, on August 20, 2006 the Government, the main political parties and certain civil society organizations concluded the Comprehensive Political Agreement (APG) providing inter alia for: (i) installation of a new National Assembly following a transparent, fair and democratic electoral process; (ii) measures relating to security, human rights, refugees and displaced persons; (iii) pursuit of the constitutional and institutional reforms necessary for the consolidation of democracy, of the rule of law and of good governance; and (iv) formation of a government of national union. In addition, there are final provisions on the creation of a permanent framework for dialogue and consensus-building on subjects of national interest; creation of a mechanism to monitor the correct fulfillment of commitments made; drafting of a Code of Good Conduct for political parties, civil society and the media; and advocacy with the international community, and particularly the European Union, for resumption of cooperation.

Source: APG, August 20, 2006

Continuation of the process of consolidation of political dialogue and of reforms to strengthen social cohesion is essential in order to create a political and social climate conducive to the pursuit of growth and poverty reduction policies. The Government therefore intends to intensify political and institutional reform with the support of the various political and social forces and of the development partners. For this purpose, the Government's goals are: (i) to consolidate the bases of democracy; (ii) to strengthen the capacities of the main democratic institutions of the Republic; (iii) to pursue reform of the army in order to guarantee its neutrality; (iv) to encourage civism; and (v) to closely involve civil society organizations in the management of public affairs.

Consolidation of the bases of democracy. Being aware that the enjoyment of human rights is a prerequisite for good governance, because it creates the necessary political and administrative processes for protecting the rights and freedoms and meeting the needs of the population, the Government intends to adopt a rights-based approach in designing legislative provisions, policies, 
programs and budget. This approach will bolster the anti-corruption measures based on accountability, transparency, assignment of responsibility, citizen participation, actors' capacitybuilding and empowerment of the poor. It will also consolidate the planning and decision-making process through the expanded consultations. A plan will thus be adopted for the mainstreaming of human rights $\mathrm{n}$ the reforms envisaged in this poverty reduction strategy, for example in the reform of administration and justice and in the implementation of international and regional mechanisms of democratic governance. ${ }^{28}$

The Government will also consolidate the democratic bases and achieve consensus among the main political forces for future electoral processes. For this purpose, it will: (i) improve the electoral framework; and (ii) strengthen the National Independent Electoral Commission by redefining its membership and duties with a view to the organization of free and democratic elections. In addition, the Truth, Justice and Reconciliation Commission will shortly be set up. The process of consensusbuilding initiated for this purpose will continue until the Commission is in place, in order to restore the Togolese people's confidence and achieve true reconciliation among Togolese citizens for a calmer democracy. The Government will also do everything possible to ensure that the Commission becomes operational.

Measures will therefore be taken to promote the role of the press in the enhancement of democracy. The aim will be to: (i) strengthen the capacities of the official press organs; (ii) to guarantee equitable access of the media to information and communication resources in accordance with the 22 commitments and the Comprehensive Political Agreement; (iii) to publicize legislation and legal precedents; (iv) human and technical capacity-building for the public and private media; and (v) promotion of democratic values and human rights by the media for the media.

Capacity-building in the main democratic institutions of the Republic. The Government will ensure that the counter-power institutions are functioning properly so as to consolidate the pluralist character of the Togolese democracy. This will include capacity-building in all the existing institutions of the Republic, including the National Assembly, the Constitutional Court, the National Human Rights Commission, and the High Audiovisual and Communication Authority. For the National Assembly in particular, a capacity-building program will be implemented with support from the partners. In addition, the national strategy for the consolidation of democracy and peace for development, the national civic training plan and the national program for the promotion and protection of human rights will be implemented.

Pursuit of the reform of the army to guarantee its neutrality. The Comprehensive Political Agreement emphasized the need to take action to allow the army to concentrate on its official role of defender of the territorial integrity of the nation. In this connection, the army has been given a new status and a consensus-building framework has recently been set up. Pursuit of the reform will enable the army to perform its mission of surveillance and defense of the territory more efficiently and its equipment will be upgraded, particularly as regards military engineering. A draft military program law will also be submitted to the National Assembly.

Promotion of civism. The Government intends to enhance the authority of the representatives of the State and the local authorities in the exercise of their functions and to ensure that the administration is independent of any pressure groups. Civism will be promoted through civics education geared to the values of the sense of the State, a conscientious civil service, systems to prevent and combat corruption and misappropriation of public funds, and communication with users. The Government will also endeavor to promote the culture of rewarding work well done and the practice of disciplinary sanctions in order to provide an added incentive for good practices in the management of public affairs, and particularly the culture of accountability.

\footnotetext{
${ }^{28}$ For example, the African Peer Review Meachanism, the Paris Declarastion and the Accra Agenda for Action on Aid Effectiveness, the Extractive Industries Transparency Initiative, the Integrated Framework for Trade-Related Technical Assistance and the African Public Service Charter.
} 
Close involvement of civil society organizations in the management of public affairs. The Government's decision to involve civil society agrees with its new vision of participatory management of public affairs, especially as regards poverty reduction, good governance, preservation of the environment, advancement of women and respect for human rights. Civil society is therefore represented at all levels of the institutional framework for implementation, monitoring and assessment of the PRSP. For this purpose, a program of capacity-building for civil society organizations will be designed and implemented.

\subsection{Promotion of institutional governance}

The Constitution of October 14, 1992, provided for the creation of a number of institutions to guarantee democracy and promote the rule of law. Most of them have now been put in place, with the exception of the Audit Office and the Economic and Social Council. In addition to these constitutional institutions, the Government has undertaken, together with the other partners, to study the creation of new institutions in a desire to achieve a calmer political situation.. The Government will work with all politicians to ensure that all shades of opinion are represented in the institutions.

Despite the Government's determination to upgrade the Togolese justice system and made it credible, this system has glaring shortcomings, aggravated by the corruption and lack of independence of the bench. These two factors are major blemishes on the image of justice and the people's confidence in the ability of the judicial institutions to help promote democratic governance. Justice is also adversely affected by the weak administration of chancery, the poor monitoring of courts due to the shortage of competent staff and the lack of rationalized budgetary supervision to enable courts to function properly.

In order to deal with all these constraints, highlighted by an in-depth diagnostic assessment in 2004, the Government, with the support of the partners, has set up a National Program the Federal Republic of Germany the Modernization of Justice (PNMJ) to promote an independent justice that is fair to everyone. The issues tackled by this program include problems of competence, equipment of courts, public access to justice, shortcomings of the prison system, and incorporation in the judicial system of requirements connected with the OHADA Act. As regards institutional governance, the Government reaffirms its commitment to build on the progress made in the modernization of justice. It therefore intends: (i) to continue implementation of the PNMJ; (ii) to put in place all the constitutional institutions and enable them to function; and (iii) to strengthen the rule of law and the security of persons and property.

Continuation of implementation of the National Program for the Modernization of Justice. This will involve: (i) drafting of legislative and regulatory texts; (ii) creation of the necessary courts for a modern system of justice; (iii) creation of operational and durable courts; (iv) upgrading of the human, material, technical and financial resources of Government Procurator's Office; and (v) capacity-building in the General Inspectorate of judicial and penitentiary services. A code of ethics will be formulated for each of the legal professions and the new texts of the Supreme Council of the Judiciary will be adopted. A national policy of legal extension services will be adopted and implemented. In the context of the improvement of the business environment, an appropriate legal and judicial framework will be studied and put in place, in order to provide real security for the business world.

Establishment of all the constitutional institutions. The Audit Office will become operational when the judges have been appointed and trained and this institution has been provided with adequate human, material and financial resources. In addition, steps will also be taken to make the Economic and Social Council operational.

Strengthening of the rule of law and of the security of goods and persons. Effective enforcement of the necessary legal texts helps to make institutions credible and is a guarantee of the security of persons and property. In addition, campaigns to make people aware of their rights and duties and of 
the importance that they should attach to human rights in the harmonious development of the country, as well as capacity-building in the security forces (police, gendarmerie, firemen and guardians of the security of the territory) to improve their human, material and technical resources, will be of great help in the achievement of the goals sought.

\subsection{Implementation of administrative reform}

A number of assessments of public administration in Togo have highlighted difficulties and inefficiencies in the management of institutions and in the human resources needed for development. These administrative inefficiencies, exacerbated by large-scale retirements of government officials and the civil service recruitment freeze, resulted in considerable capacity deficits in key development sectors. To address these shortages, the Government, with the support of its partners, launched the public administration reform process by organizing the Estates General of Public Administration (Etats Généraux de l'Administration Publique - EGAP) in 2006.

The main issues discussed during these Estates General concerned modernization of public administration, development of human resources, and training and retraining of public administration officials. To deal with the difficulties identified, the Government started in 2006 to take urgent action designed, firstly, to improve the remuneration of government officials and, secondly, to freeze some retirements. The retirement age was therefore increased to 60 for category A public administration officials in general and to 58 for officials in education and health categories B and C.

In addition, local authorities are to play an important role alongside the Government in ensuring that the basic equipment for achievement of the MDGs is provided and functions properly. In accordance with the Constitution of October 14, 1992, and in pursuance of the provisions of its article 141, Law No. 98-006 of February 11, 1998, on decentralization provides for three levels of decentralization: the commune, the prefecture and the region.

Unfortunately, enforcement of this Law has been very limited because of its shortcomings. In practice, only the thirty (30) prefectures and twenty-one (21) urban communes are operational. These communities have been headed by special delegations since 2001 . In order to jump start the decentralization process, the Government drew up a consolidation program, which it adopted in the form of the sector policy letter of June 9, 2004. It was in this context that Law No. 2007-011 of March 13, 2007 was adopted.

In the medium term, the Government intends, firstly, to continue the reform of the administration and, secondly, to accelerate the decentralization process. In this connection, the Government has the following goals: (i) to monitor the quality of services to users (citizens and enterprises); (ii) to reduce the administration's internal and external communication deficiencies; (iii) to promote land use planning; and (iv) to enhance the decentralization process.

\section{Box 3: Sector policy letter on consolidation of decentralization}

In order to enable local authorities to eventually assume responsibility for reducing poverty and improving the wellbeing of the population, particularly by delivering basic public services, on June 9, 2004 the Government adopted the sector policy letter on consolidation of decentralization, which describes the approach adopted for full implementation of the decentralization process in Togo. In this policy letter, the Government commits itself to moving towards real and effective decentralization, requiring partly autonomous regions that are strong and operational as well as effective decentralized government services. These regions and decentralized services together form a coherent and complementary mechanism for the delivery of quality public services to the public. In order to make this vision of partnership between the State and the partly autonomous regions operational, eight (8) areas of intervention were defined: (i) clarify and supplement the existing legal framework; (ii) create decentralized partly autonomous regions throughout the country; (iii) revitalize and develop the system of financing local authorities; (iv) provide partly autonomous regions with human resources and build their capacity; (v) create a mechanism to support the decentralized partly autonomous regions; (vi) improve supervision and intensify government decentralization; (vii) promote briefing, mobilization and participation of all those involved 
in decentralization; and (viii) give decentralized partly autonomous regions their own funding.

Because decentralization is a cross-cutting issue, it is a strategy which influences every other public strategy. For example, a program to consolidate this process in all sectors has been set up for a five-year period. Implementation of the program will involve a three-pronged arrangement: (i) a Decentralization Policy Guidance Commission responsible for establishing the main guidelines for the consolidation of decentralization and for ensuring that they are compatible with other sectoral policies; (ii) a Decentralization Monitoring Committee responsible for translating the policy guidelines into a series of specific technical tasks and for monitoring the conduct of the process; and (iii) a Technical Team responsible for performing the tasks needed for the preparation and implementation of the program.

Source: Ministry of the Interior, Security and Decentralization, 2004

Improvement of services to users. The achievement of this goal will require the creation of the strategic framework for the reform of public administration, involving: (i) redefinition and clarification of government missions; (ii) public administration capacity-building; (iii) rationalization of structures and standards; (iv) improved efficiency of government work; (v) promotion of a motivating and modern work environment in the administration; (vi) promotion of a programmatic and institutional framework of administrative reform in order to spearhead reform and modernization of the administration. In addition, modernization of the administration requires: (vii) depoliticization of the public administration; (viii) improvement of service delivery by creation of a system allowing questioning of the actors concerned; and (ix) evaluation of administrative performance.

Reduction of the administration's internal and external communication deficiencies. Automation, devolution of administrative procedures and promotion of information and communication technologies (ICT) are essential for the achievement of this goal.

The administration's intranet and extranet communications have shortcomings complicating the introduction of procedures for modern management of government personnel. Users of public services do not receive clear information in real time on their various concerns. Web sites, when they exist, do not give users sufficient information concerning their queries.

Within the national framework for modernization of the administration, the Government is committed to: (i) preparing guidelines for automation and ICT development; improving the flow of information between officials and users of public services, through an appropriate system of data transmission; simplifying administrative procedures and formalities in order to improve the efficiency of government services and (ii) promoting the development of an electronic platform for the administration (e-government).

Various methods will be used to facilitate access by the public to government services. Means of access to ministries and to administrative units and multimedia centers will be created.

\section{Box 4: Strategic framework for the reform of public administration}

The strategic framework for the reform of public administration responds to the need to address shortcomings in the public administration and difficulties connected with the institutional framework and management of the Government's human resources. The framework is the result of the process of public administration reform launched at the Estates General of Public Administration in 2006. This strategic framework is mainly designed to improve the quality of services to users by means of consensus-building, local management and meritocracy. The strategic directions concern: (i) redefinition and clarification of government missions; capacity-building in the Togolese public administration; (iii) rationalization of administrative structures and standards; (iv) enhanced effectiveness of government work; (v) promotion of a motivating and modern work environment in the administration; and (vi) promotion of a programmatic and institutional framework for administrative reform. The strategic framework for the reform of public administration covers the period 2008-2015 and will be implemented in two phases. The first phase (2008-2012) will consist of preparation and testing of the reform. It includes an emergency program (2008-2010) involving improved coordination of government activities, 
adoption of temporary capacity-building measures in certain ministries (Civil Service, Finance, Development, Education, Health, Agriculture, Infrastructure) and creation of the prerequisites for administration reform. The second phase (2012-2015) involves consolidation and extension of the progress made, moving away from the pilot structures and key functions to target the entire Togolese public administration in which a new regulatory framework (legal, organizational and institutional) has been adopted..

Source: Ministry of the Civil Service, Administrative Reform and Relations with the Institutions of the Republic, 2008

Land use planning. The Government intends to reduce regional and structural imbalances by pursuing a land use policy based on decentralization and devolution of the administration. The partly autonomous regions will thus be required to create and rationally manage their local resources and to promote their local development in the spirit of gender equity.

In this context, the Government adopted the National Land Use Policy Statement (DEPONAT). This Statement reflects the general thrust of the WAEMU community land use policy. Following the adoption of this Statement, a national land use policy was formulated and will provide a reference framework for all activities as soon as it has been adopted by the Government.

The main purpose of this project is to mitigate the effects of the domination of the capital, Lomé, by giving the country's other regions and towns every opportunity for development, particularly through the policy of linking of major roads, creation of administrative and social facilities (hospitals, schools, etc.) and creation of basic infrastructure to promote handicraft activities and small and medium-size industries.

In order to achieve this goal, the Government will focus on: (i) adoption of the land use policy to deal with problems of natural resource and environment management, resulting in the formulation of land use plans (ATLAS, SNAT, SRAT, SLAT); (ii) establishment of bodies for analysis, guidance and coordination of land use and decentralization at the national, regional and local levels; (iii) updating of national, regional and local land use plans; (iv) adoption of procedures for reflecting the principles of the overall land use plan in the programming of sectors and local authorities; (v) recruitment of qualified land use specialists; and (vi) training for persons involved in land use.

Box 5: National Land Use Policy Statement

In order to address shortcomings in the organization and management of the national territory, the Government adopted the National Land Use Policy Statement (DEPONAT) in 2006. This new approach to the spatial management of economic and social activities is both participatory and decentralized and takes into consideration national, regional and local, specificities, potential and constraints. The formulation and implementation of the land use policy reflects the following guiding principles: (i) national unity and solidarity; (ii) global and forward-looking vision; (iii) consistency of sectoral policies; (iv) complementarity; (v) development sustainability; (vi) participation of all actors; (vii) subsidiarity; and (viii) regional integration. The instruments for the planning and implementation of land use policy are: (i) the National Land Use Plan (SNAT); (ii) the Regional Land Use Plans (SRAT); (iii) the Local Land Use Plans (SLAT); and (iv) the Atlas of Togolese Regional Development.

Source: DEPONAT; Ministry of Cooperation, Development and Land Use

Strengthening of the decentralization process. This will result in: (i) creation of a comprehensive legal arsenal and finalization of implementing legislation; (ii) improvement of the efficiency of existing partly autonomous regions by means of an organizational and financial audit and updating of local competences; (iii) transfer of skills and resources; (iv) adoption of a strategy of information, awareness-raising, training and mobilization of actors; (v) creation of mechanisms to provide technical support (training and follow-up) and financial support to local authorities; and (vi) organization of local elections. In addition, implementation of the National Program of Decentralized Action for Environmental Management (PNADE) should be accelerated. 
In order for local management to be effective, local authorities must have responsible persons to deal with locally; hence the need for devolution of authority and capacity-building in the devolved structures. Measures for the transfer of skills and resources will therefore be studied and gradually introduced. The program of capacity-building in devolved structures will take into consideration to new demands placed on those structures by the Government's plans for grassroots development.

\section{$1.4 \quad$ Improvement of economic governance}

In the context of implementation of the Interim PRSP, the Government has embarked on reforms to improve economic governance. These include incorporation of WAEMU directives in national legislation, unification of arrangements for preparation of the government budget, introduction of the Integrated Public Finance Management System (SIGFIP), abolition of exceptional expenditure execution procedures, creation of the General Inspectorate of Finance, adoption of a strategy for clearance of the domestic debt, etc. Although the initial results of these reforms are encouraging, much remains to be done, in particular as regards predictability and monitoring of budget execution to ensure that budget revenue exceeds 18.2 percent of GDP by 2011 and that the budget surplus is at least 1 percent of GDP by the same date. In order to achieve this, the Government intends: (i) to continue fiscal consolidation; (ii) to intensify anti-corruption measures; (iii) to ensure transparent management of procurement; and (iv) to pursue coordination and sound and effective management of aid flows. The economic and financial reforms envisaged to this end will be coordinated and there will be a system for careful monitoring of their implementation.

Continuation of fiscal consolidation. Several aspects will be covered, including: (i) strengthening of domestic resource mobilization; and (ii) pursuit of improvements in the management of public spending.

The Government plans to mobilize additional domestic resources by: (i) continuing its strategy of expanding the tax base and improving collection; (ii) simplifying and rationalizing taxation and customs codes in line with WAEMU directives; and (iii) reducing exemptions, including free trade zone exemptions. To this end, the Government will take action to improve monitoring of the system of exemptions laid down in the customs and tax codes; introducing tax audits based on risk evaluation; and (v) recruitment of staff for the tax administrations.

The Government will focus on improving the management of government spending by introducing a strict budget policy. In this connection, the following priority measures are envisaged: (i) accelerated harmonization of the legal framework for public finance with the WAEMU directives; (ii) gradual introduction in government budget preparation of Medium-Term Expenditure Frameworks (MTEFs) and program budgets; (iii) complete consistency between investment budgets and medium-term expenditure forecasts; (iv) reduction of discrepancies between expenditure forecasts and actual disbursements; (v) improvement of budget nomenclature to meet analysis requirements; (vi) complete traceability of grant operations in the adopted budget and in the budget execution reports; (vii) improvement of methods for managing the annual cash flow plan; (viii) improvement of monitoring of government budget execution by SIGFIP to allow real-time monitoring of expenditure by budget item; (ix) improvement of cash management, in order to prevent accumulation of domestic arrears; (x) effective implementation of the debt clearance strategy; (xi) adoption and implementation of debt strategy; and (xii) adoption of an action plan to reform government bond issues. Budget policy will also aim to increase budget allocations for health, education, agriculture and basic public infrastructure including energy, transportation, water and sanitation. In addition, reforms will be considered to update budget procedures and particularly the preparation, execution, monitoring and validation of accounts.

The Government will place particular emphasis on controls to prevent wastage and misappropriation. The actions envisaged to this end are: (i) entry into operation of the General Inspectorate of Finance; (ii) appointment of the members of the Audit Office and its entry into operation; (iii) training of officials responsible for reporting and preparation of the final budget execution law; (iv) regular 
preparation of management and administrative accounts and draft final budget execution laws to facilitate the work of the Audit Office; (v) capacity-building in the General Government Inspectorate; (vi) processing of inspection reports; and (vi) consideration of public accounts and draft final budget execution laws.

In order to address the shortage of information on public finance management, the Government will ensure that financial documents are issued. For example, the following measures will be taken: (i) observance of the constitutional deadline for submission to Parliament of the draft finance laws; (ii) disclosure of draft finance laws to the media; (iii) regular posting on the Web site of the Ministry of the Economy and Finance of all financial documents, including expenditure statements, procurement, data on the government debt; and (iv) improvement of information on budget execution under the SIGFIP.

The Government will continue the ongoing reform of finance administration, including: (i) transformation of the Budget Directorate General; (ii) amendment of Decree No. 2001-155/PR of August 20, 2001 on the organization of the Directorate General for the Treasury and Public Accounting (DGTP) to add a department responsible for preparing revenue and expenditure accounts for audit, in order to ensure that the revenue and expenditure accounts produced by the main accountants are accurate and have sufficient supporting documentation; ${ }^{29}$; and (iii) capacity-building in the finance administration for the training and recruitment of new qualified staff. Thus macroeconomic forecasting capacity will be strengthened and there will be better linkage between forecasting and budgeting.

Strengthening of anti-corruption measures. The Government considers that the consistent and rapid implementation of reforms of public finance management will also have the direct effect of considerably reducing the risk of corruption in the management of government funds. These measures will be supplemented by the creation of a framework of transparency covering all areas of public life, so that public resources are used to provide quality public services equitably distributed to the population. In this connection, efforts will be concentrated on the following actions: (i) formulation of a national anti-corruption policy; (ii) creation of an institutional framework consistent with existing structures; and (iii) adoption of an action plan designed to prevent this scourge and to ensure equitable and transparent treatment of corruption cases by the competent courts.

Improvement of the procurement system. The Government plans a number of measures to make the system more transparent. These measures are also part of the reforms to bring the Togolese system into line with international standards in order to improve the effectiveness and efficiency of public spending. The measures are diverse and affect all areas of the procurement system in Togo. In order to achieve this goal, the Government is committed to adopting the following measures: (i) transposition of the WAEMU directives on procurement into the national legal order; (ii) drafting of a new procurement code to make procurement arrangements more transparent and less centralized; (iii) drafting of implementing texts describing procurement procedures; (iii) effective enforcement of the texts on the subject; (iv) drafting of a handbook of procedures for the use of all persons involved in public procurement; and (v) adoption of arrangements to ensure strict expenditure monitoring.

Coordination and sound and effective management of aid flows. Since coordination and sound and effective management of aid flows will bolster the confidence of donors and development partners, the Government has adopted certain measures under I-PRSP, such as application of the WAEMU regulation whereby only the Minister of Finance is authorized to incur and guarantee foreign debt on behalf of the State, adoption of a national debt strategy and establishment of a national committee on the public debt.

The Government intends to go further by creating an efficient national framework for the sound and effective management of aid flows. In this connection, the following goals will be pursued: (i)

${ }^{29}$ This formality is compulsory and essential for the functioning of the Audit Office. 
implementation of the principles of the Paris Declaration and the Accra Agenda for Action; (ii) acceleration of the process for rapid attainment of the HIPC completion point; and (iii) accelerated formulation of a national policy for management of external aid.

For this purpose, the following priority actions are envisaged: (i) efficient implementation of the FPRSP priority actions; (ii) conduct of a prospective study providing a long-term vision for Togo; (iii) formulation of a national policy for management of foreign aid, clarifying the responsibilities of the various ministries and partners for the identification, formulation, implementation and monitoring of development programs; (iii) creation of a system for aid management and of appropriate structures; (iv) formulation of an action plan for capacity-building in the area of monitoring and assessment of the Priority Action Program (PAP) of the F-PRSP; (v) briefing and training of government officials in results-based management; and (vi) establishment and effective use of the Government-Donors Committee envisaged in the PRSP institutional framework for mutual monitoring of the fulfillment of partnership commitments under the Paris Declaration. With regard to the Accra Agenda for Action, an action plan will be formulated and implemented (installation and use of a harmonized and remotely accessible data system) for this Agenda. In addition, a mechanism for technical assistance monitoring and coordination will be set up. The capacity of the officials in charge of international cooperation to negotiate and mobilize resources will also be strengthened in order to ensure adequate financing of the F-PRSP and to align support with national priorities.

In the context of implementation of the full strategy, the Government believes that sizeable aid flows can be mobilized directly by non-State actors. To this end, it intends to promote capacity-building for these actors, namely civil society organizations, with a view to achieving a better management of these resources.

\section{Second Pillar: Consolidation of the Foundations of Strong ANd SUSTAINABLE GROWTH}

Through this second strategic pillar, the Government intends, over the next three years, to look beyond immediate economic recovery by creating new foundations for stronger, more lasting, and more sustainable growth. To that end, nine key areas have been targeted in order to channel interventions in such a way as to promote economic growth: (i) strengthening the structural reforms; (ii) improving the business environment; (iii) promoting sources of economic growth; (iv) developing infrastructures to support economic growth; (v) enhancing regional integration; (vi) effectively managing natural resources, the environment, and the living environment; (vii) redistributing the fruits of economic growth; (viii) creating jobs; and (ix) promoting research.

\subsection{Strengthening the structural reforms}

For the Government, consolidating the foundations for strong and sustainable growth means first of all reducing national production factor costs. In fact, the weight of Government involvement and official capital in certain key sectors of the economy and related management problems have always been sources of major distortions in the Togolese economy, thus posing impediments to economic growth. During the years of structural adjustment, actions were carried out to remove these impediments, but not all of them achieved their goals. To improve the returns on anticipated investments in growth sectors over the coming years, the Government has resolved to see these reforms through to a successful conclusion. To that end, the following objectives have been identified: (i) restructure public enterprises; and (ii) rehabilitate the financial sector.

Restructure public enterprises. The reforms introduced at Société Togolaise de Coton (SOTOCO) and Société Nouvelle des Phosphates du Togo (SNPT) will be continued. Special attention will be given to Compagnie Energie Electrique du Togo (CEET) and Togolaise des Eaux (TdE), charged respectively with managing power and water distribution. The management standards for public enterprises will be improved across the board to make them more efficient. 
In regard to SOTOCO, its dissolution has been decided and a semipublic company, Nouvelle Société Cotonnière du Togo (NSCT), has been created in its place. The Government will hold 60 percent of the new company's capital, and the cotton producers' federation will hold 40 percent. Its management will be based on rules of transparency, and costs will be minimized and the industry's profitability will be improved through clear rules of procedure, the introduction and implementation of analytic accounting, and meaningful, regular external oversight. In the medium term, the Government intends to transfer a portion of its shares in the new company to a private strategic operator so that Government becomes a minority shareholder.

With respect to Société Nouvelle des Phosphates du Togo (SNPT), the dilapidated facilities and heavy liabilities which it inherited from the defunct companies Office Togolais des Phosphates (OTP) and International Fertilizer Group (IFG) prevent it from reaching a sufficient level of production for it to profit from the upturn in world prices and reestablish its financial viability. A strategic and financial audit now under way is focusing on the company's performance, its organizational structure, the condition of the facilities and equipment, and, more broadly, the economic, financial, social, and environmental aspects of the phosphate industry. The results of this audit will be used to develop a detailed action plan for restoring the company's long-term viability and its contribution to economic growth. Furthermore, in view of the importance of this industry in the national economy, the Government will make arrangements for periodically publishing, in the spirit of the Extractive Industries Transparency Initiative (EITI), a report reconciling the data on assessments paid to the Government and the data recorded by the Treasury. In addition, manuals of procedures will be instituted within the company to make its management more transparent.

As for Compagnie Energie Electrique du Togo (CEET), improving its performance is necessary to ensure a continuous power supply to households and businesses, which has been lacking in recent years, although the long-term solution to this problem hinges on concerted action at the subregional level. A performance contract has been set up between the Government and CEET with a specific emphasis on cost control, grid loss reduction, and the level of subsidization required to maintain the utility and increase the number of households served.

For its part, Togolaise des Eaux (TdE), which is the primary water distribution operator in urban centers throughout the country, lacks adequate means and resources for successfully carrying out all the tasks and responsibilities placed upon it by the institutional environment. In addition, there is a lack of transparency of responsibilities between TdE, on the one hand, and the Safe Drinking Water and Sanitation Sector Development Fund (FODESEPA), which has a poorly defined role and which is managed in part by TdE management, on the other. As a result, the institutional environment has not been conducive to mobilization of the financial resources which the safe drinking water sector needs in order to maintain and develop service for urban populations. Faced with this risky situation for the sector, the Government has moved to deepen its reform of the safe drinking water sector in urban areas of Togo in order to clearly distinguish the role of operator from the role of asset manager. This reform should culminate in the dissolution and liquidation of FODESEPA and the creation of an asset management company charged with programming and carrying out investments. TdE will retain its mandate to operate the service assigned to it. An affermage contract will be concluded between the Government, the operator, and the asset management company. Implementation of the reform should lead to: (i) adoption of the FODESEPA dissolution decree; (ii) adoption of the decree establishing the asset management company; and (iii) consecration of TdE's role as a company to which state property is assigned in the urban safe drinking water sector.

With respect to improving the management standards for public enterprises, the Government will see to strict enforcement of the provisions of Law No. 90-26 of December 4, 1990, particularly in regard to how the legal bodies of the enterprises function, how technical and management supervision are performed, and regular monitoring of the operations of all these mechanisms through a revitalized Management Information System. In addition, minimum standards will be established for external oversight of public enterprises, to be performed by independent auditors. 
Rehabilitate the financial sector. The reforms will focus on rehabilitation of the compromised portfolio of banks with official capital, transfer of state shares in these establishments so that Government becomes a minority shareholder, and stronger banking oversight.

With respect to rehabilitation of the compromised portfolio of banks, a securitization operation has been set in motion, thus enabling the banks involved to regain an effective equity position that meets the risk coverage ratio standard of 8 percent, and thereby creating the possibility of obtaining refinancing by the Central Bank. In addition, the BCEAO Board of Directors has given its authorization for the securities issued to be eligible for refinancing by the issuing institution. Also, a study will be carried out on setting up an entity or a mechanism for recouping compromised debt taken over by the Government.

In regard to privatization of public banks, a request for bids will be issued for the purpose of selecting model partners capable of injecting the necessary capital to meet the new minimum capital standards and bringing firsthand banking technology to the establishments.

With respect to stronger banking oversight, the objective here is to ensure that credit institutions comply with WAEMU prudential standards and prepare themselves to adapt to the planned reform of the banking regulations. From this angle, public banks will be provided with governance mechanisms based on well-defined procedures that generate reliable data.

\subsection{Improving the business environment}

The general business environment in Togo, which is already very difficult for investors and private operators, continues to regress notwithstanding the fact that investment decisions hinge on the existence of a good environment. Currently, the procedure for starting a business involves a tedious process that takes an average of 53 days (versus the regulatory standard of 14 days). The two entities in charge of this process, namely the Business Formalities Center (CFE) and the Free Trade Zone Administration Company (SAZOF), are far from satisfactory in terms of their performance. The results of the World Bank's latest "Doing Business" surveys permit a more accurate assessment of the business environment in Togo in comparison to other countries of the world. Of the 181 countries in the 2009 sample, Togo is ranked $163^{\text {rd }}$. This position is worse than in previous years $\left(154^{\text {th }}\right.$ in 2005 , $151^{\text {st }}$ in $2006,156^{\text {th }}$ in 2007 , and $159^{\text {th }}$ in 2008). The numerous constraints highlighted by these various reports include, among others: (i) the tax burden; (ii) the cumbersome administrative requirements associated with international trade, starting a business, protecting investors, and executing contracts; (iii) the functioning of the judicial system; and (iv) the difficulties of the banking system.

To address these issues, the Government has adopted the following objectives: (i) improve the general business context; (ii) revitalize the industrial free trade zone, starting with revision of Law No. 89-14 of September 18, 1989 which establishes free trade zone status for the processing of exports; (iii) improve the system of private sector development and support; (iv) improve conditions for the emergence of entrepreneurship; and (v) reduce the cost of credit and improve access to financing.

Improve the general business context. To reduce the complexity of the procedures for starting a business, the Government had already decided to set up a one-stop shop for the administrative formalities involved in starting a business. It is now of critical importance that the country adopt a more effective and more dynamic institutional framework for the facilitation of local and foreign investment. From this perspective, emergency measures will be taken in line with the recommendations of recent studies. This means setting in place: (i) a dynamic institutional framework (an effective investment promotion agency ${ }^{30}$ coupled with a true one-stop shop where all operations related to starting a business will be completed); and (ii) an efficient policy framework which will help substantially to improve the business environment. Other measures will focus on

${ }^{30}$ The reform under way at SAZOF will allow it to legitimately fill this role. 
rehabilitating the legal and judicial environment and simplifying business taxes, on top of the decision already made by the Council of Ministers in August 2008 to reduce the tax rate from 37 to 30 percent for industries and from 40 to 33 percent for other companies. In regard to the legal and judicial environment, the national program to modernize the system of justice, now under way, should help identify fitting solutions to the challenges of a shaky judicial system.

Revitalize the industrial free trade zone. The Government is aware that none of the problems identified can be analyzed in isolation, but only as part of a larger set of problems, which cannot be well understood and resolved unless a global, integrated approach is adopted. This explains why the question of improving the business environment in Togo also encompasses revitalization of the free trade zone, given its growth potential and its impact on the national economy. In fact, the growth of Togolese manufacturing industries is today being driven to a large extent by exports and, as a result, by the free trade zone. Authorized businesses in the free trade zone employed 8,220 persons at the end of 2007, with a wage bill of CFAF 5 billion. The total business volume of these businesses in 2007 came to CFAF 137 billion, of which CFAF 115 billion in exports. Cumulative investments over the period 1990-2007 totaled CFAF 75 billion (in constant prices). These results are a simple reflection of the principal advantages of the free trade zone, namely: (i) favorable tax and customs treatment; and (ii) a low wage scale for relatively skilled labor, with satisfactory productivity from the employers' point of view. In addition to the difficulties associated with factor costs (particularly electricity and telecommunications, port services, and air freight), the lack of industrial land in the port area and the currently dilapidated state of urban infrastructure in Lomé and in the interior also come into play.

Faced with this situation, the Government, while striving to reduce factor costs, the cost of port services, and air freight costs, is also committed to improving the free trade zone's performance so as to increase its growth potential. With respect to the availability of land, the planned solution is to create and develop a new free trade zone situated some 20 kilometers to the north of Lomé. Accordingly, studies will be carried out to target potential investors and site developers, based on detailed analyses of the production and transportation costs of competing companies.

Improve the system of private sector development and support. In the medium term, this will involve reorganizing existing entities to make them effective partners of the private sector. This will require, first of all, building the capacities of the National SME/SMI Promotion and Financing Guarantee Agency and the Informal Sector Organizing Commission, which will be asked to assume responsibility for providing support to private companies and informal private sector actors. Next, the semi-public and private entities that provide support for private sector development (Chambers of Trade, Chambers of Agriculture, Chamber of Commerce and Industry of Togo, National Council of Employers, private consulting firms, Association of Togolese Consultants, Association of Free Trade Zone Companies, etc.) will be revitalized to play their role more effectively. In addition, a mediumterm study will look at the possibility of recombining all these private sector development entities into a single agency called the Business Center (Maison de l'Entreprise).

Improve conditions for the emergence of entrepreneurship. Promoting entrepreneurship will involve: (i) support for actions capable of contributing to the development and training of local entrepreneurs, in particular by promoting a spirit of initiative and creativity; and (ii) development of a network of support and information serving the range of private sector economic operators. The Government will also set in place mechanisms to promote quality and productivity through: (i) implementation of an information and measurement system on standards, productivity indicators, etc.; (ii) analysis of obstacles to the development of production and productivity and of requirements in terms of standardization and actor awareness-raising, with an eye to boosting the levels of labor and capital productivity; (iii) analysis of comparative standards for the various production costs by adopting standards that are truly in tune with working conditions in the various sectors of activity; (iv) implementation of a permanent system for detecting cost overruns and poor quality; (v) completion of thorough productivity audits and forward-looking studies for ensuring the sustainability of business activities; (vi) introduction of new production techniques, new products, and growth markets; (vii) establishment of a new industrial site to house new initiatives, since the old site in the port area is 
already saturated; and (viii) establishment of a credible facility for calibrating marketers' and manufacturers' equipment (a reference laboratory containing, among other things, calibration instruments that measure basic magnitudes such as length, mass, time, electric current, pressure, volume, temperature, etc.).

To coordinate these actions most effectively, it is important to formulate a forward-looking vision of private sector development with the active participation of economic operators.

Reduce the cost of credit and improve access to financing. The Togolese financial system comprises 11 commercial banks, plus financial establishments and microfinance institutions. There are other subregional financial establishments able to finance the private sector, ${ }^{31}$ but they seem to be largely unknown to economic operators. The Togolese financial system recorded a bankarization rate $^{32}$ of 21.6 percent in 2007. This rate reflects the difficult access to bank products and services for the great majority of potential customers. One of the most serious impediments to private sector development is the insufficient range of products offered by the banking system, in relation to the private sector's actual needs. The commercial banks offer direct credit (regular credit and seasonal credit) and commitments by signature. They are very little involved in financing a business's bottom line. Direct credit typically takes the form of short-term credit directed towards commercial operations, while the private investments likely to generate strong growth (processing, etc.) require medium- and long-term credit. This gap is accentuated by the nonexistence of leasing institutions or a mortgage market. Furthermore, the SME/SMIs that apply for credit fail to obtain it, in most cases, for lack of formal entities capable of carrying out studies to demonstrate the profitability of their business. On top of all that, the banking and financial sector suffers from a number of internal constraints, such as poor lending policies, organizational problems, management problems, and intrinsic violations of banking and prudential regulations. In addition, the system has for many years endured a difficult sociopolitical environment, resulting in an excessive volume of bad debt.

In view of this somber assessment of the financial sector, the Government's goal is to help the sector better organize itself so as to find appropriate solutions for business financing and thereby help businesses strive in turn to fulfill the Government's vision, which is to make the private sector the engine of growth in the coming years. To that end, several different types of financing will be promoted.

Private sector financing by banks and regional institutions. The effort to improve the financial context is focused on the adoption of appropriate measures to make the banking system more effective at financing all the different components of the Togolese private sector (large businesses, SME/SMIs, informal sector actors, etc.). To that end, the following actions will be undertaken: (i) expand and diversify the financial services offered by the banking system already in place, consistent with the needs of economic operators; (ii) raise the awareness of entrepreneurs and provide them with information/training on financing mechanisms and financial instruments; (iii) adopt measures conducive to more professional credit allocation so as to reduce the costs incurred by customers; (iv) set up a guarantee mechanism to promote private initiative, youth entrepreneurship, and women's entrepreneurship; (v) promote the financing of private initiatives through preferential and subsidized rates for young entrepreneurs; (vi) lobby development partners for the purpose of mobilizing credit specifically earmarked for building the capacities of economic operators, mainly in regard to putting together an application, which in this case means project feasibility and management studies, with an eye to ensuring the sustainability of productive activities and miscellaneous services; and (vii) establish a Business Recovery Fund (FRE) which will facilitate access to long-term credit for Togolese businesses with terms of interest and grace periods more appropriate to their activities.

\footnotetext{
${ }^{31}$ Namely: Cauris Investment (of BOAD), Investment Guarantee Fund (GARI), African Guarantee Fund for External Trade (FAGACE), and Cultural Industries Guarantee Fund (FGIC).

${ }^{32}$ Ratio between the number of personal accounts and the size of the working population.
} 
Private sector financing by MFIs. With adoption of the National Microfinance Strategy (SNMF) in 2004, development partners, particularly UNDP and the United Nations Capital Development Fund (UNCDF), provided support for strengthening the institutional framework, thus permitting a merger of the two trade organizations (ALAFIA Consortium and the Trade Organization of Microfinance Institutions of Togo) and greater oversight by the Mutual Institutions and Savings and Credit Cooperatives Support and Monitoring Unit (CAS-IMEC). Thus, as of the end of June 2008, microfinance institutions (MFIs) were able to collect CFAF 60.3 billion in the form of deposits, i.e. 15 percent of the banking system's assets, and grant CFAF 48.7 billion, equivalent to 14 percent of all bank credit, for a total financial flow of more than CFAF 109 billion. In the same period, the number of direct service beneficiaries was 536,321 individuals and groups.

This trend has, however, been accompanied by a number of problems, as follows: (i) noncompliance with legislative, regulatory, and statutory provisions; (ii) a shaky information and management system, as reflected in the limited reliability of the financial statements of some microfinance institutions; and (iii) weak internal and external oversight mechanisms, resulting in a proliferation of cases of financial fraud and embezzlement. The scope of these problems has made it necessary to take certain measures to circumscribe the risks that have been identified. To that end, in 2008 BCEAO proposed a bill to regulate decentralized financial systems in replacement of Law No. 95-014 of July 14, 1995 which regulates mutual institutions and savings and credit cooperatives. This bill was adopted by the Council of Ministers in November 2008 and is pending adoption by the National Assembly.

\section{Box 6: National Microfinance Strategy}

With financial support from UNDP and UNCDF, a National Microfinance Strategy Support Program (PASNAM) was implemented with considerable impact on the sector in terms of improving the institutional environment, the professionalism of microfinance institutions (MFIs), and the articulation between banks and MFIs. The National Microfinance Strategy (SNMF) implemented over the period 2005-2007 was reviewed in August 2007 and led to the development of a new strategy covering the period 2008-2012. This review provided the opportunity to incorporate new needs and challenges emerging in the sector. At a total cost of CFAF 19.7 billion, the goal of the new strategy is to have a diversified, innovative financial sector that provides satisfactory coverage of the demand for services nationwide and that operates within an appropriate and favorable legal, regulatory, tax, and policy framework. The SNMF priorities for the period 2008-2012 are to: (i) recommend adjustments in regard to the adoption of a new legal and regulatory framework; (ii) streamline the sector through link-ups, implementation of common services, and MFI rehabilitation and liquidation; (iii) continue to build capacities and introduce effective management tools, including banking technology; (iv) analyze the factors permitting greater productivity for MFIs to meet the challenges of the coming years; (v) provide direct financing for MFIs while analyzing their business plans to address their needs; (vi) develop specific strategies for better coverage nationwide and the development of appropriate products for rural populations and the private sector; (vii) establish a national security fund to provide assistance in setting up MFI networks and for their reconfiguration and rehabilitation; (viii) revitalize the microfinance development fund in Togo so as to make available to MFIs a guarantee fund and an MFI refinancing mechanism; (ix) consolidate business relationships between MFIs and national and international financial institutions; $(x)$ set in place a mechanism for exchanging customer information; (xi) see to sector communication and information; and (xii) promote good governance and financial transparency.

Source: National Microfinance Committee

In addition to strengthening the institutional arrangements as stipulated in this bill, the Government's actions are consistent with the strategic goals of the revised National Microfinance Strategy and aim to contribute to poverty reduction and achievement of the MDGs. The purpose is to develop and facilitate greater access to appropriate and diversified microfinance services for poor populations, particularly women, rural inhabitants, and micro-entrepreneurs, through viable MFIs that are fully integrated into the financial sector.

To accomplish this, the Government intends to take the following priority actions: (i) strengthen the legal, regulatory, and institutional framework of the microfinance sector to ensure a secure environment for MFI activities; (ii) develop an active partnership between MFIs and local 
communities in connection with the implementation of decentralization; (iii) professionalize MFIs and allow them to develop a permanent supply of appropriate, diversified, and expanding services and products, especially in geographic areas that lack coverage; and (iv) strengthen financial inclusion by developing the articulation between MFIs and banks and setting up a guarantee fund.

Private sector financing by traditional financing systems. To support and structure the traditional financing system with an eye to its gradual inclusion in the formal sector, the Government intends to: (i) initiate consultations among all relevant stakeholders regarding local development actions; and (ii) organize - and introduce within the informal tontine financial system of Togo - "mini-credit for women," which will serve as a loss leader. The traditional financing system represented by tontines holds a large place so far as savings behavior is concerned. To support this system, the Government intends to make use of it for the purpose of formalizing the sector.

\subsection{Promoting sources of economic growth}

Through this priority area of intervention, the Government intends to expand investments aimed at revitalizing economic activity in the primary, secondary, and tertiary sectors. These investments, which will benefit all the sectors, should aim to increase the sectors' productivity and enhance their competitiveness. They should also help diversify the economy so as to reduce its vulnerability to exogenous shocks. Within each sector, the areas of activity or industries deemed most promising in terms of growth will be favored, depending on their potential and their ability to drive the rest of the economy.

For the Government, investments that are intended to promote sources of economic growth should match up with the real needs of the economy. The latter, in fact, recorded relatively sustained growth until the late 1980s, before suffering a net decline as a result of the sociopolitical crisis of 1990-2005. The annual growth rate, estimated at an average 1.1 percent, actually turned negative for certain years. Analysis of the Togolese economy reveals the existence of a narrow productive base, composed of a tertiary and services sector with no links to national production and an industrial sector only slightly integrated into the rest of the economy. The increase in growth rates achieved from 1990 to 2007 stems mainly from the contribution of the primary and secondary sectors, while the contribution of the tertiary sector has remained very low or even negative. The contribution of extractive industries has shrunk because of the drop in phosphate production. In contrast, the respective contributions of manufacturing industries and of construction and public works to GDP have risen. Recent studies commissioned by the Government ${ }^{33}$ have confirmed the existence of real growth potential and of opportunities to reverse the current downward trend. They have also identified growth markets and have targeted possible actions. Based on an analysis of the competitiveness of the economies ${ }^{34}$ of WAEMU member countries, Togo enjoys a very large comparative advantage which allows it to specialize in production of the following products: coffee, cocoa, tea, malt, spices, flour-mill products, starches, wheat gluten, oleaginous plants (shea), grains, seeds, industrial plants, medicinal plants, residues, provender, salt, sulfur, ornamental stones, gypsum, lime, and cement. Still other products may be competitive but require inter-branch specialization, as in the case of live plants and floricultural products, edible fruits, citrus or melon rinds, cocoa and its by-products, etc.

In light of the conclusions of these studies, the Government, convinced that efforts to speed up economic growth require first of all revitalizing the traditional sectors that, in the past, have made substantial contributions to the country's growth and development, intends to mobilize the advantages enjoyed by the Togolese economy to lay the foundations for stronger growth, which should in turn enable it to reduce poverty significantly. In this regard, three strategic objectives have been identified: (i) boost agricultural productivity; (ii) boost industrial productivity; and (iii) improve the competitiveness of the tertiary sector.

\footnotetext{
${ }^{33}$ Studies on sources of economic growth and the business environment in Togo.

${ }^{34}$ Source: BOAD.
} 
Boost agricultural productivity. The Government intends to reach this objective without losing sight of the substantial advantages expected from increased food crop production (maize, sorghum, rice, cowpeas, yams, manioc, etc.) and export crop output (coffee, cocoa, and cotton). It also intends to give attention to potential diversification products (fruits, vegetables, flowers, peppers, spices, etc.) which trended upward in value substantially, by 129.4 per cent, between 1998 and 2003. The Government remains convinced that, to boost production, it is of fundamental importance to promote compliance with technical itineraries and to strive for water control, the best producer price, land security, and environmentally friendly agriculture. ${ }^{35}$

To address this situation, the Government intends to define a new land tenure policy that recognizes and secures rights of customary origin, within a legal framework that allows for gradual evolution towards greater individualization, while also protecting the rights of vulnerable groups. In this regard the following actions are envisioned: (i) set in place transparent and effective land markets (ownership or rental) that will permit proper conveyance and optimal development of available resources; (ii) seek greater decentralization with the participation of local populations and customary institutions in land management and conflict management; (iii) provide women and youth with easy access to land (including the widows and orphans of patients who have succumbed to AIDS); and (iv) reduce the risk of lands being divided up through the method of inheritance, etc. From this angle, the idea is to set up a program of pilot actions in different areas representing the diversity of lands in order to identify rational land and natural resource management systems by taking into account the needs and interests of local populations, as well as the socioeconomic and ecological priorities of the Government. In the same spirit, the Government also intends to recover lands which have been degraded by phosphate mining and left in unusable condition, restore them, and return them to their owners for their farms.

The preparations now under way for an emergency program to stimulate the coffee-cocoa sector is evidence of the Government's interest in these two products that have traditionally ranked third among total exports, trailing phosphate and cotton, and that appear to be regaining the attention of growers. This program revolves around four components: (i) rehabilitate aging plantations, increase the amount of land on which robusta coffee is grown, and replant areas affected by cacao swollen shoot disease with tolerant material; (ii) set in place an effective mechanism to support replanting/ratooning and expansion of orchards; (iii) strengthen the institutional framework (coffee and cocoa sectors regulatory and development entities, trade organization, strengthening of local cooperatives, etc.); and (iv) strengthen the infrastructure (roads, warehouses). This program will also take into account the necessity of fighting bush fires.

On the subject of attractive producer prices, the Government has made the decision to abandon the practice of banning exports of food products and, in particular, grains (maize), while simultaneously striving to ensure that producers are able to profit from their efforts. To that end, the market information and monitoring system, not yet effective, will be reviewed and corrected, and the information on agricultural trade will be made stronger.

The Agricultural Statistics, Information, and Documentation Directorate and the National Food Security Agency of Togo (ANSAT), formerly the Food Security Office of Togo (OSAT), will now be strengthened so that they are able to collect, in a satisfactory way, data on food product supply and demand in the five regions of the country and disseminate this data on a timely basis. This mechanism aims to make the food product market more transparent and efficient. Also, specifically in the coffeecocoa industry, there is a Coffee-Cocoa Industry Coordinating Committee (CCFCC) which, through the TRADENET Internet platform, informs industry producers every two weeks about coffee-cocoa target prices based on world market rates. This action facilitates negotiations between producers and purchasers in the field.

\footnotetext{
${ }^{35}$ Environmentally friendly agriculture aims to maintain or improve the soil's ability to produce from one year to the next, while preserving both soil and crop quality.
} 
These two systems have only limited geographic and thematic coverage ${ }^{36}$ and there is therefore an urgent need to set up an appropriate market information system. The Government subscribes to this vision and wants to take the necessary steps in this regard to make relevant information available, in real time, on marketing and purchasing opportunities and to ensure swift improvement in the access of agricultural sector operators to all the information they need in order to boost their productivity, their competitiveness, and their income. One of the short-term priorities will be to set in place this integrated network of economic, technical, and commercial information, charged with collecting, analyzing, and disseminating data on the production and trade of agricultural products. This network could expand its scope to include information on new technologies, the availability of inputs (selected seeds, fertilizers, and plant and animal health products), international/subregional market opportunities and access conditions, etc.

The Government recognizes the critical importance of agricultural inputs in general and fertilizers in particular, indeed to such an extent that it has made this one of the central pillars of its policy. Recently, following creation of the Agricultural Inputs Purchasing and Management Office (CAGIA), the Government has gone to considerable effort to order and distribute subsidized fertilizers to the benefit of producers. However, the appropriateness of direct government involvement in supplying and transferring this product will continue to be studied. Apart from the distortions they cause on the domestic market, fertilizer subsidies also carry the risk of partly financing agriculture in neighboring countries. With an eye to ensuring harmonious and effective development of the agricultural inputs market, the Government is committed to studying, along with producers, private operators, and the competent international institutions involved on site, the status of agricultural inputs in Togo, in order to devise together appropriate solutions to the problems of availability, accessibility, and rational pricing policy for fertilizers. In addition, the Government intends to promote Integrated Soil Fertility Management (ISFM) as a way to develop the use of organic fertilizers.

\section{Box 7: Integrated Soil Fertility Management}

The purpose of Integrated Soil Fertility Management (ISFM) is to improve productivity through integrated agricultural intensification, combining locally available enriching agents with inorganic fertilizers from elsewhere. ISFM aims to promote a number of strategies, including: (i) participatory development of water and soil conservation methods and soil fertility maintenance and enrichment techniques, using a combination of organic and mineral fertilization; (ii) facilitation of organizational and institutional development so as to improve access to external inputs for farmers and strengthen their role in relation to policymakers; and (iii) market development for agricultural inputs and products and development of credit systems. IFDC-Africa (International Fertilizer Development Center) works closely with the Togolese Agricultural Research Institute on this approach, and their experience shows that an emphasis needs to be placed not only on research and the dissemination of ISFM techniques, but also on the selection of appropriate sites and reliance on participatory approaches for institutional development and for greater collaboration between farmers, the private sector, and policymakers at the regional and national levels.

Source: IFDC (2000)/Ministry of Agriculture, Livestock, and Fisheries

The problem of quality control is so acute that the Government has made this a priority. The main issue is to adopt the norms and standards that are necessary to provide quality control over imported or exported agricultural inputs and products, consistent with international standards and the conventions ratified by Togo, and then to set in place an appropriate system (analytic laboratories, border inspection posts, fraud prevention services) to enforce these standards.

Stockraising in Togo is characterized by poor mastery of zootechnical parameters by producers and remains seriously threatened by epidemics. The cattle herd, which is largest in the northern part of the country, receives transhumant animals from bordering countries, specifically Burkina Faso and Niger. Small livestock (poultry, sheep, goats, pigs, etc.) are often raised by women and small producers. Modern, commercial poultry farming is being developed on the outskirts of the country's major cities.

\footnotetext{
${ }^{36}$ One of the constraints to effective dissemination of market information is the fact that telecommunications networks cover only a small part of the country (just 5 percent).
} 
The fisheries output, which is relatively low, comes primarily from maritime fisheries. Fish farming remains marginal, despite the potential benefits and opportunities offered in this area. The level of animal product consumption coverage has not specifically increased, so the coverage rate for national animal product consumption is roughly 70 percent and for fishery products the rate is below 50 percent.

To promote livestock and fisheries production, the Government intends to assist stockbreeders and fishermen as follows: (i) support the development of family-based stockraising involving short-cycle species; (ii) provide information, awareness-raising, and technical assistance for stockbreeders and fishermen; (iii) organize stockbreeders and fishermen into groups and umbrella organizations and promote the emergence of a joint-trade organization; (iv) strengthen epidemiological surveillance and promote widespread vaccination against major epidemic diseases; (v) promote slaughterhouses and cold storage; (vi) manage fish breeding stations and water impoundment for aquaculture development; (vii) develop fishery products unloading sites; (viii) create water points, pasturage, and livestock roads.

Also, given the problems created by transhumance, the Government will strive to: (i) develop and implement harmonized measures to prevent and mitigate risks and conflicts related to transhumance; and (ii) set in place a national committee and prefecture committees on transhumance endowed with the necessary resources for monitoring transhumance.

In addition, since the processing of meat and fishery products is a critical element of value enhancement and competitiveness for intensive, high value-added agriculture, the Government also intends to promote the preservation and processing of meat and fishery products as follows: (i) organize marketing channels and develop product outlets; and (ii) promote the development of industries and hubs of agricultural enterprises revolving around agricultural industries.

The Government is convinced that the impact of these policies and measures cannot be properly assessed unless the results of agricultural research are highlighted, on the one hand, and the system for collecting and generating statistical information on the agricultural sector is operational and effective, on the other. Accordingly, governmental action will attempt to make up for the lack of human resources in the area of statistics and the inadequacy of the financial and material resources of relevant agencies, so as to improve the performance of the agricultural sector information system.

Based on the strategy for agricultural recovery adopted by the Government, a National Agricultural Development Plan will be prepared and will encompass all the priority actions cited above in regard to boosting agricultural productivity. In addition, this plan will cover: (i) the creation of Planned Agricultural Development Zones (ZAAPs); (ii) national waterway system management through improved monitoring of watercourses and bottomlands; and (iii) reclamation, rehabilitation, and recovery of water bodies and lakes, as well as river beds, for improved flood control. It will also address environmental protection, greater involvement of women in agricultural development, and HIV/AIDS prevention. In addition, the Government has reaffirmed its commitment to implement the National Food Security Program (PNSA), validated in 2008, to the satisfaction of the Togolese population, which is increasingly exposed to natural disasters. 


\section{Box 8: National Food Security Program}

Faced with ever increasing food insecurity, in February 2007 Togo entered into a broad process of consultation and participatory development of a National Food Security Program (PNSA). This program aims to ensure food security for all segments of the population nationwide, with no discrimination. To reach this goal, six strategic areas of intervention have been identified: (i) promote the right to food and promote good governance in regard to food security; (ii) improve productivity and develop plant, livestock, and fishery products; (iii) boost the value of plant, livestock, and fishery products; (iv) ensure sustainable management of natural resources and the environment; (v) promote water control and domestic water for villages for multiple purposes; and (vi) promote good nutrition and nutritional education. The institutional framework set in place to monitor PNSA implementation includes several different levels: the baseline body, the decision-making body, the coordinating and consultative bodies, and, finally, the body charged with management and monitoring and evaluation of the program. The total cost of the PNSA through 2015 is estimated at CFAF 100 billion, of which 85 percent will be financed through external resources.

Source: Ministry of Agriculture, Livestock, and Fisheries / FAO

Boost industrial productivity. Increasing the overall productivity of the industrial sector hinges to a large extent on the productivity of extractive industries and manufacturing industries. In addition, efforts will be made to tap growth potential through development of the construction and public works (BTP) sector and handicrafts.

In the case of extractive industries, the principal minerals currently being mined are phosphate, limestone, and, to a lesser extent, iron. Other minerals are extracted by artisanal and small-scale operations.

Between 1988 and 1989, phosphate output peaked at 3 million metric tons, and the company running the phosphate operation at that time ${ }^{37}$ was considered the "lungs" of the Togolese economy. Unfortunately, the profits generated by this activity and the very substantial support that the company received from banks were not used to finance maintenance and renewal of the heavy equipment indispensable to the company's operations. Inadequate plant and poor business management led the company into virtual bankruptcy, and output fell to 750,000 metric tons in 2007, well below the figure for 1966 (1.07 million metric tons). In addition to this decline in production, the negative environmental impacts of the phosphate mining activities also raise concern, especially in terms of water pollution, coastal erosion, land degradation, and deterioration of the living environment.

Limestone/clinker accounted for 2.7 percent of Togolese exports in 1998 (at a value of CFAF 4,055 million) but had risen to 40.8 percent (CFAF 57,400 million) by 2006. Clinker and cement are now Togo's leading export.

In regard to bauxite and iron, an Indian-based company is planning to mine the bauxite deposit in the town of Agou, located roughly 110 kilometers to the northwest of Lomé, and the Bandjéli (Bassar) iron deposit located some 400 kilometers north of the capital.

The inconsistencies of the Mining Code make it impossible to turn a real profit in the Togolese mining sector. In fact, the Mining Code published in February 1996 and revised in 2003 (Law No. 2003-012) has never been backed by an implementing decree and there is no mine registry. Two articles of the Mining Code appear to contain inconsistencies or fail to take recent developments into account: (i) Article 55 stipulates that any company awarded a concession shall freely cede 10 percent of its shares to the Government; and (ii) Article 60 deals with the procedure for settling any possible disputes between the concessionaire and the Government.

${ }^{37}$ Office Togolais des Phosphates (OTP). 
In view of the growing number of exploration permits in Togo, the Government is aware of the need to develop a Draft Standard Agreement to ensure a fair distribution of the fruits of sector growth. In addition, the Government will endeavor to correct the imperfections of the Mining Code as soon as possible, while taking into account the provisions laid out by the framework law on the environment. The Government also intends to initiate strategic discussions on a possible return of the growth boom experienced by the sector in the past, particularly in regard to the phosphate industry.

In the case of manufacturing industries, the Government believes that, until a serious option for processing commodities before placing them on the international market has been developed, the Togolese economy will continue to suffer the negative effects of raw material prices. There is thus a need to seize processing opportunities and avoid a situation of being confined to the same processing industries (breweries and biscuit, oil, and soap factories) and also to take risks based on the Chinese model of development in the diversification of export products. Accordingly, governmental action will consist of studying ways and means so that, in the future, Togolese phosphate can be processed into phosphatic fertilizer, cotton into thread for the hosiery trade and the production of traditional fabrics, cocoa into chocolate and by-products, etc. Emphasis will be placed in particular on promoting agroprocessing industries. In this regard, there is an opportunity to take advantage of the benefits of the Clean Development Mechanism (CDM). ${ }^{38}$

In the case of the construction and public works sector, the real problem is the lack of adequate resources (human, financial, and material resources, standardized procurement procedures, etc.). These inadequacies have had repercussions on infrastructure development. With respect to program management, the Government will take steps to ensure that actions are coordinated between the various technical and financial parties involved. In the case of large and complex works with external financing, the contracting authority relies on consultants to perform studies. For more effective and efficient execution of the tasks incumbent upon the contracting authority, it appears necessary to recruit additional higher-level employees (engineers and managers) to strengthen the existing team.

In order to avoid a monopoly in the area of equipment leasing, the Government will undertake a reform of the legal framework of the equipment leasing company Société de Location de Matériels (SLM) and will upgrade its material, financial, and human capacities. Employees of oversight and consulting firms will receive specific training at seminars and/or workshops. In addition, the Government proposes to: (i) compile a list of local construction and public works companies and oversight firms; (ii) suggest equipment leasing solutions for SMEs; (iii) engage in discussions with banks on guarantees to be provided by SMEs and financing for revolving funds for businesses that are awarded contracts; and (iv) develop a public contracting authority legal framework.

The Government remains convinced that the growth potential associated with financial transfers from the diaspora can be put to use in the construction and public works sector. It is likely that, for the moment, these transfers serve mainly to meet family needs (health, education, and other expenses for members of the expanded family). Many Togolese of the diaspora dream of carrying out a project at home (farm, small processing unit) pending their ultimate return. However, either the funds given to family members to implement these projects are diverted from their original purpose, or the lack of management capacity causes the projects to fail. Efforts will be made to identify original and workable solutions for mobilizing these savings and channeling them towards productive projects (and not just the real estate business). If viable avenues are found, such transfers invested in the Togolese economy could have a significant impact on medium-term economic growth.

In addition, the Government will ensure that all private enterprises (mining companies, manufacturing companies, etc.) provide training to their employees on the prevalence of HIV/AIDS. All these private companies should also incorporate environmental impact studies into their activities.

\footnotetext{
${ }^{38}$ The CDM is an economic arrangement for financing carbon that was developed under the Kyoto Protocol. Its primary goal is to reduce greenhouse gas emissions worldwide by rewarding the installation of emission reduction technologies in developing countries.
} 
The handicrafts sector is an important link in the country's socioeconomic development; as a matter of fact, it employs roughly 15 percent of the working population. As part of its effort to promote the sector, on June 11, 1998 the Government adopted Law No. 98-011 establishing the organizational structure and operations of regional chambers of trade in each of the country's five economic regions and in the municipality of Lomé. Today, these six regional chambers are operational. However, the handicrafts sector faces a number of difficulties: (i) the absence of a national handicrafts policy; (ii) insufficient attention to the needs of the handicrafts sector when drawing up the national budget; (iii) the lack of pilot centers for artisan apprenticeship, retraining, and skills development; (iv) the critical lack of appropriate work tools and equipment, which weakens the production capacities in terms of adequate quality and quantity; (v) difficult access to credit and grants; (vi) weak marketing and distribution channels; and (vii) the absence of a permanent framework of consultation between various stakeholders in the handicrafts sector.

In view of the above, the Government intends to implement the following priority actions: (i) formulate and implement a national handicrafts development policy; (ii) deploy field units of the National Handicrafts Directorate; (iii) create a virtual gallery of handicrafts; (iv) set in place a technological data bank and reference centers for handicrafts; (v) create pilot centers for artisan apprenticeship, retraining, and skills development; (vi) establish a guarantee fund to provide financing for artisans; (vii) support artisans' participation in international expositions; and (viii) develop marketing channels for handicrafts.

Improve the competitiveness of the tertiary sector. This hinges mainly on the competitiveness of the Lomé Port Authority (PAL), the diversification of commercial activity, and development of the country's tourism potential.

Improving the competitiveness of the Lomé Port Authority. The PAL handles the bulk of all port services related to Togo's international maritime activities, including 80 percent of maritime trade. However, despite its strategic position as the subregion's sole deep-water port, it remains underutilized and its efficiency could be improved to boost its contribution to the national economy and take advantage of its full potential. The major challenges to be met by the PAL in order for it not only to maintain its position, but also improve its contribution to the national economy, are as follows: (i) increase the level of investment in infrastructure, both within the port itself and in the road system serving its immediate surroundings and countries of the hinterland; (ii) adjust the functions and mission of the PAL in line with its new role as port "proprietor" (as opposed to its former role as port operator), involving the regulation and oversight of port operations. While the privatization of container handling has brought a very significant improvement in performance (the pace has risen from 5-6 containers per hour to 18-20), it has also resulted in a virtual monopoly and a sub-optimal level of coordination; and (iii) reduce the amount of time required for passing through the Lomé port: the PAL is recognized for relatively swift passage through the port and has recently made additional progress in this area (an average of roughly two days for containers) after some slippage. On the other hand, a recent comparative study of prices charged by the PAL and other competing ports showed that the PAL's rates are higher than those of Tema and Cotonou. ${ }^{39}$ There is a risk of losing customers, especially because the competing ports have made major investments to capture new market shares. Currently, there is no tracking of containers and there is thus no way for operators to monitor the status and location of loading and unloading activities.

To meet these enormous challenges, the Government has set the goal of developing the PAL's full potential and making it a true instrument for promoting economic growth. Large investments will be made for the purpose of expanding port infrastructure so as to increase capabilities and boost the output of the maritime transport chain: this will involve construction and rehabilitation of the road infrastructure serving the port (roads within the port area, bypasses, and roads for avoiding critical

\footnotetext{
${ }^{39}$ A 20-foot container headed to Burkina Faso and unloaded in Lomé would cost CFAF 267,269 excluding transit fees and transportation costs; in Tema, the same container would cost CFAF 114,463 (cf. study on sources of economic growth in Togo, November 2008).
} 
areas along the Lomé-Cinkassé corridor), expansion of the Sahel terminal, and the development of dry port infrastructure. In addition, measures will be taken to improve the effectiveness and efficiency of port management. These measures will involve redefining the mission and functions of the PAL, restoring the PAL's authority over concessionaires, and strengthening the role of coordination. With respect to the cost of port passage, it will be important to: (i) set up a task force charged with making proposals for optimizing the cost of port passage. It is the responsibility of the PAL to ensure the overall competitiveness of the Lomé port and avoid a loss of market share. This means that the port authority must have reliable and accessible information for making decisions about rates; and (ii) systematically establish the principle of competition in the awarding of licenses, unless this is incompatible with rational port operations.

Diversification of commercial activity. Togo has a worldwide reputation as a business crossroads. This fact gives the country high commercial potential, which unfortunately has been squandered by the sociopolitical crisis that struck the country. Commercial activities have become very undiversified and characterized by distortions largely attributable to the preponderance of informal operators. Domestic trade generally involves imported products and foreign trade is focused on a few agricultural products that are mostly exported in raw form. Generally speaking, commercial activities are characterized by structural weakness as reflected in the following key indicators: (i) a negative trade balance; (ii) an economy that is highly dependent on a limited number of exports (cement, clinker, phosphates, cotton); (iii) a downward trend in the export of certain products such as coffee and cocoa; and (iv) the disappearance or near-disappearance of certain exports (ricin, kapok, copra, palm kernel, shea) despite the existence of robust international demand.

The failure to adequately exploit Togo's export potential stems from insufficient coordination between regulatory bodies, the weakness of the system, a lack of information on export markets, low and irregular output, and problems associated with product quality. The supply of exports is limited by the low volume of national manufacturing output. The manufactured products that are typically exported are products derived from agriculture and fisheries or textile products and they represent only a small portion of national production. For its part, the service sector is faced with problems of incidental expenses and extra costs generated by corruption and recurrent harassment.

To address these issues, the Government is committed to helping the trade sector through actions designed to promote diversification and tap the various opportunities offered at the international level. Certain products with high potential should be promoted, particularly exotic and off-season products. Unexplored export areas should also be looked into. From this perspective, the following measures will be implemented on a priority basis: (i) develop and implement a trade policy; (ii) promote domestic trade; (iii) strengthen activities that promote foreign trade; (iv) strengthen the activities of the Ministry of Commerce in line with the objective of promoting foreign trade; (v) formulate and implement a trade development strategy; and (vi) finalize and implement, with the support of partners, an integrated master program of technical assistance for trade as a way to promote economic growth within the framework of the Doha Declaration.

With respect to services, the need to strengthen financial services is of particular importance, specifically as follows: (i) develop bank financing appropriate to the export industry; (ii) establish a bank charter specifying the relationship between credit institutions and their customers; (iii) improve the loan recovery terms, particularly the guarantee liquidation process; (iv) create a mortgage market so that credit institutions with portfolios containing property loans can refinance their assets; (v) institute more flexible financing terms for SME/SMIs by creating interest subsidy funds appropriate to their size; (vi) create a national loan recovery framework; (vii) reduce police harassment and police controls which drive up the cost price of products; and (viii) popularize the use of computers and, to that end, lower the taxes on computer equipment.

Development of a new tourism economy based on the country's cultural potential. Tourism's contribution to the national economy, noteworthy in the 1970s and 1980s, fell during the period of sociopolitical crisis and the hotel and tourism infrastructure deteriorated. Its contribution is now very 
limited. And yet, the natural assets (sandy beach, varied flora and fauna, sites of interest to tourists, museum, archeological remains, etc.) are still intact. To develop them, the following actions are needed: (i) continue and complete the financial adjustment of state-run hotels (privatization of semipublic hotels); (ii) define a clear policy to promote tourism, with an emphasis on ecotourism; (iii) draw up a tourist sites development plan; (iv) update sector regulations and see to their enforcement; (v) actively publicize tourism in Togo (advertising posters, production of brochures and documentaries on Togolese tourism opportunities, etc.); and (vi) raise the awareness of local communities concerning the development of local tourism. The Government has in fact made the decision to set up tourist facilities in the most remote areas so as to encourage travel by those who are interested, as well as to develop tourist sites and highlight traditional celebrations and assorted cultural events. An incentive framework will be created to enable the private sector to develop a hotel industry around rehabilitated tourist sites and protected areas.

\subsection{Development of infrastructures to support economic growth}

The country faces a tremendous deficit in terms of economic infrastructure to support growth, especially in the areas of transportation, energy, and telecommunications. The quantitative and qualitative inadequacy of the road transportation infrastructure remains an obstacle to growth of the Togolese economy. In the Togolese road system, just 21 percent of the national roads are paved. Moreover, paved roads and bridges are for the most part in a state of decay as a result of the absence of periodic maintenance and monitoring in recent years. Service roads in many areas with high agricultural potential are not passable year round and some remain cut off.

Railroad transportation is practically nonexistent within the Togolese transportation infrastructure. It is now limited to freight transport (cement). The virtual disappearance of railroad transportation deprives economic operators of an inexpensive means of transport, especially for cargo, both within the country and to countries of the hinterland. In addition, this virtual disappearance poses a problem for the cost-effective mining of certain deposits.

As for air transportation, the two international-class airports in the country remain underutilized in relation to their capacity. This situation is tied to the fact that Togo had ceased to be a magnet for tourists, vacationers, investors, and businessmen because of its lengthy sociopolitical crisis. With the current climate of appeasement and the measures designed to revitalize tourism in Togo, the Lomé airport in particular could see more business.

In regard to energy, the country's lack of adequate energy infrastructure and resources currently represents a major impediment to economic activity. Indeed, despite the actions carried out in recent months by the Government to increase the supply of electric power, the demand for electric power remains unsatisfied, and the country continues to depend too heavily on neighboring countries to supply electric power with, as a corollary, frequent power cuts that affect all sectors of activity of the national economy.

With respect to modern telecommunications services, which remain vital for the business environment and particularly for foreign trade and for services (banks, insurance, transportation, etc.), the costs are still relatively high ${ }^{40}$ compared to other countries of the subregion, despite the technological advances in this area. Major efforts need to be made to provide private sector actors with less expensive, quality telecommunications services and to improve fair access in all regions of the country to this supplementary service which is a very important production factor for most economic actors.

In view of the above, the Government is firmly committed to making major investments to develop a network of economic infrastructure in good condition, offering high-quality, competitive services and thus conducive to efficient market supply, reduced production costs, and the development of economic activities. By so doing, Togo could take greater advantage of its favorable geographic position at the

\footnotetext{
${ }^{40}$ Because of the state monopoly on facilities.
} 
heart of the WAEMU common market and its proximity to other ECOWAS growth markets and thereby compensate for the narrowness of its market. Accordingly, governmental action is aimed at developing transportation infrastructure, energy resources, and telecommunications.

Development of transportation infrastructure. In the area of transportation infrastructure, top priority will be given to overland transportation. From this point of view, the objectives are to: (i) improve the competitiveness of Togolese products on the domestic and foreign markets by reducing transport costs; (ii) reduce the isolation of remote areas in order to develop their agricultural potential; and (iii) guarantee the competitiveness of the Togolese road corridor leading from the port of Lomé and providing a supply route to countries of the hinterland. To reach this goal, the road system is in urgent need of rehabilitation. Consequently, the Government intends to: (i) rebuild and rehabilitate bridges destroyed by the most recent flooding; (ii) construct, rehabilitate, upgrade, and maintain urban and feeder roads, as well as national roads and interstate national roads; and (iii) widen or duplicate segments of major access roads to the capital. As for the railroad system, rehabilitation and extension of the south-north central axis will help facilitate cargo transport, both within the country and on towards countries of the hinterland.

In addition, accompanying actions are also necessary to build the institutional capacities of the overland transportation sector. In particular, actions are needed to: (i) improve the quality of management and strengthen credit execution and absorption capacities in the sector; (ii) upgrade the statistical and geographic information systems; (iii) improve sector coordination and governance; and (iv) better organize inter- and intra-urban transportation. The Government's transportation sector development strategy will also involve a participatory approach to HIV/AIDS control along the entire road system.

Development of energy resources. With a view to economic recovery, the Government is giving particular attention to energy services as a factor of production. The goal is to be able to satisfy the energy requirements of businesses and households. For this to happen, electric power supply sources need to be diversified and costs reduced, and the country needs to tap its potential in terms of hydroelectric infrastructure. In the medium term, projections point to the positive impact of the West African gas pipeline going into production and providing cheaper energy. Thus, the intention is to continue the efforts to complete large regional energy projects, particularly the Adjaralla dam and interconnection of the Nigerian, Beninese, and Togolese systems.

In addition, these measures will be accompanied by institutional and regulatory reforms of the electric power sector. The sector review and the anticipated CEET reform will guide the Government's future actions. A rural electrification strategy will be set in place, along with the establishment of a national rural electrification agency and a rural electrification fund.

Furthermore, energy services are indispensable for developing productive potential in rural areas. A sufficient supply of energy is necessary for the processing of products, thus permitting the creation of added value, as well as for the development of small-scale product processing and preserving units in rural areas, the development of SME/SMIs in all fields (services, handicrafts, etc.), and the provision of other basic services (water supply, telecommunications, etc.). Accordingly, the Government will strive, in accordance with commitments made pursuant to the ECOWAS/WAEMU White Book, ${ }^{41}$ to promote access, especially in rural and periurban areas, to modern energy services (electricity, power generation, modern fuels), which will contribute substantially to improving the welfare of individuals. In this regard, the Government will make every effort to implement the program of support for developing traditional energy resources and promoting renewable ones. The Government also intends to promote the use of solar energy for public lighting (roadways, schools, health centers, etc.).

\footnotetext{
${ }^{41}$ The White Book for a regional policy on access to energy services in rural and periurban areas in order to meet the MDGs, adopted on January 12, 2006 by the Heads of State of WAEMU and ECOWAS member countries, signals a major change of approach by broadly recognizing the role of energy services in reducing poverty in West Africa and recommends that at least half of the rural and periurban population of member countries be provided with access to modern energy sources by 2015 .
} 
A consistent energy sector policy will be set in place that reflects the priority actions discussed above and the synergy that exists among them.

Development of telecommunications. Efforts should be made to improve national coverage, diversify services in this area, and improve the quality and reduce the cost of telecommunications services. Increased investment will be encouraged with an eye to covering the entire country. To that end, the Government intends to accelerate the process of opening the capital of the national telecommunications company (TOGOTELECOM) to the private sector, thus creating the right conditions for raising the necessary resources on the regional and international financial market. The Government also intends to develop a regulatory framework that will be conducive to a more competitive environment, quicker development of information and communication technologies, especially mobile telephone service and Internet access, and a reduction of the digital divide, primarily for the purpose of making high-quality, less expensive telecommunications services available to private sector actors and accessible to a greater proportion of the population. In addition, the Government will develop a clear telecommunications development policy so as to create the necessary synergy and consistency among these different actions.

\subsection{Enhancing regional integration}

The Togolese economy has the potential to revitalize its markets and deepen the investment opportunities that are essential from the perspective of consolidating the foundations for strong and sustainable economic growth. The country's membership in the regional economic communities, WAEMU and ECOWAS, gives it certain advantages for fuller integration into the world economy and better use of the multilateral trade system for effective poverty reduction.

The Government's objective is to promote a regulatory framework conducive to intensification of intra-community trade based on stronger regional integration. To that end, governmental action will focus on continuing to bring national laws and regulations in line with community statutes. Special attention will be given to the goal of better organizing the Abidjan-Lagos corridor in order to reduce the risks of exposure to HIV/AIDS. Public authorities will also give attention to the management of cross-border protected areas.

In addition, the Government will pursue a trade policy that aims to diversify commercial activity and capitalize on the various opportunities offered at the subregional, regional, and international levels. To that end, actions will be undertaken to: (i) develop and implement a trade policy that strengthens activities to promote foreign trade; (ii) strengthen and improve human and institutional capacities for managing and promoting commercial activities so as to become more actively integrated in the trade liberalization schemes under way; (iii) revitalize the OHADA National Commission; and (iv) strengthen the country's active presence in subregional, regional, and international trade organizations.

Moreover, the Economic Partnership Agreement (EPA) between the European Union and West Africa offers prospects for national economic development from which the country could benefit. For that purpose, the Government intends to be actively involved in the negotiations for an EPA as a potential source of growth and development for Togo. In connection with economic and trade integration, Togo would very much like to see WTO technical assistance strengthened, and to take advantage of the JITAP program, ${ }^{42}$ as well as other programs of international organizations active in this area.

\subsection{Effective management of natural resources, the environment, the living environment, and natural disasters}

The Government has opted for strong but environmentally friendly growth. This is the reason why the necessity of effective management of natural resources, the environment, and the living environment is simultaneously integrated with the goal of consolidating the foundations for strong and sustainable

\footnotetext{
42 Joint Integrated Technical Assistance Program.
} 
economic growth. Togo does in fact possess great potential in terms of its natural, ecological, cultural, and anthropological resources. However, sociopolitical unrest, exacerbated by the country's poverty, essentially hijacked the sector through anarchical resource exploitation, resulting in steady degradation of forest and wildlife resources. Natural resources, the environment, and the living environment occupy a very important place in the economy of any nation, and their sound management is an indispensable element of the poverty reduction process.

To improve the living environment and living conditions of the population with a view to sustainable economic and social development, an environmental policy has been developed, which aims to promote: (i) sound management of natural resources and the environment; and (ii) effective management of the living environment. In addition, effective, efficient, and coordinated management of natural disasters is indispensable in order to cope with such shocks which can undermine efforts and result in the destruction of resources.

Effective management of natural resources and the environment. The Government's foremost concern is to expeditiously implement the environmental policy in order to prevent the country's environmental and natural resource heritage from being wasted.

\section{Box 9: National Environmental Policy}

The Government has formulated a National Environmental Policy with the participation of development stakeholders. The broad outlines of this policy are to: (i) effectively integrate an environmental dimension in the development policies, plans, programs, and projects of all sectors of activity; (ii) eliminate or reduce the negative environmental impacts of public and private development projects and programs; (iii) strengthen national capacities for managing the environment and natural resources; and (iv) improve the living environment and the living conditions of the population. The objectives flowing from these goals are to: (i) promote sound management of natural resources and the environment in all areas of activity; and (ii) consolidate economic recovery measures that are designed to ensure ecologically viable foundations for development. To achieve these objectives, the Government will place a priority on the following actions: (i) strengthen national environmental management capacities; (ii) promote integrated management of the coastal areas; (iii) prevent and manage natural disasters; (iv) promote participatory natural resource management; (v) reduce the pressure on natural resources; and (vi) strengthen subregional and international cooperation in the area of environmental management. Implementation of the National Environmental Policy has been addressed in the National Environmental Action Plan (PNAE), which in turn encompasses a National Environmental Management Plan (PNGE). Thus, the PNAE is a strategic framework of discussion, consultation, programming, and action for identifying and prioritizing environmental concerns, designed to permit the development of an effective system for planning and managing natural resources and the environment with a view to sustainable development.

Source: Ministry of Environment and Forest Resources

To strengthen the national framework for environmental and natural resource management, the Government has decided to: (i) incorporate an environmental dimension in development policies, strategies, plans, and programs by formulating and implementing a national sustainable development strategy (SNDD); (ii) improve the legal and institutional framework for environmental and natural resource management; (iii) strengthen the legal, institutional, technical, and financial capacities of the various sectors of activity and categories of development stakeholders involved in environmental management; and (iv) develop the environmental awareness of populations by formulating and implementing an environmental communication strategy.

For integrated management of the coastal areas, the Government intends to promote integrated development consistent with the carrying capacity of coastal ecosystems. For that purpose, a specific framework of sustainable environmental management and coastal erosion control will be developed for the coastal areas. In addition, the restoration of seriously degraded ecosystems and industrial pollution control will be given priority treatment in managing the coastal areas. 
Reducing pressure on natural resources means that their use needs to be rationalized through appropriate tools and techniques for promoting sustainable economic and social development. The priority actions to be undertaken by the Government in this area are to: (i) conserve and promote biodiversity; (ii) control desertification and soil deterioration; (iii) reduce greenhouse gas emissions and other sources of pollution; (iv) promote private and community-based forestry; and (v) increase the plant cover through reforestation and the management and restoration of natural forests.

In order to strengthen regional and international cooperation in the area of environmental management, the Government intends to develop, within a community and international framework, concerted management of cross-border natural resources and environmental issues.

Effective management of the living environment. Apart from the natural resources sector, there are major environmental problems that are sources of ambient air pollution in residential areas and that affect the quality of the living environment. These problems include: (i) the proliferation of unauthorized garbage dumps and outdoor defecation; (ii) the practice of dumping toilet water and wastewater on public thoroughfares; (iii) pollution of surface and underground water resources; (iv) air pollution in urban areas caused by various emissions, particularly from the vehicles used; and (v) illicit traffic in dangerous products (gasoline, pharmaceutical products and other chemical products, heavy metals, radioactive materials, etc.). In the area of pollution prevention and control, the Government intends to promote: (i) environmentally sound management of the various categories of waste; (ii) sound management of chemical products; (iii) protection of the living environment in urban and rural areas from all forms of pollution (including ocean pollution); (iv) development of the areas around lagoons for recreational purposes; and (v) the creation of green spaces in urban and semi-urban centers.

The housing sector, for its part, is characterized by the absence of institutions specialized in land-use planning and the lack of production and financing of housing for low- and middle-income populations. The sector is further characterized by the absence of a consistent legal and regulatory framework for urban planning and construction, as well as the absence of a real housing policy. State-owned property is also surrounded by legal uncertainty, because all the provisions pertaining to expropriation are not always followed in terms of allowing the owners involved to invoke their rights. As a consequence, the latter exert constant pressure in hopes of recovering their property.

The Government, preoccupied by the scope of these problems, has set in place institutions tasked with designing and managing implementation of an appropriate policy in this area. Thus, in this regard, the Government adopted an Urban Sector Policy Statement in 1998 that called for the development and implementation of a national housing strategy (SNL).

\section{Box 10: Urban Sector Policy Statement}

The main objective of the National Urban Sector Policy is to promote the development of viable human settlements. It comes in response to Togo's development needs and, as such, revolves around the following specific objectives: (i) rebalance the Togolese urban framework; (ii) define, based on property liberalism, the institutional and legal framework of city production; (iii) strive for a better distribution of competence and resources between the Government and local communities; (iv) stem the decline in living conditions in urban areas; and (v) encourage inter-municipal groups and partnerships. To achieve the objectives that the Government sets for itself in the National Urban Sector Policy, the following actions were selected: (i) encourage the mobilization of financial and human resources at the local level; (ii) encourage increased investment in urban areas proportionate to the economic weight of urban centers in the national economy; and (iii) ensure the development of Information, Education, and Communication targeting urban actors.

Source: Ministry of Urban Planning and Housing

Updated in 2007, the national housing strategy has the following objectives: (i) reorganize the housing sector; (ii) improve the housing stock; and (iii) mobilize financial resources and allocate them wisely. The priority actions identified for strengthening the sector are to: (i) set in place a consistent 
institutional and legal framework; (ii) set in place reliable spatial planning tools; (iii) simplify the regulations pertaining to urban planning and construction; (iv) organize information; (v) improve the level of community participation; and (vi) produce a large number of low-cost parcels. In addition, the Government intends to compensate the owners of expropriated properties to avoid the uncertainties surrounding these properties.

Effective and efficient management of natural disasters. Analysis of the emergency situation in Togo reveals the increasingly recurrent nature of certain disasters, which, combined with the negative effects of poverty, injects a humanitarian dimension that has now grown complex and more worrisome. Despite the remarkable advances relative to the 2007 experience, disaster management still suffers from inadequate resources and management mechanisms.

Drawing a lesson from 2007 and 2008 flood management, the Government has undertaken, with the support of TFPs and particularly the United Nations System, efforts aimed at developing a national disaster risk reduction strategy, developing and implementing a comprehensive early warning system, and completing a number of studies, specifically on the institutional framework for disaster prevention and management, the baseline situation, the identification and mapping of at-risk areas, and new climate trends and associated risks.

In view of the country's vulnerability, the Government intends to include disaster risk reduction in the early warning strategy and give attention to the issues of coastal erosion in the southern part of the country and the fight against desert encroachment, a source of drought in the northern part.

The Government, aware of its roles and responsibilities, is mobilizing its efforts through stakeholders in the Assistance Organization Plan (ORSEC) for the purpose of building capacities to prepare for and respond to (with emergency assistance) future disasters. In view of the current situation, steps will be taken to ensure better organized and better coordinated preparation and response. In this context, a National Contingency Plan will be set in place as a management tool and as an ongoing participatory process for predicting imminent events and the resources and services required to reach the objectives identified, according to an established order of priority. In addition, the operational capacities of the assistance structures (including the fire station) will be upgraded with specialized equipment, as will those of the General Directorate of National Meteorology so as to improve the quality of weather forecasting. Lastly, a national support fund for natural disasters and emergencies will be established to provide assistance to the victims of crises and disasters.

\subsection{Redistributing the fruits of economic growth}

The Government intends to make the full poverty reduction strategy a genuine tool for reducing inequalities by creating a framework conducive to an equitable redistribution of the fruits of economic growth, which means promoting channels for the redistribution of national wealth. To that end, the following measures are envisioned: (i) develop a tax policy favorable to the poor; and (ii) implement a redistribution policy that favors the poorest and most vulnerable areas.

Pro-poor tax policy. Appropriate mechanisms will be set in place to ensure more equitable taxation among different socioprofessional brackets. In this regard, the Government intends to revise the tax laws so as to incorporate provisions designed to: (i) increase the participation of the wealthier brackets and rationalize the informal sector's contribution (simplification of collection methods, lower rates, taxes on external signs of wealth); (ii) make the collection methods more effective (low cost and high yield); and (iii) make taxes nondiscriminatory by establishing across-the-board regulations and eliminating all risks of arbitrariness. Also, the possibility of incorporating an eco-tax ${ }^{43}$ into the tax system will be studied as a way to avoid environmental degradation caused by human action. In addition, the Government will implement a system of incentives for businesses and institutions that

\footnotetext{
${ }^{43}$ This amounts to a tax on damage inflicted on the ecosystem.
} 
work to gradually reduce the pollution or other environmental degradation generated by their production systems in line with the provisions contained in the framework law on the environment.

Redistribution in favor of poor areas. The Government intends to earmark mobilized resources in order to finance, among other things, the social safety nets and regional development hubs envisioned for the purpose of reducing regional imbalances and promoting community development (cf. fourth strategic pillar).

\section{$2.8 \quad$ Job creation}

As a key instrument of poverty reduction, employment lies at the heart of the Government's concerns in the area of development policy. For the Government, the issue of employment warrants treatment on two different levels - first of all, with respect to economic growth, inasmuch as job creation hinges on efforts to ensure strong and sustainable growth. This is moreover the reason why the Government places special emphasis on the private sector, such that the private sector will be in a position to create jobs to complement the Government's potential in terms of administrative jobs. The second level of employment analysis centers on the perception of employment as an aspect of the development of human capital. Viewed from this angle, the idea is to assess the social dimension of employment.

The employment situation in Togo is characterized by a growing lack of job security, a substantial contraction of the labor market, the increasingly informal nature of employment, and an unemployment rate (including underemployment) estimated at more than 30 percent in 2006, according to data from the QUIBB survey. Furthermore, this situation is reflected in explosive growth of the informal sector, which occupies, including the agricultural sector, more than 80 percent of the working population. In this context, the situation for youth is characterized by a lack of future prospects and a lack of adequate mechanisms for encouraging and supporting employment- and income-generating initiatives.

With this in mind, the Government has set for itself the objective of creating the legal, institutional, and economic conditions for job creation and income growth. To promote employment, an Employment Promotion and Poverty Reduction Policy Framework Paper was drafted in 2004.

\section{Box 11: Employment Promotion and Poverty Reduction Policy Framework Paper}

The Togolese Government, with ILO and UNDP support, has established a framework for formulating and implementing an Employment Promotion and Poverty Reduction Policy. The general objectives governing this framework paper, drafted in 2004, are to: (i) establish greater visibility for the job and labor market; (ii) establish a legal and institutional environment conducive to productive employment; (iii) expand a range of credit systems to make them accessible to all developers, from micro- and small-scale through mid-size and large enterprises; (iv) improve the quality of services in the area of extension, support, and advice for developers and businesses; and (v) create and see to the implementation of various forms of social protection for different categories of workers. To attain these objectives, the following strategic targets have been identified: (i) build the capacities of institutions that promote employment; (ii) restructure the National Directorate of Employment Promotion; (iii) strengthen job market information systems; (iv) upgrade training courses leading to qualification; (v) improve the legal framework; (vi) promote the right to work; (vii) embrace the necessary political will and commitment; (viii) develop self-employment; and (ix) strengthen the social dialogue.

Source: Ministry of Civil Service, Labor, and Employment (2004)

Every effort will be made to ensure diligent and consistent implementation of the updated provisions of this policy. In addition, the Government will develop a public-private partnership on the issue of employment as a way to discuss with the private sector the impediments to job creation that the private sector runs into, and to come to common agreement about what needs to be done in the future so that youth will be increasingly integrated into the national production system. 
The priority actions identified by the Government are to: (i) develop self-employment and women's access to more and better jobs, promote youth and vulnerable groups' access to decent jobs, and improve informal sector activities; (ii) strengthen the micro-lending and micro-insurance mechanisms; (iii) upgrade training courses leading to qualification and revitalize the National Fund for Job Apprenticeship, Training, and Skills Development, the Youth Economic Initiatives Support Fund (FAIEJ), and the Youth Integration Fund.

To ensure the sustainability of these government actions, important measures will be taken to: (i) make the National Employment Agency (ANPE) operational; (ii) develop and implement programs to support the integration or reintegration of vulnerable groups, especially impoverished individuals; (iii) establish a map of job opportunities for youth and women in the prefectures and sub-prefectures of Togo; (iv) promote the business culture through training seminars and by including it in training curricula; and (v) strengthen the social dialogue through various forms of communication.

As part of the quest for a lasting solution to the unemployment problem, especially among youth, the Government will study the best possible way to ensure, by overhauling the educational system, that young people return to the land and that volunteership on the part of young graduates is encouraged. To absorb a substantial portion of the pool of unemployed youth, the Government has come down in favor of following a labor-intensive approach to urban development, the reconstruction of economic and social infrastructure (rural roads, schools, health centers, etc.), and the development of agricultural lands.

\subsection{Promoting research}

The research that is supposed to guide the country's development is today in a state of acute crisis, as Togo has no major research centers. The few centers that do exist are underequipped and lack adequate support, which keeps them from fully playing their intended roles. Furthermore, higher education and the agricultural, industrial, artisanal, and other research centers lack the necessary means to carry out their research projects.

To catalyze development and consolidate growth, the Government has taken steps to: (i) create a research support fund; (ii) award funding for research in higher education; and (iii) provide research grants to doctoral students since 2005. While building on this progress, the Government's goal for the next three years is to stimulate genuine enthusiasm for research, especially in the area of agricultural productivity, by coming up with the resources needed to develop better performing and higher valueadded varieties in the subsectors promising greatest growth. These new varieties will also need to be adapted to the harmful effects of climate change that the country is experiencing. The priority actions in this area are to: (i) identify the crops best suited to each agro-ecological zone; (ii) provide support to research laboratories for the development of short-cycle, pest- and disease-resistant varieties; and (iii) identify improved systems of crop preservation and agricultural product processing.

In addition, the Government will make every effort to promote an appropriate partnership arrangement between universities and businesses so that the latter will contribute to funding for university research, the results of which should ultimately be useful to businesses for increasing their productivity. In this context, the Government will strive for a better match between the training provided in the universities and the real needs of the labor market. For that purpose, the intention is to set up an inter-trade representative council charged with assessing and proposing courses of study in higher education, as well as at the various levels of technical and vocational training. 
Consistent with the priority given to the social sectors in the interim strategy, the Government, through this pillar, intends to retain the same focus and, what is more, step up its efforts to meaningfully address the concerns of the Togolese people, in whose view poverty primarily manifests itself in the non-satisfaction of their basic social needs: education, health care, water and sanitation, food, etc.

Governmental action will focus on: (i) promoting the education and training system; (ii) developing the health system and health services; (iii) improving the nutritional status of the general public; (iv) improving access to safe drinking water and to sanitation infrastructure; (v) promoting gender equity and equality; (vi) promoting social protection; and (vii) promoting youth, sports, and recreational activities.

\subsection{Promoting the education and training system}

Over the last 15 years, the Togolese education system has been hit by severe financial constraints due to the country's socioeconomic circumstances, in combination with the suspension of cooperation with the principal development partners. This situation, on top of strong school enrollment demand, has resulted in a deterioration of teaching conditions and major structural problems.

At the pre-primary level, coverage remains very low and there is a lack of arrangements for dispensing early childhood education, which has led to the development, mainly in rural communities, of Local Initiative Kindergartens (JEDILs) financed entirely by parents who are themselves already poor.

At the primary school level, performance indicators have steadily deteriorated in recent years (some 10 percent of children lack access, and roughly 28 percent of those who enroll fail to complete the cycle). In these conditions, just 66 percent of children in the generation now entering school will reach the end of primary school by 2015 . This situation is of concern to the Government as it seeks to achieve the MDGs pertaining to universal primary school enrollment.

In the first cycle of secondary school, there are a number of factors negatively impacting the level of performance, including the deterioration of both facilities and instruction (inadequate and inappropriate facilities and teaching conditions, insufficient numbers of teachers and their limited qualifications, etc.), the disparity of supply between regions and based on gender (a girl/boy parity index of 0.71 and an enrollment ratio of 41 percent for girls, versus 58 percent for boys), a sixth grade access ratio of 52 percent, and a high repeater rate of approximately 24 percent. The low retention and completion rates and the scope of the losses (repeaters and drop-outs) pose constraints to improving the internal cost-effectiveness. Anticipation of the pressure of school enrollment demand over the next six years, based on current trends in the primary cycle, reflecting a situation sparked by the elimination of school fees in public primary education, is a signal that justifies the priority actions which the Government intends to implement in order to correct the inequalities and improve the yield.

In the second cycle of secondary school, in addition to deteriorating facilities and teaching conditions (outdated infrastructure and equipment, absence of teaching materials), the low enrollment ratio (21 percent as a national average, with 12 percent for girls versus 34 percent for boys), the high repeater rate $(31$ percent), and the low retention rate (68 percent) are some of the factors that heighten the Government's concerns over the education system's internal inconsistencies.

In regard to technical and vocational training, the low level of qualification of teacher/trainers and their low level of supervision (one inspector for every 545 teachers), the outdated and inappropriate infrastructure and equipment, the inadequate work stations, and the absence of teaching and working materials all mean that vocational training remains largely theoretical. The decline of public services has opened the way to private sector development which emphasizes not only interregional but also gender disparities (a girl/boy parity index of 0.3 overall and 0.039 in industrial sectors). This issue of equity also arises among the teaching ranks, where the parity index is 0.05 . With this in mind, the 
Government intends to make every effort to provide the subsector with the necessary means to play its assigned role, namely to enable both young people and adults to acquire the knowledge and know-how they need in order to become integrated into the workforce, and, more broadly, to address the country's social and economic development needs by means of appropriate training programs and mechanisms.

Higher education and research, similar to the other subsectors, suffer from inadequate facilities, outdated teaching equipment, and a failure to plan the management of flows, resulting in a poor match between the number of individuals trained and the country's real social and economic development needs. To address this situation, the Government intends to redefine and readjust the mission of this component of the education system by incorporating it into an approach of harmony and complementary consistency with other components of the sector.

The age 15-45 literacy component has not received the attention it needed in the past. As a consequence, the illiteracy rate remains high (40.4 percent), especially among women.

The recent integration of this component into the education sector bodes well for its inclusion in overall sector policy. Efforts will thus be undertaken, with the active participation of partners, to enhance the effectiveness of literacy education programs and thereby lower the current illiteracy rate to 21 percent by 2015, with a special emphasis on reducing gender and regional disparities.

To address this situation, the Government has begun, with the support of technical and financial partners, to develop a sectoral strategy in which it intends to reaffirm the priority placed on the education sector in a long-term vision of its development aimed at achieving the MDGs. This strategy requires that an overall sector policy be developed, with clearly stated priorities at each level, and that the importance and the role of literacy education in the poverty reduction process be affirmed. The foundations of this strategy center on the following: (i) increase to 26 percent the share of internal government resources devoted to current expenditures for education; (ii) improve access, equity, and child retention at all levels, especially for basic education and particularly for girls, children in difficulty, those living with disabilities, and vulnerable and underprivileged populations; (iii) improve the quality of education in all regards and particularly with respect to the system's internal efficiency and facility conditions at all levels; (iv) improve the relevance of the curricula (by including, among other things, modules on the environment) and adapt the curricula in line with the country's development needs; (v) improve the management and steering of the education and training system; and (vi) develop and promote an effective partnership policy.

In the area of pre-primary education, the rate of coverage will be raised from 9 percent to 18 percent in 2015 and 23 percent in 2020. To reach these targets, efforts will be made to: (i) establish community-based supply, to be subsidized and organized by the Government, for rural populations; (ii) improve the level of supply both quantitatively and qualitatively by rehabilitating existing infrastructure and building new classrooms; (iii) train trainers; (iv) recruit and train male and female educators; and (v) diversify the facilities with integrated and flexible programs.

In the case of primary education, governmental action will focus on increasing the level of supply and stimulating the level of demand with an eye to achieving universal primary education, i.e. a firstgrade access rate of 100 percent in 2012 and a primary school completion rate of 83 percent in 2011 and fully 100 percent in 2015. To that end, the Government intends to: (i) boost the system's capacity in terms of facilities to ensure broad school access and full primary school enrollment; (ii) make basic education free; (iii) recruit and train teachers; (iv) provide schools with textbooks and teaching materials; (v) transform the Local Initiative Schools (EDILs) into public primary schools, cover the related operating costs, and integrate volunteer teachers into the ranks of State teachers through a competitive recruitment exam; (vi) establish school meal programs and school health units; and (vii) implement a policy aimed at reducing the frequency of repeaters, consistent with the 10 percent benchmark of the Fast Track Initiative. 
In the case of the first cycle of general secondary education, the plan is to improve the yield in harmony with the second cycle of secondary education, technical education, and vocational training by controlling the rate of transition from primary to secondary education (with the objective of a decrease from 78.5 percent in 2007 to 74 percent in 2011 and 65 percent in 2020), raising the survival rate from 68.3 percent in 2007 to 72 percent in 2011 and 80 percent in 2020, and greatly reducing the repeater rate, bringing it down to a level that can guarantee the internal efficiency of this cycle. In this area, the Government's priorities are to: (i) overhaul the curricula; (ii) strengthen the partnership with the private sector; and (iii) provide schools with teaching materials in adequate numbers, well-equipped laboratories, and sports facilities.

As for the second cycle of general secondary education, the Government's objective is to improve its yield in harmony with technical education, vocational training, and higher education by controlling the rate of transition from the first to the second cycle of secondary education, improving the survival rate, and bringing down the repeater rate in line with the specified quality standard. The Government intends to: (i) improve the conditions of student facilities; (ii) reduce the frequency of repeaters; (iii) reduce class sizes; and (iv) significantly increase the level of educational spending per student.

In the case of technical education and vocational training, the following actions will be taken: (i) revisit the supply of technical education and vocational training in relation to economic demand and in partnership with the private sector; (ii) renovate school infrastructure and facilities; and (iii) develop integrative vocational training to improve labor productivity in the agricultural and non-agricultural informal sector.

For higher education and research, the Government intends to: (i) bring the infrastructure up to standard; (ii) establish, in harmony with secondary education, an educational guidance strategy for controlling student flows; (iii) reshape the distribution of students between scientific and literary/legal courses and between the public and private sectors; (iv) develop, on a targeted basis, university research; and (v) strengthen and gradually expand the bachelor/master/doctor system.

In the area of literacy education, from the perspective of cutting the illiteracy rate in half by 2015 , the intention is to: (i) adopt a new approach based on existing models that involve contracting out certain services; (ii) develop a structured partnership between non-State actors charged with providing services and the Government, which remains responsible for organizing and coordinating the literacy education programs; (iii) develop specific and functional literacy programs for unenrolled youth and those who have left school, as well as for women and girls, so as to encourage and facilitate their attainment of autonomy and their integration into the sustainable development and poverty reduction process; and (iv) train trainers.

All these measures will take into account the specific education and training needs of vulnerable groups and disabled individuals by implementing inclusive education programs. In addition, governmental action will focus on implementation of the HIV/AIDS control strategy in the educational ranks where this strategy already exists (primary, secondary, and technical education) and on prompt development of this strategy where it is still lacking (higher education and literacy education).

\subsection{Development of the health system and health services}

The health system assessment revealed both progress and shortcomings in the sector. Progress has been made in the area of immunization coverage, the availability and use of treated mosquito netting, maternal and child health, and coverage of serious malaria cases in children. The infant mortality rate has fallen slightly. On the other hand, coverage in terms of functional infrastructure has remained at a standstill in the country, health facilities are poorly equipped and ill suited, and the rate of patient satisfaction with health service delivery remains low. The HIV epidemic is now being stabilized. However, there are worrisome disparities based on area of residence, age, and sex. While the Directly Observed Treatment Short Course (DOTS) has been successfully expanded to all districts, 
improvements in the indicators have not followed. Health system management capacities are weak, and institutional reforms reflecting the hospital policy are not implemented. In addition, the hospitals generate a large quantity of waste, the nature of which requires sound and specific management.

To improve health system performance and reach the Millennium Development Goals in the health field, the Government has identified four strategic goals which are laid out in the National Health Development Plan. Accordingly, these goals form the foundation for the health component of the present strategy paper, which reaffirms them as strategic poverty reduction objectives of the Government.

\section{Box 12: National Health Development Plan}

The 2009-2013 National Health Development Plan (PNDS) reflects the Togolese Government's political commitment to address the country's health problems. It is the concrete culmination of a lengthy process targeting major health problems as identified through a bottom-up approach and based on results-oriented planning. Developed with the support of public and private health sector actors, other related sectors, development partners, and civil society, the PNDS represents the outcome of several policy workshops for setting priorities. The main problems uncovered by the baseline survey are: (i) high maternal and infant mortality rates; (ii) high prevalence of malnutrition and micronutrient deficiencies in children from 0 to 5 years of age; (iii) the persistence of HIV and sexually transmitted diseases, malaria (the leading cause of infant and child mortality), and tuberculosis; (iv) the persistence of fairly frequent, potentially epidemic diseases, diseases to be eradicated, eliminated, and controlled, and emerging and re-emerging diseases; (v) the high prevalence of cases of wounds and trauma; and (vi) the emergence of non-transmittable diseases. These problems are further compounded by the shortage of human resources in the health system, outdated and inadequate facilities and equipment, dilapidated infrastructure, weak management and coordination capacities, etc. In view of the problems identified, four strategic goals were formulated: (i) strengthen the institutional framework and management of the health system; (ii) improve the health of mothers, children, adolescents, and the elderly; (iii) prevent and control transmittable and non-transmittable diseases; and (iv) promote intersectoral collaboration, coordination, and partnership. The priority objectives flowing from these strategic goals are to improve maternal and child health and significantly reduce the impact of diseases, especially malaria, tuberculosis, and HIV/AIDS, through human resources development, infrastructure rehabilitation, and the upgrading of medical and technical equipment. In addition, implementation and monitoring and evaluation mechanisms are planned at all levels of the system to ensure the rational use of resources, based on the criteria of efficiency, equity, accountability, and the obligation to produce results.

Source: Ministry of Health

Strengthen the institutional framework and management of the health system. The Government intends to pursue national health system reforms and thereby provide the system with the necessary capacities for successfully implementing actions that will help achieve the MDGs in the health field by 2015. To that end, the priority actions are to: (i) strengthen the legal and institutional framework; (ii) increase the general public's access to health services; (iii) build management capacities, especially at the district level; (iv) revitalize human resources development; (v) improve the availability and accessibility of essential drugs, vaccines, and other high-quality consumables; (vi) mobilize financial resources for the health sector; (vii) promote health-related research; and (viii) improve the availability of reliable information for decision-making purposes.

Improve the health of mothers, children, adolescents, and the elderly. The impact sought through this component is to meet the health objectives relating to mothers and children. In this area, the Government will make every effort to carry out the following priority actions: (i) increase the use of mother-child couple services from 80 to 90 percent; (ii) strengthen clinical care services by expanding assisted births, emergency obstetrical care, and free neonatal care; (iii) strengthen the immunization system; (iv) improve Prevention of Mother to Child Transmission (PMCT) coverage from 11 to at least 80 percent; (v) reduce the rate of malnutrition in children under 5 years of age from 26 to 20 percent; (vi) make available at least one social center for youth per region; and (vii) develop services appropriate to the health needs of the elderly. 
Prevent and control transmittable and non-transmittable diseases. Inasmuch as the health sector is dominated by problems related to transmittable and non-transmittable diseases, this component aims to reverse the trend and thereby lessen the weight of disease-related morbidity and mortality. Special emphasis will be placed on HIV/AIDS (availability of antiretroviral drugs throughout the country, prevention and treatment of opportunistic infections), tuberculosis, and malaria, which carry a very large socioeconomic burden. In addition, efforts will be made to deal with non-transmittable diseases through the STEPWISE approach recommended by WHO. To achieve success, the following actions will be carried out: (i) reduce morbidity and mortality due to HIV, tuberculosis, malaria, other diseases, and injuries and trauma; (ii) ensure a healthy environment; (iii) make the entities charged with preparing for, and responding to, emergency situations and disasters fully operational; (iv) bring up to scale the entities responsible for coverage and reintegration of the disabled; and (v) set in place appropriate services to provide health coverage to persons in specific settings, including the workplace.

Intersectoral collaboration, partnership, and coordination. In regard to this strategic objective, the Government aims to increase the effectiveness of intersectoral collaboration in searching for solutions to problems whose causes go beyond the scope of the health sector. It also intends to strengthen the national and international partnership, as well as the Government's role in the ownership of sectoral development policies and strategies and the coordination and mobilization of resources. All dimensions (national and international) will be taken into account. Coordination will cover not only the interventions of national health sector actors, but also those of health development partners. As such, the priority actions are as follows: (i) strengthen intersectoral collaboration; (ii) expand and strengthen the framework of consultation with different health partners; (iii) improve the coordination of interventions; and (iv) improve resource mobilization capacities.

\subsection{Improving the nutritional status of the general public}

According to the results of the MICS3 survey (2006), 26 percent of children under 5 years of age have insufficient body weight and close to 24 percent of children suffer from growth retardation. However, the micronutrient indices (for iron, iodine, and vitamin A) showed substantial improvement during the period under review. In general, the northern regions and, more specifically, the Savanes region, are the areas where malnutrition is most endemic. A distinction should be drawn between chronic malnutrition (on the rise for ten years now, especially in the northern regions) and acute malnutrition (which has fallen greatly over the last few years ${ }^{44}$ ). The incidence is higher in rural areas than in urban areas, and there is often a positive correlation between the mother's educational level and improvements in children's nutritional indices.

In view of this worrisome situation in regard to nutritional status in the country, the Government has set for itself the following objectives: (i) increase the effectiveness of existing programs and promote new ones to prevent and control nutritional deficiencies in mothers and children; (ii) raise the awareness of the general public, and particularly of vulnerable groups, concerning the impact of a healthy diet; and (iii) improve the institutional framework of diet and nutrition.

Efforts to increase the effectiveness of existing programs and promote new ones to prevent and control nutritional deficiencies will focus on implementation of the Accelerated Strategy for Child Survival and Development, the promotion of foods rich in micronutrients, and the enrichment/fortification of foods. In addition, the national dietary strategy for infants and young children, in the context of HIV, will be implemented, along with the development of school meal programs in preschools and primary schools in vulnerable areas. The Government will also see to the implementation of a nutritional program for adolescent girls, pregnant women, and nursing women, on the one hand, and a system of animal-health, plant-health, dietary, and nutritional monitoring, on the other. Lastly, the Government will also initiate and implement specific programs for dietary coverage

44 Togo's rate now matches the average rate for the "maritime" subregion. 
of vulnerable persons (senior citizens, HIV/AIDS patients, and mothers and children with severe nutritional deficiencies).

In order to raise the awareness of vulnerable groups concerning the impact of a healthy diet, informational, awareness-raising, and educational campaigns will be carried out, targeting all public actors and civil society, concerning the importance of a good diet to maintain good health.

Finally, efforts to improve the institutional framework will focus on the implementation of measures designed to strengthen the institutional capacities and legal framework for promoting good diet and nutrition and improve the information system and data collection mechanism of the diet and nutrition sector.

\subsection{Improving access to safe drinking water and to sanitation infrastructure}

The baseline survey of water resource management in Togo points to the existence of a number of physical constraints, such as: (i) climatic constraints (drought, irregular rainfall, and the poor spatial distribution of rainfall); (ii) geological constraints (nine-tenths of the country consists of platform and old sedimentary areas largely or entirely unfavorable to the formation of high-capacity aquifers); and (iii) hydrogeological constraints (steadily increasing salinization of Continental Terminal waters, one of the main aquifers of the coastal sedimentary basin).

The weaknesses in collecting and measuring climatological, hydrological, and hydrogeological data have strong implications for: (i) managing water resources for different purposes (drinking water, irrigation, hydroelectric power, etc.); (ii) evaluating the availability of water resources and accurately assessing the impact of climate change on same; and (iii) evaluating floods and preventing flooding and other water-related disasters.

In the area of safe drinking water supply, there are three distinct contexts: rural, semi-urban, and urban. In all three contexts, the status of safe drinking water supply is worrisome nationwide. According to data from the MICS3 survey of 2006 and the report of the MDG consulting mission (validated in July 2007), overall service rates for drinking water and liquid sanitation infrastructure remain low: (i) 34 percent had access to safe drinking water (21 percent in rural areas, 24 percent in semi-urban areas, 39 percent in urban areas, and 44 percent in Lomé) in 2007; (ii) 32 percent of the population used improved toilet facilities (67 percent in urban areas and just 10 percent in rural areas); and (iii) no indicator concerning rainfall drainage in town and cities of semi-urban and urban areas.

These data show that: (i) a large portion of the population is exposed to the risks of water-based diseases; (ii) the time devoted to the task of obtaining water is substantial, particularly for girls and women, and is one of the principal factors underlying the low school enrollment ratios for girls and the low level of women's involvement in income-generating activities; (iii) the inadequacy of the Safe Drinking Water Supply and Sanitation (AEPA) facilities and their difficult access are major constraints to poverty reduction in Togo; and (iv) much remains to be done in order to improve the general public's access to drinking water and liquid sanitation infrastructure on a permanent basis.

To meet these challenges and attain the Millennium Development Goals, the Government has established five priority objectives, as follows: (i) improve the water resource management system through the Integrated Water Resource Management (IWRM) approach; (ii) improve the general public's level of access to safe drinking water in rural, semi-urban, and urban areas; (iii) improve the level of access to liquid sanitation services by promoting appropriate infrastructure; (iv) promote good hygiene and sound health practices; and (v) develop and implement an Information, Monitoring, and Assessment System (SISE) for the safe drinking water and liquid sanitation sector. 
Integrated Water Resource Management (IWRM) is the subject of a three-volume document, written in 2005 and validated in 2007: a baseline survey of the water sector, policy and strategy recommendations and the resulting action plan, and a proposed Water Code. This document establishes a vision of the water and sanitation sector in Togo for the year 2025. In response to the sector appraisal, the national vision for the water sector encompasses the following objectives: (i) provide safe drinking water in sufficient quantities, adequate sanitation infrastructure, and a healthy environment accessible to all; (ii) ensure the provision of water for agricultural and fishery needs and a sufficient and regular supply, in terms of quantity and quality, for the entire Togolese population and for ecosystems maintaining their hydrological, biological, and chemical functions; and (iii) make water available for the essential needs of the general public, power generation, industrial production, food production, and ecosystem conservation, without cross-border conflicts or flooding. To provide these objectives with the force of law, the preliminary draft of the Water Code sets the following benchmarks: (i) put into legal terms the water policy and IWRM concepts and principles; and (ii) define the specific rules concerning authorizations, levies, uses, and protective measures, notwithstanding the regulatory provisions that need to be established elsewhere. The specific objectives of the preliminary draft of the Water Code are to: (i) satisfy the needs of the general public in the area of safe drinking water supply; (ii) develop water as an economic resource; (iii) ensure that water is distributed among different uses and activities in such a way as to reconcile the requirements of public health and civil protection, water conservation and free flow, protection against flooding, agriculture, fisheries, industry, hydroelectric power generation, transportation, tourism, recreation, and all other legitimate human activities; (iv) plan the use and management of water resources at the catchment basin level; (v) develop and protect water supply structures and facilities; (vi) ensure rational management of water uses; (vii) protect water resources from all forms of pollution and control floating vegetation; (viii) conserve and restore water resources; and (ix) protect aquatic ecosystems.

Source: Ministry of Mining, Energy, and Water

Improve the water resource management system through the Integrated Water Resource Management (IWRM) approach. Governmental action will consist of the following: (i) implement integrated water resource management in Togo; (ii) establish the institutional framework and make it fully operational; (iii) implement a legal framework consistent with the policy and strategies adopted, and ensure effective enforcement of the statutes and regulations; (iv) improve knowledge and monitoring of water resources, demand, and use; (v) develop effective participation by all actors in the management of water resources; (vi) establish IWRM master plans at the catchment basin level and nationwide and implement concerted programs to develop water resources consistent with IWRM principles; (vii) promote multiple-use water management; and (viii) promote integrated management of shared water resources.

Improve the general public's level of access to safe drinking water in rural, semi-urban, and urban areas. The Government has made the decision to: (i) implement, through a participatory process, the water supply and liquid sanitation policy in rural and semi-urban areas; (ii) supply safe drinking water to rural populations, especially in the areas most underserved to date, and with a special emphasis on semi-urban centers where the coverage rates are the lowest; and (iii) establish water supply systems in cities where they are lacking and strengthen the existing systems (Lomé, Kara, Pagouda, Niamtougou, and Pya).

Improve the level of access to basic sanitation services by promoting appropriate infrastructure that is accessible to all. The actions identified by the Government aim to: (i) facilitate household access to decentralized liquid sanitation systems by implementing a subsidization policy; (ii) build public latrines and urinals; (iii) complete emergency works for effective drainage of rainwater in the city of Lomé and implement a sustainable maintenance system; (iv) strengthen national capacities; and (v) develop liquid sanitation master plans for the cities of Togo patterned on the Lomé master plan.

Promote good hygiene and sound health practices. The Government intends to implement the following actions: (i) educate and inform households and communicate with them to promote their acceptance of appropriate financing, use, and maintenance of sanitary facilities for removing or 
eliminating excrement and for collecting and removing wastewater; (ii) develop dumping sites and raise the awareness of sewage disposal companies and organize them into industries so that sewage sludge and wastewater are emptied at these sites; and (iii) expedite surveys of rural and semi-urban areas to better grasp the impact of the services provided. In addition, to improve health conditions and pollution, the Government intends to rehabilitate sanitation services as expeditiously as possible and establish intermediate and final dumping sites.

Develop and implement the Information, Monitoring, and Assessment System (SISE). Within the framework of the National Statistics Development Strategy, the Government proposes to provide the safe drinking water and liquid sanitation sector with institutional and technical instruments for ensuring the accuracy of data, from bottom to top, and for monitoring and assessment of the programs responsible for implementing investments in the sector. These instruments target information and indicators of financing, completion, results, and access to the various sector services. In this area, the following priority actions are planned: (i) develop the content of the information, monitoring, and assessment system; and (ii) implement this system, which will take into account the integrated water resources information system specified in the priority measures of the action program for integrated water resource management.

\subsection{Promoting gender equity and equality}

According to the MICS3 survey of 2006, the Togolese population has a slight female tilt (51 percent female versus 49 percent male). In addition, women work more than men, based on the finding that the labor force participation rate for women was 79.1 percent in 2006, versus 78.5 percent for men, according to the QUIBB survey.

Despite this potential, women are the victims of many discriminatory situations, particularly in regard to access to education, health care, employment, and leadership positions; furthermore, they are also the victims of sociocultural obstacles that confer upon them a degrading and inferior status. To address these forms of discrimination, the Government proposes to: (i) promote gender equity and equality through education; (ii) facilitate women's access to decent jobs and leadership positions; (iii) promote gender issues in the human rights arena; and (iv) strengthen the institutional framework for implementing the national gender equity and equality policy.

Gender equity and education. The literacy rate for women is 44.4 percent, versus 70.3 percent for men. In the school system, the girl/boy parity index in 2006 was 90 percent in primary schools and 80 percent in secondary schools. These quantitative disparities are mirrored by a qualitative disparity that begins to emerge in the secondary cycle, when the education system artificially steers girls towards short and literary studies, while boys are much more likely to pursue long and scientific studies. To correct these imbalances, the Government intends to: (i) establish a fair access, retention, and completion mechanism at all levels of the education system, which will require improving the school map to ensure better access for girls at all levels, raising awareness to keep girls in secondary school and higher education, promoting a policy of steering girls towards scientific and technical studies, and providing advocacy for a gender-sensitive updating of the education, training, and literacy policy; and (ii) ensure that the different needs of girls and boys, and men and women, are taken into account in the education, training, and literacy sector, which means promoting the development of an information system on the status of girls and boys in the school system, strengthening the capacities of education sector staff and planners in the area of gender, integrating gender into the training curricula, and taking into account the specific needs of girls and persons living with disabilities in the school infrastructure.

Women's access to jobs and leadership positions. Women are often confined to the informal sector and limited to jobs that offer little security. The Government intends to reverse this trend in the medium term. The goal is essentially to increase women's productivity and income. Governmental action in this area will focus on the following: (i) increase the presence of women in the various productive sectors; (ii) contribute to boosting the productive capacity of women; (iii) contribute to 
equal access to employment and the labor market; and (iv) promote women's access to leadership positions.

Gender equity and human rights. Equal access to rights is the pre-eminent condition for exercising citizenship. To meet this challenge, the Government proposes to: (i) ensure equal exercise and enjoyment of civil and political rights by men and women; (ii) eliminate discriminatory provisions, revise the statutes, and fill the legal gaps in the national laws; and (iii) reduce violence against women and children.

A stronger institutional framework for implementing the national gender equity and equality policy. Since adoption of the Interim PRSP, the Government has worked to strengthen the institutional framework for implementing the national gender equity and equality policy. These efforts should be consolidated by two actions: (i) strengthen the role of the ministry responsible for the advancement of women and gender rights; and (ii) provide institutional support to civil society organizations involved in implementing gender rights.

In addition to the strategic objectives cited above, the Government intends to support women's associations in particular and undertake specific actions to modify the cultural, social, and political norms and the distribution of political and economic power so as to promote equality between men and women.

\subsection{Social protection}

The Government's concerns in the area of social protection are focused on measures to protect the general public against social risks of all types. As such, three broad issues will be taken into consideration: (i) insurance; (ii) assistance and poverty management; and (iii) safety and health in the workplace.

So far as insurance is concerned, social protection in Togo is managed by two institutions, the National Social Security Fund for the private and semipublic sectors and the Togo Retirement Fund for the public sector. Private insurance companies active in this area operate with no guidelines, sometimes resulting in considerable confusion and uncertainty for the insured. Their influence is negligible. The few initiatives to set up health or assistance mutuals do not yet offer the clear visibility and effectiveness necessary for providing a sound social protection model and reach less than 4 percent of the total population. Also, in the case of the civil service, coverage is typically limited to an old age pension and family benefits, while coverage in the private and semipublic sectors encompasses old age and disability pensions, occupational risks, and family allowances. Health insurance is almost nonexistent.

Assistance and poverty management fall mainly to the National Solidarity Agency and other government entities (the ministries in charge of social action, health, and civil protection) which lack ample resources and strategic policies. Profiles of vulnerability and major disability have not been developed, which results in a great deal of approximation and improvisation with respect to coverage. The humanitarian and charitable organizations active in this area operate without clarity or guidelines concerning selection criteria and service packages.

The issue of workplace safety and health, a key pillar of social protection, has long remained on the back burner. Morbidity, mortality, and accidents related to the performance of occupational activities are legion, due to a number of factors: the laws are outdated or incomplete; entities have atrophied or are not operational; risk mapping is nonexistent; qualified personnel are not available; actors have a hazy perception of their rights and obligations. In other words, Togolese workers, whether in the formal sector or the informal economy, the agricultural sector, or in urban or rural areas, are not generally protected against the major risks to which they are exposed by their occupational activities. 
In view of the above, the Government intends to take measures consistent with commitments 85 and 87 of the social dialogue memorandum of understanding in order to ensure, in the medium term, a minimum of social protection for all citizens, men and women alike, including all workers in the formal sector or the informal economy, whether wage-earners or self-employed, urban or rural, industrial or agricultural, and for specific vulnerable categories as well (the unemployed, the disabled, pregnant women, vulnerable children, the elderly, disaster victims, the homeless, etc.).

To that end, the following priority actions will be taken: (i) expedite a study-assessment to pin down the real situation in the area of social protection; (ii) perform a diagnostic audit of current social protection service delivery organizations; (iii) develop a national policy on social protection; (iv) raise the awareness of the Togolese population concerning the stakes and the responsibilities incumbent upon them in ensuring the sustainability of any solutions that are implemented; and (v) set in place an action plan to make the policy operational.

\subsection{Promoting youth, sports, and recreational activities}

The Government believes that youth must be privileged actors in the socioeconomic, cultural, and political transformations underway in Togo; indeed, for any nation, it is today's youth that must take the reins tomorrow. Furthermore, the Government recognizes that, during the periods of sociopolitical unrest that the country has endured, Togolese youth have faced tremendous difficulties in terms of education and training, health care, socioeconomic integration, sports, culture, and recreational activities. For this reason, the Government intends to: (i) promote a good match between training and employment for youth; (ii) provide a cultural, sports, and socioeducational framework (including socioeducational youth centers) necessary for youth to blossom; (iii) provide quality education to youth, including youth with disabilities, and facilitate their access to ICTs; (iv) improve the health status of youth in a healthy environment; (v) reduce the inequalities between young boys and young girls in regard to access to production factors and decision-making; (vi) implement the HIV/AIDS prevention and control plan of the Ministry of Youth; and (vii) develop and implement a coverage plan for the unemployed.

In addition, the Government intends to encourage the development of sports and promote the expansion of recreational activities. The following actions are priorities in this area: (i) develop the practice and culture of sports by crafting a legal framework for sporting activities, by developing a national program on recreational activities, and by creating, renovating, and developing sites or parks for recreational activities throughout the country; (ii) participate in the influence of sports in the country by promoting sports and organizing school and university championships throughout the country; and (iii) encourage the practice of sports in school and student settings by developing Physical and Sports Education (EPS) teaching programs in schools and universities, encouraging the practice of physical education, and providing educational oversight and monitoring of EPS teachers in accordance with teacher evaluation regulations.

\section{Fourth Pillar: Community Development and Reduction of Regional IMBALANCES}

In relation to the goals of the interim poverty reduction strategy, this pillar constitutes a new strategic thrust. Two reasons undergird this pillar: (i) the necessity of implementing a local pro-poor policy reflecting real needs as expressed by citizens themselves in regard to grassroots development; and (ii) the fact that poverty is amplified when policies fail to take inter- and intra-regional imbalances into account. It is thus important to address simultaneously the concerns about grassroots development and those that pertain to regional imbalances.

The general objective of this pillar is to set in place appropriate conditions for implementing the poverty reduction strategy at the grassroots level in such a way as to provide local populations with a "common vital minimum." 
To achieve this objective, the Government intends, on the one hand, to strengthen local governance and grassroots development support mechanisms so as to ensure effective participation by grassroots organizations in the poverty reduction process and, on the other, to develop regional and local potential with a view to promoting local development and thus preventing any worsening of inter- and intra-regional imbalances.

\subsection{Strengthening local governance and community development support mechanisms}

The Government is aware of the importance of the decentralization process in community development. Through this pillar aimed at improving governance, the Government has reaffirmed its commitment to bring this process to a swift and successful conclusion, especially inasmuch the Government recognizes that Togo is lagging behind other countries of the subregion in this regard. Furthermore, the Government remains convinced that simply setting up decentralized structures is not by itself enough to ensure effective community development, and early consideration must be given to the best way for local elected officials to organize the lifeblood of their communities for better participation in the development process, on the one hand, and the human, financial, technical, and logistic resources which these future local authorities will need if they are to be able to work effectively alongside the Government in achieving substantial poverty reduction, on the other.

The objectives identified in this area are to: (i) provide local communities with the instruments they need in order to make decentralization operational by promoting a local dynamic; (ii) induce communities to set up a system for planning, managing, and monitoring and evaluating development actions by promoting appropriate local development management tools; and (iii) strengthen the mobilization of resources to finance local development through the implementation of mechanisms for accrediting local organizations and promoting access to inclusive finances, accessible to poor communities and individuals.

Promote a local dynamic. To make the dynamics of decentralization viable, it is important to build the institutional and organizational capacities of local communities, thus enabling them to manage regional and local development through a participatory approach and in partnership with the Government. For this purpose, the Government intends to: (i) organize the socioeconomic, political, and cultural structures of planning, guidance, and steering with a view to effective ownership of the poverty reduction strategy at the local level; and (ii) build the capacities of local actors.

In regard to the organizations of the decentralized management structures, the capacities of local communities will be strengthened so that they can become the cornerstone of decentralized development with a view to significant poverty reduction. To that end, the Government intends to rehabilitate and strengthen, each with respect to its own mission, the decentralized planning frameworks, of which the main elements are: Village Development Committees (CVDs) at the village level, Canton Development Committees (CCDs) at the canton level, Local Planning Committees (CLPs) at the prefecture level, Regional Planning Committees (CRPs) at the regional level, and both Regional and Local Participatory Monitoring Committees (CRSP/CLSPs). Thus, official mechanisms will be set in place for recognition and accreditation of community-based organizations (CBOs), including CVDs, Neighborhood Development Committees (CDQs), and their specialized committees, and the capacities of these organizations will be strengthened. The Government will see to the formation, within each Local/Regional Planning Committee, of specialized committees and technical coordination units.

To address the lack of sufficient expertise within municipalities and create a pool of expertise for communities to draw upon, the Government plans to strengthen the Municipal and National Quadrilogues $^{45}$ and thereby promote a four-sided framework of consultation among Government, local

\footnotetext{
45 The Quadrilogue is a committee set up for a multi-sided dialogue about services of critical importance to the general public. It is set up at the local community level (basically the municipality) by representatives of the Government, the local
} 
communities, the private sector, and civil society. The partnership with the Union of Togolese Municipalities will provide another means of governmental action in this area.

To make development projects viable, the Government intends to promote intermunicipal collaboration. The Government will see to the participatory preparation of development projects and the formation of intermunicipal agencies.

In regard to building the capacities of local actors, the Government, aware of the decisive role of civil society and the private sector in supporting local communities, intends to build the capacities of such non-State actors in order to improve their service delivery within the framework of promoting sustainable development at the regional and local levels. To that end, the Government proposes to assist these actors through the following actions: (i) strengthen their organizational and technical capacities; (ii) clarify their legal status; and (iii) form an operational partnership with a view to assisting them in their resource mobilization efforts.

The experience of the special delegations of urban municipalities has highlighted a number of issues that could compromise the viability and effectiveness of communities, particularly the legitimacy of local authorities in making decisions of public interest and the development of a broad consensus concerning the management of city affairs. Building human capacities is an indispensable step in promoting local development and ensuring effective implementation of decentralization. The capacities of local planning entities need to be strengthened in the areas of design, analysis, implementation, and monitoring. Efforts should target not only local elected officials, but also the prefecture administration.

Sound management of local resources within the framework of decentralization requires well trained men and women. Accordingly, the capacities of local elected officials will be strengthened in the areas of proactive strategic planning, operational planning, project management, results-oriented management, annual work plans, and procedures for mobilizing resources through technical and financial partners. These topics will be supplemented by special attention to project ownership, the development of bidding documents, accounting, the monitoring and evaluation system, personnel management, and communication techniques.

Along similar lines, the prefecture administration will be provided with the necessary tools to better assess the consistency between municipal planning instruments and national policy and to ensure proper compliance with commitments made by municipalities in connection with the contractualization of projects under their territorial jurisdiction with the Government.

The baseline survey shows that the local communities which exist today operate under difficult conditions. Within the framework of implementation of Law No. 2007-011 of March 13, 2007 on decentralization and local liberties, a study will be conducted to identify the types of infrastructure apt to improve the working conditions of local elected officials. In addition, the issue of local economic governance should be examined in order to rationalize budget decisions and make public spending more effective, with an eye to boosting the local public savings needed to increase the level of local investment.

Promote the participatory planning of local development. With the support of development partners, a planning process has been set in place, since the time of the five-year plans, to allow for the bottom-up identification of needs. Under this institutional mechanism, deconcentrated government services monitor the implementation of local development projects. The inadequate coordination of actions by different development partners, the difficulties in mobilizing resources due to the diversity of financing mechanisms, and the complexity of certain procedures and arrangements for managing local development projects all hinder effective coordination of development actions aimed at meaningful poverty reduction.

community, economic operators, and beneficiaries. 
The Government has decided to apply the PRSP at the regional and local level with an eye to ensuring consistency among the interventions of different actors and promoting responsible participation by the general public in the management of local communities. This will mean, among other things, the establishment of local development programs built around the Village Action Plans (PAVs) and operational strategies and action plans for sectoral policies and programs. The purpose of these programs will be to make available to each region, prefecture, and decentralized municipality a bank of microprojects for the development and management of small-scale activities that can serve as a reference point for interventions by all stakeholders - Government, donors, civil society and private sector organizations, service providers, and beneficiaries - the implementation of which will be carried out by the Regional Public Investment Programs (PRIPs), the Millennium Village Joint Program, the Multiyear Microproject Programs (PPMRs), the Community Development Program (PDC), and the development projects and programs of various actors. The Government will reinforce these local development programs to ensure effective coordination of this dynamic at the central level and to ensure consistency at the national level. Each local development program (spanning three years) will be broken down each year into an annual work plan, a credit consumption plan, a procurement plan, and an indicator performance chart.

The Government will see to implementation of a decentralized information and communication system and a matching database to ensure real-time availability of the information needed to carry out particular actions. This activity will include efforts to raise citizens' awareness of the stakes of local elections and promote their participation in the management of public affairs. The communication system will also be a mechanism for generating information for monitoring and evaluating implementation of the various plans and thus of the PRSP.

Strengthen the mobilization of resources to finance local development. To ensure the mobilization of local resources for municipal development, a dynamic partnership will be developed with local actors. This partnership will extend to the control of local finances, the promotion of microfinance, and the development of an accreditation mechanism.

In regard to controlling local finances, the Government intends to deconcentrate the Directorate General of Taxation (DGI) by separating tax base operations, duty payments, and the issuing/placing of assessment notices and receipts in order to improve the poor flow of information between DGI and the offices of the account managers/public accountants of local communities.

Studies on local finances will be used to clarify the legal environment of local taxation and to establish a database on the full range of potential for each municipality, prefecture, and region in order to round out the study on local finances and taxation and then determine the best arrangements to be made for transferring the necessary resources to local communities. In a similar vein, building the capacity of communities to mobilize and transparently manage their resources will heighten the level of commitment on the part of taxpayers.

In regard to promoting microfinance, microfinance has been identified as the second instrument to be promoted as a measure to accompany resource mobilization for the development of local communities. The Government is aware that microfinance institutions (MFIs) are nonprofit organizations and, as such, cannot maintain a presence in communities where the clientele is not sufficient to allow them to cover the additional risks associated with their presence in such communities. Accordingly, the Government intends to work alongside future municipal authorities and to study the best way to cover these additional costs, inasmuch as its goal is to see MFIs cover all communities where the demand for financing for economic activities arises primarily in the form of microcredit.

In Togo, there has been rapid growth of MFIs involved in financing the activities of informal sector operators, encompassing small trade, handicrafts, and small farms, all of which contribute significantly to the national economy. The Government intends to promote financing for the informal sector and to support MFIs for that purpose by establishing a microfinance guarantee fund that will be used, among other things, to: (i) finance women's income-generating activities; (ii) finance small agricultural 
activities undertaken by professional rural farmers; (iii) assist in organizing agricultural industries, both upstream and downstream, so as to ensure production, processing, and marketing; (iv) encourage financing for small artisanal activities by providing organizational support; (v) encourage financing for artists and groups of artists operating in the sociocultural sector and thereby help them develop their initiative and their talent in the areas of culture, recreation, theater, cinema, sports, etc.; (vi) support innovations within MFIs; and (vii) establish a guarantee fund for equipment acquisitions.

In regard to implementation of a local organization accreditation mechanism, a chart will be developed that lays out the conditions and procedures applicable to a local organization that might be accredited.

The implementation of actions falling within the sphere of local governance and community development will require the creation of an ad hoc agency charged primarily with organizing, structuring, professionalizing, and accrediting community-based organizations and grassroots groups. In addition, the Government intends to establish a Community Development Support Fund with a view to providing these entities with assistance in financing community projects and incomegenerating activities.

\subsection{Reduction of regional imbalances through the development of regional and local potential}

The analysis of poverty in Togo reveals disparities. The more urban Maritime (including LoméGolfe) and Plateaux regions have a relatively low poverty incidence, while the more rural Central, Kara, and Savanes regions have a high incidence of poverty. This fragmentation produces a population flow from north to south and from rural to urban areas. In demographic terms, the Maritime (including Lomé-Golfe) and Plateaux regions, which make up just 40 percent of the country's land area, concentrate nearly 67 percent of the country's population. Failure to develop the potential of northern regions, on the one hand, and rural areas, on the other, is a direct consequence of this situation. Furthermore, the population pressure generated by this population flow is contributing to the gradual impoverishment of southern regions and urban areas.

To reduce these regional imbalances and poverty itself will require developing the economic potential of each region. To that end, the Government will implement actions aimed at better exploiting this potential. More specifically, in the three northern regions where the poverty incidence is greatest, especially the Savanes region, measures will be taken to ensure: (i) balanced emergence of development hubs; (ii) balanced development of human capital; (iii) balanced upgrading of infrastructure in support of growth; and (iv) spatialization of projects and programs.

Balanced emergence of development hubs. To stem the migratory flows at the root of the inter- and intra-regional imbalances, the Government intends to stimulate wealth creation at the local level by tapping into the potential of each region. To that end, the Government intends to promote the balanced emergence of growth and development hubs. The idea is to develop activity hubs that will then drive the regional socioeconomic dynamics. Thus, governmental action will aim to develop agricultural hubs, industrial hubs, and service hubs (commercial, tourist, and other services).

In regard to agricultural hubs, the principal natural resources (soil, water, vegetation) and the climatic conditions provide Togo with substantial potential for agricultural development. The country's agroecological regions are favorable for the development of agricultural products such as cotton, sorghum, millet, rice, yams, tomatoes, onions, groundnuts, and cowpeas in the Savanes region; cotton, maize, sorghum, yams, tomatoes, rice, cowpeas, soy, groundnuts, cassava, and millet in the Kara region; cotton, maize, sorghum, millet, rice, cassava, yams, cowpeas, groundnuts, and soy in the Central region; cotton, maize, cowpeas, groundnuts, and rice in the eastern part of the Plateaux region; coffee, cocoa, oil palm, maize, cassava, yams, and rice in the western part of the Plateaux region; and maize, cassava, cotton, oil palm, and vegetables in the Maritime region. The Government therefore intends to promote agricultural hubs based on diversified, productive, modern, and environmentally 
friendly agriculture, focusing on these regional products, around the Zio, Lili, and Yoto valleys in the Maritime region; the Mono valley and Litimé in the Plateaux region; the Mô plain, the Mono plain, and Adélé in the Central region; Dankpen, Bassar, and Assoli in the Kara region; and the Oti plain and the Cuesta area in the Savanes region. In addition, with respect to livestock and fisheries, the Government intends to rehabilitate and refocus the activities of the three ranches (Avétonou in the Plateaux region, Adélé in the Central region, and Namiélé in the Savanes region) to improve cattle breeding, on the one hand, and develop maritime fisheries in the Maritime region, on the other.

Furthermore, because of the high incidence of poverty in these areas, the Government intends to give special treatment to the prefectures of Kpendjal, Tandjoaré, Oti, and Tône in the Savanes region, the prefectures of La Binah, Bassar, La Kéran, Dankpen, and Doufelgou in the Kara region, and the prefectures of Sotouboua, Tchamba, and Blitta in the Central region. The prefectures of Wawa and East Mono in the Plateaux region and Vo, Yoto, and Avé in the Maritime region will also receive priority treatment due to the particularly high incidence of poverty in these areas, despite the fact that they are located in regions where the overall poverty incidence is relatively low.

In regard to industrial hubs, their emergence hinges on the development of mineral resources as well as the development of agroprocessing surrounding the agricultural hubs. Thus, industrial hubs will be developed in a balanced fashion around the mining potential and the agricultural hubs of each region. Specifically, the feasibility of the following actions will be studied: (i) rehabilitate the Alokoègbé and Agou oil mills and the Ganavé starch mill in the Maritime region; (ii) promote the installation of a fruit processing plant in Danyi and rehabilitate the SONAPH palm nut processing plant in Agou, as well as the cotton ginning operations in Talo and Notsé and the textile factory in Datcha; (iii) promote the development of industries around the Nyaoulou marble deposits, agroprocessing in Sotouboua, and the processing of cashew apples and seeds in Tchamba in the Central region; (iv) rehabilitate the UPROMA agricultural equipment production facility and the TOGOTEX textile factory in Kara in the Kara region; and (v) rehabilitate the Nassablé rice hulling facility and promote tomato and fruit processing facilities in the Savanes region.

The service hubs, for their part, are composed of commercial hubs, tourist hubs, and other service hubs (financial services for businesses, telecommunications services, and remote services).

With respect to commercial hubs, there are a number of strategic trading crossroads in Togo that draw commercial actors together, sometimes from beyond national borders. Indeed, the commercial vitality of cities such as Vogan and Assahoun in the Maritime region, Anié and Badou in the Plateaux region, Sokodé and Blitta in the Central region, Kétao and Kabou in the Kara region, and Cinkassé, Koundjoaré, Gando, and Yembour in the Savanes region makes them genuine commercial hubs and marketplaces with a subregional tilt. The Government will strive to consolidate the appeal and the competitiveness of these hubs by providing them with modern market infrastructure and facilitating their accessibility to other regions of Togo, and even other countries of the subregion.

As for tourist and cultural hubs, Togo has an abundance of tourist sites such as the Slave House, Lake Togo (Agbobrafo), and the Bayémé zoological and botanical park in the Maritime region; Kpimé and Akloa waterfalls, Agou peak, and the wall of Agbogbo in the Plateaux region; Abdoulaye forest and Fazao park in the Central region; the blast furnaces of Bandjeli, the castles of Koutamakou, and the Djamdè-Sarakawa wildlife complex in the Kara region; and the Oti-Kéran and Oti-Mandouri reserved forests, the Nano caves, the Namoundjoga rock paintings, and the Pana crocodile pond in the Savanes region. These tourist hubs will be developed through clusters of tourism projects judiciously spread throughout the country.

In the case of services such as financial, telecommunications, and remote services, these all hold potential for the emergence of regional economies. Development of these services around large cities such as Tsévié, Atakpamé, Sokodé, Kara, and Dapaong is a way to enhance their status as regional centers. It is also a boon to medium-size cities such as other prefecture seats, especially the poorest of them, and helps establish them as true employment opportunity centers. 
Balanced development of human capital. The emergence of growth and development hubs in the various regions requires that a minimum human resources potential be achieved. This in turn requires balanced development of human capital through access to education, health care, water, and sanitation in order to meet the human resource needs of the regional hubs.

In the education sector, targeted analysis has shown that the Savanes region has the lowest primary school enrollment ratio, with a gross primary school enrollment ratio of 96.0 percent, while the ratio is equal to or greater than 100 percent in the other regions. This situation may be explained by the fact that children are not sent to school or there are not enough schools in the area (student capacity). Even though efforts still need to be made with respect to the demand for education, this region has specific problems in regard to education supply.

In view of the above, the Government intends to strengthen several of the overall education initiatives so as to increase significantly the supply of education services in the Savanes region, and especially in the Kpendjal and Oti prefectures where the problem is most acute. In addition, the Government intends to set in place, in each region, a minimum action package for technical education and vocational training critical to the emergence of these hubs.

With respect to health care, the Savanes region and, to a lesser extent, the Central and Kara regions face specific difficulties in regard to the proximity of health services. This situation has an impact on mother and child health care in these regions. In contrast, inhabitants of Lomé-Golfe and, to a lesser extent, the Maritime region are much less vulnerable to malaria and HIV/AIDS.

From this perspective, the overall initiatives for increasing the supply of health services should be strengthened, on a priority basis, in the Savanes region, followed by the Central and Kara regions. With respect to mother and child health, initiatives should focus first of all on the Savanes region, followed by the Kara region. However, with respect to malaria protection and HIV/AIDS prevention and control, Lomé-Golfe and the Maritime region should be the key targets.

With respect to access to water and sanitation, unlike the situation of access to education and health care where the Central and Kara regions and especially the Savanes region lag behind overall, difficult access to safe drinking water and sanitation is much more of a problem in the Plateaux region particularly and in the Maritime region as well. However, the Savanes region ranks third in this regard.

With this in mind, the Government intends to strengthen substantially the water and sanitation initiatives in the Plateaux and Maritime regions and in the Savanes region. In addition, specific measures will be taken regarding the use of latrines in the Savanes and Kara regions.

Balanced upgrading of infrastructure in support of growth. The Government intends to support the emergence of regional hubs by instituting incentive measures for promoting private entrepreneurship through the development of transportation, energy, and telecommunications infrastructure. In this regard, the Government intends to expand urban road systems, as well as power and water systems, on the outskirts of Lomé, and to improve the sanitation system and the quality of urban roads in the city of Lomé.

With respect to the administrative regions, major rural roads will be opened or rehabilitated in each region to ensure better access to all growth and development hubs. Similarly, national and interstate roads of strategic importance to development of the hubs will also be rehabilitated or paved. In addition, medium-term planning calls for gradual electrification of villages and expansion of the telecommunications system in each region.

Furthermore, the supply of urban transportation, mainly private, is not sufficient for citizens to be able to travel quickly at any time of day. The Government, working with municipalities and the private 
sector, will make every effort to ensure that the sector is better organized and that both rural and urban transportation are improved.

The Government intends to expand the power grid and promote the development of renewable energies in rural centers in order to encourage the development of SME/SMIs. The rate of access to electric power will be raised from 28 to at least 50 percent in all regions.

Measures will be taken to ensure that Internet systems are established and improved in all prefectures. The digital divide will be reduced so that underprivileged segments of the population can afford communication expenses.

Spatialization of development projects and programs. The objective is to ensure that the regional dimension is carefully considered in the development of public investment projects. To that end, governmental action will focus on integration of this dimension at the sectoral and central levels.

It will be important initially to encourage strategic discussions within each sector with a view to determining the outcomes planned for each region of the country. These discussions should lead to the development of maps of development projects and programs for each region and in each sector. In local communities, the same exercise will be carried out, based on the development hubs planned in each region, and also based on the actions planned with respect to balanced development of human resources and balanced upgrading of infrastructure in support of growth. Then, based on the results of these exercises, the Government intends to promote the implementation of clusters of development projects and programs that will serve as benchmarks nationwide for all planning (central, regional, or local). By "cluster of projects and programs," the Government means a package of projects and programs flowing from the sectoral maps of outcomes per region and the maps of outcomes compiled on the basis of regional development hubs and regional social safety nets. For each cluster, or each group of clusters, a spatial agenda will be worked out that situates the different project sites within an overall scheme, with a consistent vision, a more carefully thought-out geographic positioning, and cartographic documents. This is how the Government is preparing, over the coming years, to implement its integrated approach to national development, starting with regional and local development plans and strategies and uniting them into a national development strategy.

So far as the central dimension of development project and program spatialization is concerned, the Government intends, at the heart of budget discussions, to establish priorities based on the clusters of projects and programs targeting the regions. In other words, inter- and intra-sectoral arbitration in budget conferences will revolve around these clusters of projects and programs in conformity with the Priority Action Program set up for implementing the full poverty reduction strategy. Budget appropriations will be aligned with the order of priority of these development project and program clusters. Special attention will be given to the country's poorest and most vulnerable regions. From this perspective, the Government reaffirms its commitment to see through to a successful conclusion the joint initiative for the promotion of Millennium Villages and poverty reduction in Togo. 


\section{Box 14: Joint initiative for the promotion of Millennium Villages and poverty reduction in Togo}

The Millennium Village program is fully consistent with the reduction of intra- and inter-regional imbalances. It aims to achieve the Millennium Development Goals and promote the development of the poorest rural areas by ensuring citizens' access to technologies that can stimulate their agricultural productivity and improve their health, education, and market access. This nationwide program is spread over five years and targets 10 rural municipalities located in the poorest regions of the country: three each in the Savanes, Kara, and Central regions and one in the Maritime region.

The principal actions targeted under this program are to: (i) develop agricultural potential; (ii) improve producers' access to agricultural credit, inputs, and veterinary products; (iii) enhance tourist sites through development and participatory management; (iv) develop private initiatives; (v) improve the processing techniques for local agricultural products; (vi) improve women's knowledge of and access to property and credit; (vii) promote school enrollment by girls; (viii) rehabilitate and create local markets and other economic infrastructure; (ix) improve access to education, health care, safe drinking water, and sanitation; and ( $\mathrm{x}$ ) improve access to transportation infrastructure, power sources, and ICTs.

Given the innovative approach and the necessary learning that should come with it, two phases are envisioned: the first will last two or three years and focus on two pilot municipalities in the Savanes region; the second will also last two or three years and will cover the eight remaining municipalities. The first phase is under way in the municipalities of Kountoiré and Naki-Est, both of which are located in the Savanes region, the country's poorest, and more specifically in the prefectures of Oti and Kpendjal, which are the poorest prefectures in Togo. Based on a participatory approach involving first and foremost the target communities so that they will be autonomous after the program, along with public authorities, donors (particularly the United Nations System), the private sector, and other stakeholders, the Millennium Village program is an initiative in which the Government is greatly invested. The initial start-up phase raised US \$18,327,000 dollars, of which 27 percent was contributed by the Government and public authorities, 9 percent by the target communities, 46 percent by donors, and 18 percent by the private sector and other stakeholders.

Source: Ministry of Cooperation, Development, and Land Use 


\section{CHAPTER 5: MACROECONOMIC FRAMEWORK FOR THE STRATEGY}

The purpose of the framework for the full poverty reduction strategy is to determine the profile of the macroeconomic aggregates compatible with the choices underlying this strategy. Based on assumptions about developments in the global economic situation, the subregional economic environment, and the national development context, the framework forecasts trends in the resources that can be mobilized to implement the strategy, priority expenditures to which these resources will be allocated, and the expected overall results. The framework also takes into account the overall financing of the strategy. Financing details will be spelled out in the Priority Action Program, which is the programmatic framework for translating the F-PRSP strategic options into development programs and projects which will serve as platforms for the projected priority expenditures. The macroeconomic framework also lays out the major absorption risks for which solutions will need to be found if the framework is to be realistic and the measures planned under the full poverty reduction strategy are to be effective.

Consistent with the macroeconomic framework for the interim strategy, the full strategy framework remains very circumspect, especially because of the uncertainties about the recovery of world growth, the country's vulnerability to exogenous shocks, the persistence of the lingering effects of the food crisis in the subregion, and of course the fact that Togo is just emerging from a lengthy period of political and economic fragility. While respecting the country's ambition to follow the path of an emerging nation, this framework hinges on a gradual revival of growth, with the potential to accelerate growth and achieve the Millennium Development Goals (MDGs). Accordingly, the macroeconomic framework provides for two scenarios: a baseline scenario and an alternative scenario for acceleration towards meeting the MDGs.

The baseline scenario is consistent with the macroeconomic framework that was agreed to along with the $\mathrm{IMF}^{46}$ in connection with the three-year program supported by the PRGF. It focuses on continuing to improve the management of public finances and implementing structural reforms to revive economic growth and foreign competitiveness within the framework of the WAEMU fixed exchange system. Carrying out these reforms in the economic context described above would serve to increase the GDP growth rate by 3 percentage points between 2008 and 2011. Total public expenditures and, in particular, public investment expenditures should grow respectively by 4 and 2 percentage points of GDP over this period without generating inflation. In these conditions, a GDP growth rate of some 4.1 percent and a budget deficit well below 5 percent of GDP are expected in 2011.

Rooted primarily in the rehabilitation of public finances, this baseline scenario does not adequately incorporate the investments required to meet the MDGs. The alternative scenario offers the possibility of accelerating towards meeting the MDGs based on the Initiative of the United Nations SecretaryGenera ${ }^{47}$ to accelerate implementation of the commitment made by the G8 countries at the Gleneagles Summit in 2005 to double assistance to poor countries over the next three years, raising it to US \$85 per person and then maintaining it at this level. Given the current level of ODA in Togo (roughly US $\$ 11$ per person in 2008), the MDG scenario depends on improving the mobilization of resources needed to finance public expenditures in the sectors targeted by the MDGs. As a consequence, the new expenditure profile would add an extra point and a half to growth in GDP over the period from 2008 to 2011 in comparison to the baseline scenario.

\footnotetext{
${ }^{46}$ At the time of its mission of February 11-25, 2009. Following this mission, the IMF felt it necessary to make certain revisions, but the Togolese authorities are in favor of adopting the targets set on February 25.

${ }^{47}$ Ten pilot countries, including Togo, were named in this initiative.
} 


\section{BASELINE SCEnARIO}

The baseline scenario postulates a medium-term reform strategy to gradually raise the economic growth rate and lay the groundwork for a viable budget and a good external reserves position. Achieving this scenario thus depends greatly on satisfactory implementation of the reforms planned under this strategy. In these conditions, an increase in the primary budgetary balance becomes a goal in order to obtain a surplus of at least 1 percent of GDP by 2011 to avoid accumulating new payment arrears and to reduce the necessity of resorting to new loans. Likewise, the reform strategy is counting on an increase in foreign aid of close to three percentage points of GDP between 2008 and 2011 and an overall easing of the debt under the HIPC Initiative.

Table 8: Principal macroeconomic framework indicators

\begin{tabular}{|c|c|c|c|c|c|}
\hline Principal indicators & 2005-2007 & 2008 & 2009 & 2010 & 2011 \\
\hline Real GDP growth rate & 2.4 & 1.1 & 1.7 & 3.3 & 4.1 \\
\hline Public investment rate (as a percentage of GDP) & 4.0 & 3.9 & 4.8 & 7.1 & 7.0 \\
\hline Consumer price index & 3.3 & 8.7 & 2.8 & 2.1 & 2.5 \\
\hline Current balance (as a percentage of GDP) & $-6.2 *$ & -6.6 & -4.3 & -4.2 & -3.6 \\
\hline Primary budgetary balance (as a percentage of GDP) & -0.5 & 0.4 & -0.6 & 0.6 & 1.0 \\
\hline Total budgetary balance (as a percentage of GDP) & -3.1 & -1.0 & -3.2 & -2.0 & -1.0 \\
\hline
\end{tabular}

Source: Togolese authorities - IMF, February 25, 2009

* Average figure for 2006 and 2007

The principal arguments of the macroeconomic framework resulting from the baseline scenario are: (i) resumption of growth; (ii) price stability; (iii) consolidation of public finances; (iv) a strong domestic contribution to the financing of the strategy; (v) alignment of resources with national priorities; (vi) sustainability of the balance of payments deficit; and (vii) control of money supply.

Resumption of growth. Sustained growth of 3 additional percentage points is anticipated over the strategy implementation period, rising from 1.1 percent in 2008 to 4.1 percent in 2011. Such growth hinges first of all on activating gains in productivity in the primary and secondary sectors during the period 2009-2010.

Table 9: Real growth in sectors of activity

\begin{tabular}{|l|c|c|c|c|c|}
\hline & $\mathbf{2 0 0 5 - 2 0 0 7}$ & $\mathbf{2 0 0 8}$ & $\mathbf{2 0 0 9}$ & $\mathbf{2 0 1 0}$ & $\mathbf{2 0 1 1}$ \\
\hline Primary sector & $\mathbf{1 . 9}$ & $\mathbf{2 . 9}$ & $\mathbf{2 . 3}$ & $\mathbf{3 . 1}$ & $\mathbf{5 . 4}$ \\
\hline Agriculture & 1.3 & 3.1 & 2.4 & 3.0 & 6.0 \\
\hline Livestock, forestry, and fisheries & 3.7 & 2.9 & 2.0 & 3.5 & 4.0 \\
\hline Secondary sector & $\mathbf{3 . 9}$ & $\mathbf{0 . 8}$ & $\mathbf{2 . 8}$ & $\mathbf{4 . 5}$ & $\mathbf{3 . 4}$ \\
\hline Extractive industries & -7.2 & -0.6 & -2.0 & 7.2 & 8.1 \\
\hline Manufacturing industries & 7.9 & 5.0 & -1.0 & 2.5 & 2.5 \\
\hline Construction and public works & 11.1 & 0.9 & 20.0 & 9.0 & 2.5 \\
\hline Electricity, water, and gas & 2.6 & -11.0 & 3.0 & 2.5 & 2.5 \\
\hline Tertiary sector & $\mathbf{0 . 7}$ & $\mathbf{- 0 . 1}$ & $\mathbf{0 . 9}$ & $\mathbf{3 . 0}$ & $\mathbf{3 . 5}$ \\
\hline Market tertiary sector & $\mathbf{0 . 6}$ & $\mathbf{0 . 4}$ & $\mathbf{0 . 9}$ & $\mathbf{2 . 6}$ & $\mathbf{3 . 5}$ \\
\hline Trade & 3.5 & -0.5 & 1.0 & 2.0 & 3.5 \\
\hline Transportation, warehousing, and communications & 1.4 & 1.7 & 1.0 & 3.5 & 3.5 \\
\hline Banks and insurance & -17.3 & 14.2 & 1.0 & 3.0 & 3.5 \\
\hline Other services & -7.7 & 0.0 & 0.2 & 3.0 & 3.5 \\
\hline Nonmarket tertiary sector & $\mathbf{0 . 9}$ & $\mathbf{- 1 . 3}$ & $\mathbf{1 . 0}$ & $\mathbf{3 . 8}$ & $\mathbf{3 . 5}$ \\
\hline GDP & $\mathbf{2 . 4}$ & $\mathbf{1 . 1}$ & $\mathbf{1 . 7}$ & $\mathbf{3 . 3}$ & $\mathbf{4 . 1}$ \\
\hline
\end{tabular}

Source: Togolese authorities - IMF, February 25, 2009

Real growth in the agricultural sector will be the highest in 2011; this requires massive investments in the sector throughout the period of implementation of the full strategy so that the sector's potential is boosted with a view to obtaining real growth of more than 5 percent in 2011. A substantial increase in food and cash crop (cotton, coffee, and cocoa) production lies at the heart of the agricultural sector reforms. 
To achieve the growth objectives, major efforts will also be necessary in order to revive phosphate production in 2010 on a sustainable basis. The volume and quality of investments in terms of economic infrastructure (energy and roads) are variables on which the vitality of economic activity will depend, particularly in regard to services, over the implementation period of the full strategy. In addition, the non-physical infrastructure (financial services, business climate, etc.) also affects the profitability of the tertiary sector as a whole.

On the demand side, the overall investment rate increases steadily during the period. From 12.6 percent in 2008, it would climb to 17.5 percent of GDP in 2011. A consistent level of savings due to aid flows and other transfers, expected to derive from the new economic context, results in an improved savings-investment balance over the period, rising from -6.7 percent in 2008 to -3.3 percent in $2011 .^{48}$

Price stability. Despite the increase in domestic demand, which would be caused primarily by the level of government spending needed to finance the socioeconomic infrastructure, barring external shocks, domestic price stability is reflected in the full strategy framework. In practice, the goal will be to maintain price stability and to bring down the inflation rate to within the WAEMU limit, which is no more than 3.0 percent. This result would be obtained through a strong increase in output and an effective community monetary policy.

Consolidation of public finances. The budgetary policy will aim to improve government revenue and control government spending in order to limit any gaps in financing. Thus, the tax pressure rate will improve, rising from 16.4 percent in 2008 to 17.4 percent by 2011. The increase in tax revenue would be promoted by the simplification of administrative procedures related to the payment of taxes by the institutional units. This would stem from the implementation of the one-stop shop, without neglecting economic growth per se, which would enlarge the tax base. It would support the increase in budgetary revenue, which would rise from the equivalent of 17.1 percent of GDP in 2008 to 18.2 percent in 2011.

On the other hand, operating expenses were lower than past trends, since the Government chose the option of emphasizing financing for socioeconomic infrastructure. Thus, current expenditures would rise only from the equivalent of 15.8 percent of GDP in 2008 to 16.5 percent in 2011, while capital expenditures over the same period would rise from 3.9 percent to 7 percent of GDP.

In this context, the budget deficit (excluding grants based on payment orders) remains slightly higher than 5 percent of GDP throughout the period. This is quite sustainable because, based on available information about financing likely to be mobilized, the residual financing requirement to be raised for the TOFE is only about CFAF 37.5 billion in 2009, CFAF 26.3 billion in 2010, and CFAF 9.3 billion in 2011. The resources that the country is able to receive through the PRGF and IDA grants for 2009 and 2010 fully cover this financing gap. A greater commitment of the international community alongside the Government of Togo to support its socioeconomic recovery efforts will be necessary to cover the financing gap for 2011.

\footnotetext{
48 The data on the savings-investment balance should be viewed in opposition to the data on the current balance for the corresponding years (cf. Table 8) because the former is the opposite of the current balance.
} 


\begin{tabular}{|c|c|c|c|c|}
\hline \multirow{2}{*}{ Government } & \multicolumn{4}{|c|}{ Baseline Scenario } \\
\hline & 2008 & 2009 & 2010 & 2011 \\
\hline & \multicolumn{4}{|c|}{ (as a percentage of GDP) } \\
\hline REVENUE AND GRANTS & 18.7 & 19.1 & 21.9 & 22.5 \\
\hline REVENUE & 17.1 & 16.9 & 17.6 & 18.2 \\
\hline GRANTS & 1.6 & 2.2 & 4.3 & 4.3 \\
\hline TOTAL EXPENDITURES & 19.7 & 22.6 & 23.9 & 23.5 \\
\hline CURRENT EXPENDITURES & 15.8 & 16.6 & 16.8 & 16.5 \\
\hline Domestic current primary expenditures & 14.6 & 14.7 & 15.0 & 15.2 \\
\hline Interest on the public debt & 0.8 & 1.0 & 1.0 & 0.5 \\
\hline Current expenditures using external financing & 0.4 & 0.9 & 0.8 & 0.8 \\
\hline INVESTMENT EXPENDITURES & 3.9 & 5.9 & 7.1 & 7.0 \\
\hline Domestic contribution & 2.1 & 3.1 & 2.0 & 2.0 \\
\hline External sources & 1.8 & 2.8 & 5.1 & 5.0 \\
\hline Domestic primary budgetary balance & 0.4 & -1.0 & 0.6 & 1.0 \\
\hline Budgetary balance based on payment order excluding grants & -2.5 & -5.7 & -6.3 & -5.3 \\
\hline Budgetary balance based on payment order & -1.0 & -3.5 & -2.0 & -1.0 \\
\hline Change in arrears & 0.0 & -0.9 & -0.7 & -0.5 \\
\hline Total balance (cash basis) & -0.9 & -4.4 & -2.7 & -1.5 \\
\hline Financing & 0.9 & 4.4 & 2.7 & 1.5 \\
\hline Domestic financing & -1.0 & 0.6 & -0.3 & -0.5 \\
\hline External financing & $1.9^{*}$ & 1.0 & 1.1 & 1.4 \\
\hline Consists of: Drawings & 0.5 & 1.5 & 1.6 & 1.5 \\
\hline Debt retirement & -1.8 & -1.5 & -1.4 & -0.1 \\
\hline Settlement of the debt and arrears & -33.0 & 0.0 & -19.1 & 0.0 \\
\hline Reschedulings obtained & 15.0 & 0.0 & 0.0 & 0.0 \\
\hline Debt cancellation & 18.0 & 0.0 & 19.1 & 0.0 \\
\hline Financing gap** & 0.0 & 2.8 & 1.9 & 0.9 \\
\hline
\end{tabular}

Source: Togolese authorities - IMF, February 25, 2009

*In reality, for fiscal year 2008, there was a surplus of 0.3 percent of GDP carried forward to the next fiscal year (which should figure in the gap). Since fiscal year 2008 is closed, the financing line was balanced as such on the basis of the external financing line.

**This line incorporates both the special financing line and the residual financing requirement line of the financial operations table adopted in agreement with the IMF.

A strong domestic contribution to the financing of the strategy. The effort to mobilize resources will be very intense at the domestic level. In 2009, 2010, and 2011 respectively, domestic resources will finance 74,70 , and 73 percent of the total budget comprising estimated total public expenditures for each year. External resources that have already been announced will be used to finance 14, 23, and 24 percent of the budget respectively over this period. The financing gaps thus work out to 12, 7, and 3 percent respectively over this period. Sources for financing these gaps have already been identified but, in reality, advocacy needs to be stepped up in this area.

Table 11: Total budget and financing of the F-PRS (in billions of CFAF)

\begin{tabular}{lccc}
\hline & 2009 & 2010 & 2011 \\
\hline Estimated public expenditures & 301.2 & 334.2 & 349.4 \\
Domestic resources* & 222.0 & 232.6 & 255.7 \\
External resources** & 41.7 & 75.3 & 84.4 \\
Financing gap & 37.5 & 26.3 & 9.3 \\
\hline
\end{tabular}

$*$ total revenue + domestic financing + change in arrears

** external financing + grants 
Alignment of financial resources with national priorities. To reflect the Government's intention to put resources where the needs are greatest in order to meet national priorities, the breakdown of the framework's supplemental budget favors the priority sectors, namely health, education, agriculture, water and sanitation, and infrastructure, particularly for transportation, energy, and telecommunications. ${ }^{49}$ Taking into account spending related to specific needs in terms of personnel recruitment, operating expenses over the period 2009-2011 will show a steady increase of 3 percent per year for all sectors. Investment expenditures have been discounted for non-priority sectors at a rate of 4 percent, while the priority sectors share the rest of the supplemental budget released for each year of the framework. Thus, total expenditures in the priority sectors rise from 45.5 percent of total spending in all sectors between 2005 and 2007 to 67.4 percent by 2011 .

Table 12: Breakdown of the framework's total budget between priority sectors and other sectors (in billions of CFAF)

\begin{tabular}{|c|c|c|c|c|c|c|c|c|c|c|c|c|c|c|c|}
\hline & \multicolumn{6}{|c|}{ Performance } & \multicolumn{9}{|c|}{ Projection } \\
\hline & \multicolumn{3}{|c|}{$2005-2007$} & \multicolumn{3}{|c|}{2008} & \multicolumn{3}{|c|}{2009} & \multicolumn{3}{|c|}{2010} & \multicolumn{3}{|c|}{2011} \\
\hline & Op. & Inv. & Total & Op. & Inv. & Total & Op. & Inv. & Total & Op. & Inv. & Total & Op. & Inv. & Total \\
\hline Priority Sectors & 59.67 & 24.59 & 84.26 & 75.94 & 37.52 & 113.46 & 80.52 & 88.83 & 169.35 & 86.70 & 112.75 & 199.45 & 93.66 & 141.89 & 235.56 \\
\hline Education & 40.31 & 3.03 & 43.33 & 51.36 & 1.63 & 53.00 & 54.60 & 9.65 & 64.25 & 58.99 & 13.38 & 72.37 & 64.22 & 17.94 & 82.16 \\
\hline Health & 11.90 & 6.43 & 18.34 & 13.92 & 12.43 & 26.35 & 14.94 & 26.47 & 41.41 & 16.41 & 33.01 & 49.42 & 17.80 & 40.99 & 58.79 \\
\hline Agriculture & 3.65 & 1.82 & 5.47 & 5.06 & 16.31 & 21.37 & 5.21 & 23.88 & 29.10 & 5.37 & 27.42 & 32.78 & 5.53 & 31.72 & 37.25 \\
\hline Water/Sanitation & 2.37 & 3.60 & 5.97 & 0.38 & 1.50 & 1.89 & 0.40 & 8.20 & 8.60 & 0.41 & 11.32 & 11.73 & 0.42 & 15.13 & 15.55 \\
\hline Infrastructure & 1.44 & 9.71 & 11.15 & 5.21 & 5.64 & 10.86 & 5.37 & 20.63 & 26.00 & 5.53 & 27.61 & 33.14 & 5.70 & 36.12 & 41.82 \\
\hline Transportation & 1.10 & 9.67 & 10.77 & 0.96 & 5.61 & 6.57 & 0.99 & 19.21 & 20.21 & 1.02 & 25.56 & 26.58 & 1.05 & 33.28 & 34.34 \\
\hline Energy & 0.34 & 0.04 & 0.39 & 4.25 & 0.04 & 4.29 & 4.37 & 1.41 & 5.79 & 4.51 & 2.05 & 6.56 & 4.64 & 2.84 & 7.48 \\
\hline Telecommunications & - & - & - & - & - & - & - & - & - & - & - & - & - & - & - \\
\hline Other Sectors & 78.33 & 7.61 & 85.93 & 90.98 & 4.56 & 95.54 & 93.71 & 4.74 & 98.45 & 96.52 & 4.93 & 101.45 & 99.42 & 5.13 & 104.54 \\
\hline Debt & 15.01 & - & 15.01 & 32.52 & - & 32.52 & 33.40 & 0.00 & 33.40 & 33.30 & 0.00 & 33.30 & 9.30 & 0.00 & 9.30 \\
\hline Total & 153.01 & 32.20 & 185.19 & 199.43 & 42.08 & 241.51 & 207.63 & 93.57 & 301.20 & 216.52 & 117.68 & 334.20 & 202.38 & 147.02 & 349.40 \\
\hline
\end{tabular}

A sustainable balance of payments deficit. In conjunction with an improvement in the terms of trade, exports will begin to increase in 2010 after a decline of 2 percentage points of GDP in 2009 compared to $2008 .^{50}$ Transfers will increase slightly over the period 2010-2011 after a decline in 2009. Private transfers in particular will remain in decline throughout the period 2009-2011, reflecting the negative impact of the international financial crisis on transfers from the diaspora to Togo. On the other hand, the public transfers hoped for will grow throughout this period. As a result, current external payments over the period 2009-2011 should record ${ }^{51}$ an average deficit of approximately 4 percent of GDP versus 6 percent over the period 2006-2008. Gross international reserves will be equivalent to more than three months of imports over the implementation period of the strategy.

Controlled money supply. Over the last three years, Togo has had strong growth in the money supply, averaging 15 percent, despite the persistent problems faced by various banks which are now being straightened out. Through the reforms carried out in this sector, the money supply should grow by an average of 10 percent during the F-PRS period. In accordance with the common monetary

\footnotetext{
${ }^{49}$ In the telecommunications sector, the Government will make sure that TogoTelecom's investment plan incorporates the goal of providing the sector with state of the art infrastructure likely to reduce communication costs throughout the country.

${ }^{50}$ Exports would come to 21.5 percent of GDP in 2009 versus 23.5 percent in 2008 . They would then increase to 27.5 and 27.9 percent respectively in 2010 and 2011.

${ }^{51}$ Also because of a slight increase in imports over the period 2010-2011 consistent with internal demand.
} 
policy in the WAEMU countries, the priority is price stability and a conservative lending policy in the economy.

\section{Alternative Scenario fOr ACCEleration ToWards Meeting The MDGs}

This optimistic scenario is based on additional amounts of Official Development Assistance (ODA) to be mobilized under the initiative of the Secretary-General of the United Nations for the MDGs in Africa, in connection with the commitment made by the G8 in Gleneagles to increase ODA to poor countries. Implementation of this commitment should cause per capita ODA to climb to US \$85 in 2010. This scenario assumes that the country will indeed reap the benefits of this commitment, extended to 2011 to take into account the likely impact of the global financial and economic crisis on the total volume of ODA.

To reach the target of US $\$ 85$ per person in 2011, ODA for Togo should climb from US $\$ 61$ million in 2008 to US \$204 million in 2009, US \$354 million in 2010, and US \$511 million in 2011, which works out to an average of US $\$ 356$ million per year during the period 2009-2011. This would boost per capita ODA from US \$11 in 2008 to US $\$ 36$ in 2009, US $\$ 60$ in 2010, and finally US $\$ 85$ in 2011 , assuming a linear progression.

Table 13: Additional flows to be mobilized under the Gleneagles scenario

\begin{tabular}{|l|c|c|c|c|c|}
\hline & $\mathbf{2 0 0 8}$ & $\mathbf{2 0 0 9}$ & $\mathbf{2 0 1 0}$ & $\mathbf{2 0 1 1}$ & Average (2009-2011) \\
\hline Projected per capita ODA (US\$) & 11 & 19 & 31 & 32 & 27 \\
\hline Additional financing requirements for scaling-up (US\$ millions) & - & 153 & 184 & 251 & 196 \\
\hline ODA resources based on Gleneagles (US\$ millions) & 61 & 204 & 354 & 511 & 356 \\
\hline Expected per capita ODA based on Gleneagles (US\$) & 11 & 36 & 60 & 85 & 60 \\
\hline Additional ODA based on Gleneagles (US\$ millions) & - & $\mathbf{9 5}$ & $\mathbf{1 7 0}$ & $\mathbf{3 1 9}$ & $\mathbf{1 9 5}$ \\
\hline
\end{tabular}

Source: Togolese authorities

The ODA amounts for scaling-up were calculated on the basis of additional external financing requirements for meeting the MDGs on top of the ODA amounts already projected. These additional external financing requirements for meeting the MDGs hinge on additional investments in priority sectors, where implementation of the planned interventions should accelerate the process of achieving the MDGs in Togo. Accordingly, the expected additional external resources for scaling-up and reaching the target of US \$85 per person in Official Development Assistance have been directed almost entirely towards spending in MDG priority sectors.

It is anticipated that the additional resources will be principally earmarked for public expenditures in MDG-related sectors with a view to a more rapid scaling-up in attaining the MDGs. The additional investments are laid out in the following table: 
Table 14: Additional investments for accelerating towards the MDGs (as a percentage of GDP*)

\begin{tabular}{|l|c|c|c|c|}
\hline & $\mathbf{2 0 0 9}$ & $\mathbf{2 0 1 0}$ & $\mathbf{2 0 1 1}$ & Average (2009-2011) \\
\hline Education & $1.4 \%$ & $1.4 \%$ & $1.8 \%$ & $1.5 \%$ \\
\hline Health & $1.0 \%$ & $1.1 \%$ & $1.4 \%$ & $1.2 \%$ \\
\hline Gender & $0.2 \%$ & $0.2 \%$ & $0.3 \%$ & $0.2 \%$ \\
\hline Agriculture & $0.6 \%$ & $0.7 \%$ & $0.8 \%$ & $0.7 \%$ \\
\hline Water and Sanitation & $0.2 \%$ & $0.6 \%$ & $1.0 \%$ & $0.6 \%$ \\
\hline Energy & $0.3 \%$ & $0.7 \%$ & $1.5 \%$ & $0.8 \%$ \\
\hline Roads & $0.3 \%$ & $0.8 \%$ & $1.0 \%$ & $0.7 \%$ \\
\hline Governance & $0.0 \%$ & $0.1 \%$ & $0.2 \%$ & $0.1 \%$ \\
\hline $\begin{array}{l}\text { Other sectors (employment, community development, } \\
\text { statistics, environment, etc.) }\end{array}$ & $0.0 \%$ & $0.1 \%$ & $0.1 \%$ & $0.1 \%$ \\
\hline
\end{tabular}

Source: Togolese authorities

*These GDP levels were determined during the IMF mission in February.

In regard to the macroeconomic framework, the impact of the additional resources to be mobilized under the Gleneagles commitment would be felt through the substantial boost in investments apt to accelerate the process of meeting the MDGs. The macroeconomic impact analysis of the increase in assistance under the Gleneagles scenario carried out by the IMF $^{52}$ shows that a permanent increase in assistance would have a positive and lasting impact on growth and per capita GDP. Specifically, the results of the analysis show that growth in GDP would be one percentage point higher, on average, over the first ten years and that the positive impact of the increased assistance would be relatively greater on the accumulation of public and private capital because the country was deprived of financial support from donors for more than a decade.

In view of the significant benefits that Togo could derive from the Gleneagles scenario, the Government intends to organize, through the Government/Donor Committee, a round table with all the country's TFPs to be held every six months as a way to step up advocacy efforts to concretize the Gleneagles commitments. At a purely domestic level, the Government is aware of the enormous challenge that it faces in terms of building the absorption capacities of the Togolese economy. It intends to make every effort to gradually meet this challenge.

\section{Risk Analysis AND Prospects for ACHIEVING the MDGs}

The reference scenario for implementing the strategy is very circumspect. It is based on very realistic targets in terms of the macroeconomic framework. However, certain risks may take on added importance in reality. These risks are connected with: (i) exogenous shocks (lack of good climate conditions, volatility of world prices for agricultural products, higher oil prices, etc.); (ii) resource absorption capacity (cumbersome budgetary procedures, disbursement delays, capacity problems, etc.); (iii) quality of resource assignment (level of real attention to the priorities of the strategy); (iv) slow implementation of the various structural reforms, especially in the sectors of energy, roads, and telecommunications; (v) pace of reforms to improve the business environment; and (vi) presidential elections without clashes and without violence.

In addition, a lack of political commitment could complicate effective implementation of the strategy. All ministry officials must bring unprecedented leadership to the strategy implementation process, which is key to achieving the HIPC Initiative completion point and setting the country on the path to economic emergence. Implementation of the institutional framework thus becomes a top priority.

On the part of non-State actors, it is important: (i) that civil society play a dynamic role in mobilizing individuals, groups, and communities so as to facilitate social interaction and promote local ownership of and participation in strategy implementation; (ii) that the private sector enter into a key partnership with government and civil society and that frameworks of consultation be set in place for this purpose; (iii) that development partners support the process and help absorb potential exogenous shocks that

\footnotetext{
${ }^{52}$ IMF, The Macroeconomics of Scaling-up Aid: The case of Benin, Niger, and Togo, September 2008.
} 
could interfere with the macroeconomic objectives; ${ }^{53}$ and (iv) that the beneficiaries, i.e. local citizens, take real ownership of the strategy and become actively involved in implementing, monitoring, and evaluating it.

In addition to the risks already identified in connection with the baseline scenario, implementation of the optimistic scenario shines a bright light on the capacity problems that could hinder the mobilization of resources tied to the Gleneagles commitments and the absorption of these resources if they should actually materialize. The main constraints identified revolve around: (i) the Government's weak institutional and human capacities; (ii) inadequate capacities at the central and sectoral levels for managing and monitoring resources (planning, programming, budgeting, monitoring and evaluation); (iii) inadequate capacities for mobilizing the resources needed for program implementation; and (iv) nonexistent capacity in regard to formulating and implementing forward-looking policies.

To lift these constraints and accelerate Togo's progress towards meeting the MDGs, the priorities are to: (i) create and make use of delegated contracting authority agencies to accelerate the implementation of investment projects; (ii) make use of the operational services of United Nations System agencies (particularly UNDP) by subcontracting government procurement with a view to accelerating the acquisition of equipment and the provision of goods and services to the general public; (iii) strengthen the capacities of the line ministries in the areas of programming, implementation, and monitoring and evaluation of development programs and projects (build capacities in terms of skilled human resources, logistics and work tools, and training); (iv) strengthen the operational capacities of the Administrative and Financial Directorates of priority ministries in regard to programming and the monitoring of procurement procedures; (v) set in place an information system that provides a detailed, consolidated, and forward-looking vision of official development assistance (with regular updating); (vi) establish twice-yearly consultations between project coordinators and entities in charge of coordinating and managing official development assistance; and (vii) provide training to administrative officials on the central themes of effective public service, such as exercising leadership functions and the importance of a monitoring system.

${ }^{53}$ Thus, it is particularly important that the Government/Donor Committee be set up. 


\section{CHAPTER 6: INSTITUTIONAL FRAMEWORK AND MECHANISMS FOR IMPLEMENTING AND MONITORING THE STRATEGY}

The Poverty Reduction Strategy Paper, as a strategic orientation framework of development, is the principal reference point for poverty reduction interventions. As such, it is also perceived as the leading instrument for ensuring consistency among sectoral and regional development policies. Its institutional steering mechanisms should reflect effective Government leadership and create the conditions for greater synergy among interventions and a more dynamic partnership with donors, the private sector, and civil society within the context of implementing the law on decentralization in Togo. Indeed, the level of participation and ownership by all actors will be one of the key criteria for assessing the PRSP process.

\section{INSTITUTIONAL FRAMEWORK}

Implementation of the full strategy depends on the fulfillment of three essential conditions, namely: (i) development of the Priority Action Program; (ii) set-up of the new institutional framework; and (iii) capacity-building for the key actors expected to serve as the driving force of the institutional framework. Implementation and monitoring/evaluation of the F-PRSP will be managed by the following institutional mechanisms:

National Council on Development Policy and Poverty Reduction (CNPDLP). Chaired by the Prime Minister, this is the body charged with guiding and assessing progress in the implementation of the poverty reduction strategy and all economic and financial programs based on development policy reviews. CNPDLP is made up of representatives of all branches of Government and of nongovernmental stakeholders, i.e. civil society organizations, unions, the private sector, the Economic and Social Council (to be established), religious denominations, and technical and financial partners. It meets once a year, on the occasion of the annual PRSP review. Following each annual review, the Prime Minister, accompanied by a few CNPDLP members, will present to the National Assembly, at a consultative session, a report on the actions implemented annually under the PRSP, and will solicit the observations and advice of lawmakers with a view to boosting the effectiveness of the country's poverty reduction process.

Interministerial Committee on Poverty Reduction Strategies (CISLP). This committee oversees implementation of the national strategy by periodically reviewing reports on the workings of the Technical Steering Committee for the Poverty Reduction Strategy. Based on these reviews, CISLP provides guidance for efficient and coordinated implementation of PRSP interventions in all sectors. It is also charged with monitoring the Millennium Development Goals and the Paris Declaration at the national level. CISLP should periodically hold working sessions with consultative bodies, i.e. the Government/Donor Committee and the Network of Civil Society Organizations, to monitor and evaluate the PRSP. It should hold at least one working session with each of these entities prior to the annual PRSP review. CISLP includes all Government Ministers. The Minister of Finance chairs this committee, the Minister of Development is vice-chair, and secretarial functions are performed by the Permanent Technical Secretariat.

Technical Steering Committee for the Poverty Reduction Strategy (CTP). This committee handles technical coordination of projects based on periodic reports and performance charts submitted to it, and closely monitors all priority PRSP operations, and especially macroeconomic stabilization measures and sectoral or cross-cutting reforms introduced under the PRSP and/or cooperative programs with international institutions. The Technical Steering Committee includes - in addition to the Secretaries-General of ministries participating in CISLP (or the Cabinet Directors, in the case of ministries that have no Secretary-General) - the BCEAO National Director. CTP members are organized, based on their sector of competence, into four Technical Subcommittees (SCTs): SCT 1 on Governance, SCT 2 on Growth Policies, SCT 3 on Economic Infrastructure, and SCT 4 on Social 
Sectors. The Technical Steering Committee's secretarial functions are performed by the Permanent Technical Secretariat of the PRSP. The Secretary-General of the Ministry of Finance chairs the Technical Steering Committee, assisted by three vice-chairs. The four technical subcommittees are chaired by the chairperson and the three vice-chairs.

Permanent Technical Secretariat of the PRSP. This secretariat has been created to meet the need for a lasting structure equipped with substantial permanent expertise and capable of coordinating all technical activities associated with the development, implementation, monitoring, and evaluation of the PRSP. The Permanent Technical Secretariat of the PRSP is thus the keystone of the entire PRSP institutional framework. It is led by a Permanent Technical Secretary.

Sectoral PRSP Committees. These committees are charged with monitoring and evaluating the implementation of PRSP operations at the sectoral level. They exist within each line ministry and are chaired by the Secretaries-General of the line ministries (or the Cabinet Directors in the case of ministries that have no Secretary-General), with the Directors of Studies and Programming serving as recorders, assisted by the Permanent Technical Secretariat of the PRSP. Other members include one representative per technical directorate, coordinators/directors of programs or projects in the relevant sector, one representative per subsidiary agency and/or oversight entity, representatives of civil society and the private sector involved in the sector, and representatives of technical and financial partners.

Regional Participatory Monitoring Committees (CRSPs). The CRSPs carry out participatory monitoring and evaluation of projects and programs at the regional level. These entities are independent and autonomous vis-à-vis the national structures, but are the latter's counterparts. The regional committees will work in close collaboration with prefecture administrations and local civil society organizations, as well as local private sector actors, to monitor implementation of the PRSP in their regions. Each CRSP is made up of the future Regional Governor, who will serve as chairperson; the Regional Director of Development, who will handle the secretarial functions; and representatives of municipal councils, prefecture councils, the regional council, directorates of deconcentrated government agencies in the region, traditional chiefs, the Regional Chamber of Agriculture, the Regional Chamber of Trade, nongovernmental organizations, women's development associations, trade union organizations, and Village Development Committees. Pending the conclusion of the decentralization process, the CRSPs may be chaired at the outset by the prefects of regional capitals.

Local Participatory Monitoring Committees (CLSPs). At the municipal level, Local Participatory Monitoring Committees will be established. These committees, chaired by the future Mayors, will be responsible for monitoring operations implemented under the PRSP in their municipalities. Each local committee is made up of representatives of municipal councils, NGOs operating in the municipality, women's development associations, farmer organizations, traditional chiefs, and Village Development Committees. The CLSPs will be set up gradually as new municipalities are created. In existing municipalities, the CLSPs will be chaired by the local authorities in place.

Once the priority monitoring mechanisms are in place and consolidated, a Government/Donor Committee will be set up, to be co-chaired by the Minister of Cooperation and a donor representative designated by his/her peers. This committee is the preferred agency for dialogue between the Togolese Government and its technical and financial partners. Also, a specific mechanism for monitoring and consultation on F-PRSP matters will be put in place at the initiative of nongovernmental actors to provide concurrent monitoring and evaluation. The Government will make every effort to establish the Government/Donor Committee as promptly as possible by mutual agreement with TFPs, as well as to set up, in cooperation with civil society actors, the CSO Network for PRSP/MDG monitoring and evaluation. In addition, in view of the crucial role in governmental action played by the Permanent Secretariat charged with monitoring reform policies and financial programs, the Permanent Secretary will be a member of CNPDLP and CISLP. 
Figure 1: Institutional framework for monitoring and evaluation of the PRS

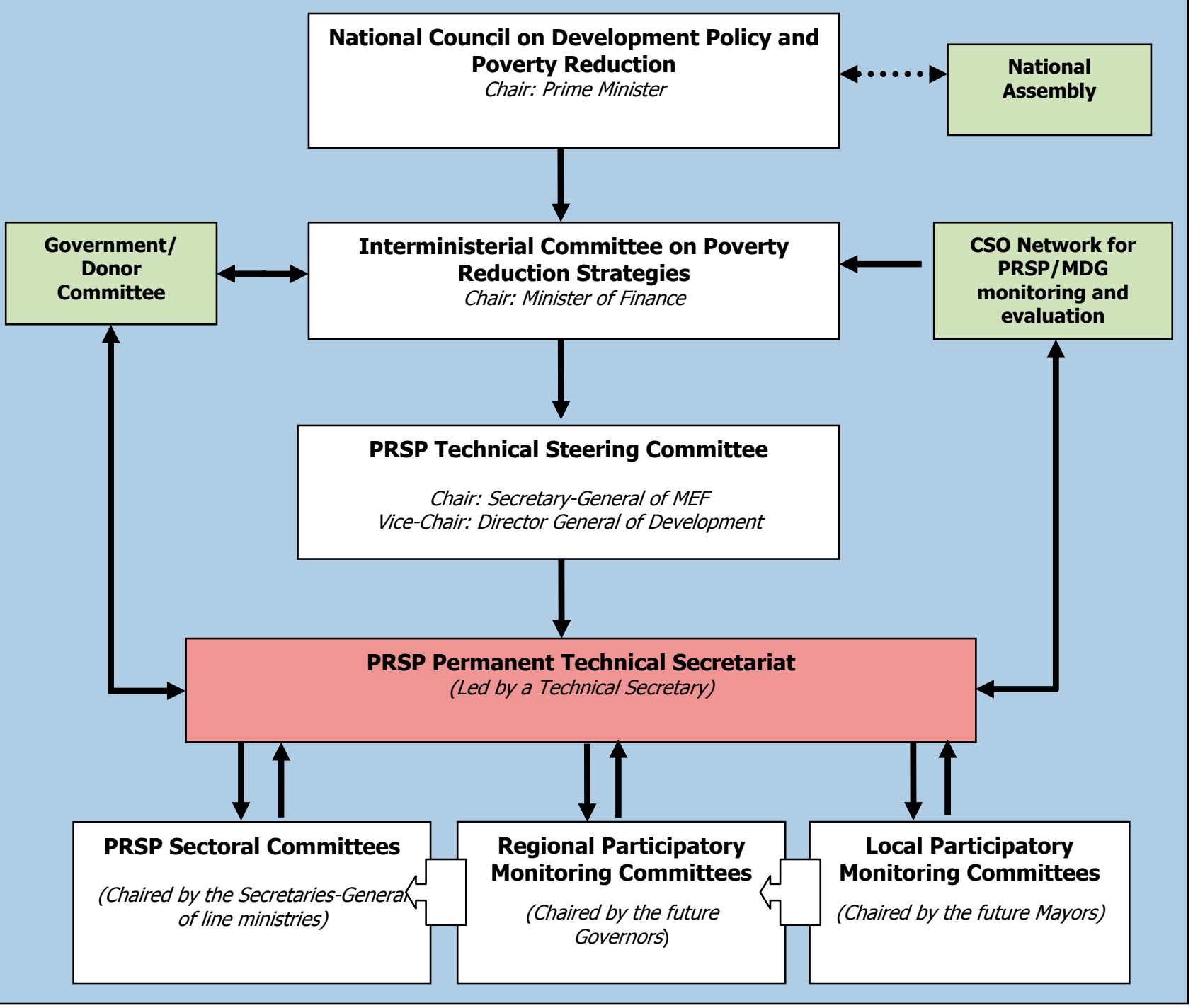

\section{INFORMATION SYSTEM FOR MONITORING AND EVALUATION OF THE STRATEGY}

In the interest of ensuring that the PRS is monitored in a consistent fashion, the various stakeholders mentioned above will coalesce around a PRSP monitoring and evaluation information system. These various stakeholders will have five essential roles to play: (i) production of data and information; (ii) analysis of results derived from this data and information; (iii) creation and maintenance of databases and survey bases; (iv) dissemination of analyses in the form of reports; and (v) system-wide coordination.

The purposes of this information system will be to: (i) systematically produce basic indicators and/or information for monitoring PRSP operations and achieving the MDGs; (ii) produce information for monitoring poverty reduction programs and projects; (iii) produce information for assessment of the impact of policies, programs, and projects; and (iv) produce regionally and locally disaggregated information.

The information system for monitoring and evaluating the PRS and MDGs will be partly based on sectoral information systems already existing, particularly in the areas of health care (SNIS), 
education, HIV/AIDS, finance, and rural development. The system consists of three components, or sub-systems, which complement each other and are thoroughly interlinked: (i) Sub-system for "Monitoring of Household Living Conditions"; (ii) Subsystem for "Monitoring of Programs and Projects"; and (iii) Subsystem for "Impact Assessment."

\subsection{Sub-system for "Monitoring of Household Living Conditions"}

The purpose of this sub-system is to systematically produce and manage indicators concerning household living conditions and/or basic information for assessing poverty and for monitoring the PRSP and MDGs. These will essentially be results indicators or global impact indicators based on the 'monetary poverty,' 'basic needs poverty,' 'capacity or opportunity poverty,' and 'social exclusion poverty' approaches. These indicators are regularly updated on the basis of national accounts, statistical surveys, and administrative statements. The system will be under the authority of the Permanent Technical Secretariat of the PRSP (PTS-PRSP), with the Directorate General of Statistics and National Accounts (DGSCN) handling technical coordination.

\subsection{Sub-system for "Monitoring of Programs and Projects"}

The purpose of this sub-system is to monitor the financial and physical execution of poverty reduction programs and projects. Its indicators involve inputs and outputs. Input monitoring refers to the monitoring of the level of financial resources allocated to programs and projects. It also includes the monitoring of available human and physical resources. Monitoring of outputs generated by the implementation of project and program activities refers to the monitoring of the output of povertyreducing services (e.g. construction of schools, health centers, hydraulic infrastructures, roads, etc.). This monitoring helps determine the existence and status of investments planned under poverty reduction programs and projects. Most of the data required for this purpose is derived from the administrative files of program and project agencies, and from the internal statistics of the supervisory ministries. In order to function properly, this sub-system requires the establishment of Medium-Term Expenditure Frameworks (MTEFs) as frameworks for budget planning and execution. Technical coordination will be handled by the Plan Execution Oversight Directorate in collaboration with the Directorate General of Budget (including the department responsible for program and project preparation).

\subsection{Sub-system for "Impact Assessment"}

Impact assessment makes it possible to identify those changes in the wellbeing of individuals in a specific population group that can be ascribed to a particular program or policy. Impact assessment involves studies of a specific project, program, or policy and of a well-defined population. The results of these assessments are used to guide decisions regarding the expansion, modification, or elimination of a given policy, program, or project, and to rank public interventions by order of priority. It is a tool to aid decision-making, and also has the advantage of enhancing the visibility of programs vis-à-vis the population as a whole. This final sub-system is under the technical coordination of the Directorate of Economy (DE). 
Figure 2: Information system for monitoring and evaluation of the PRS

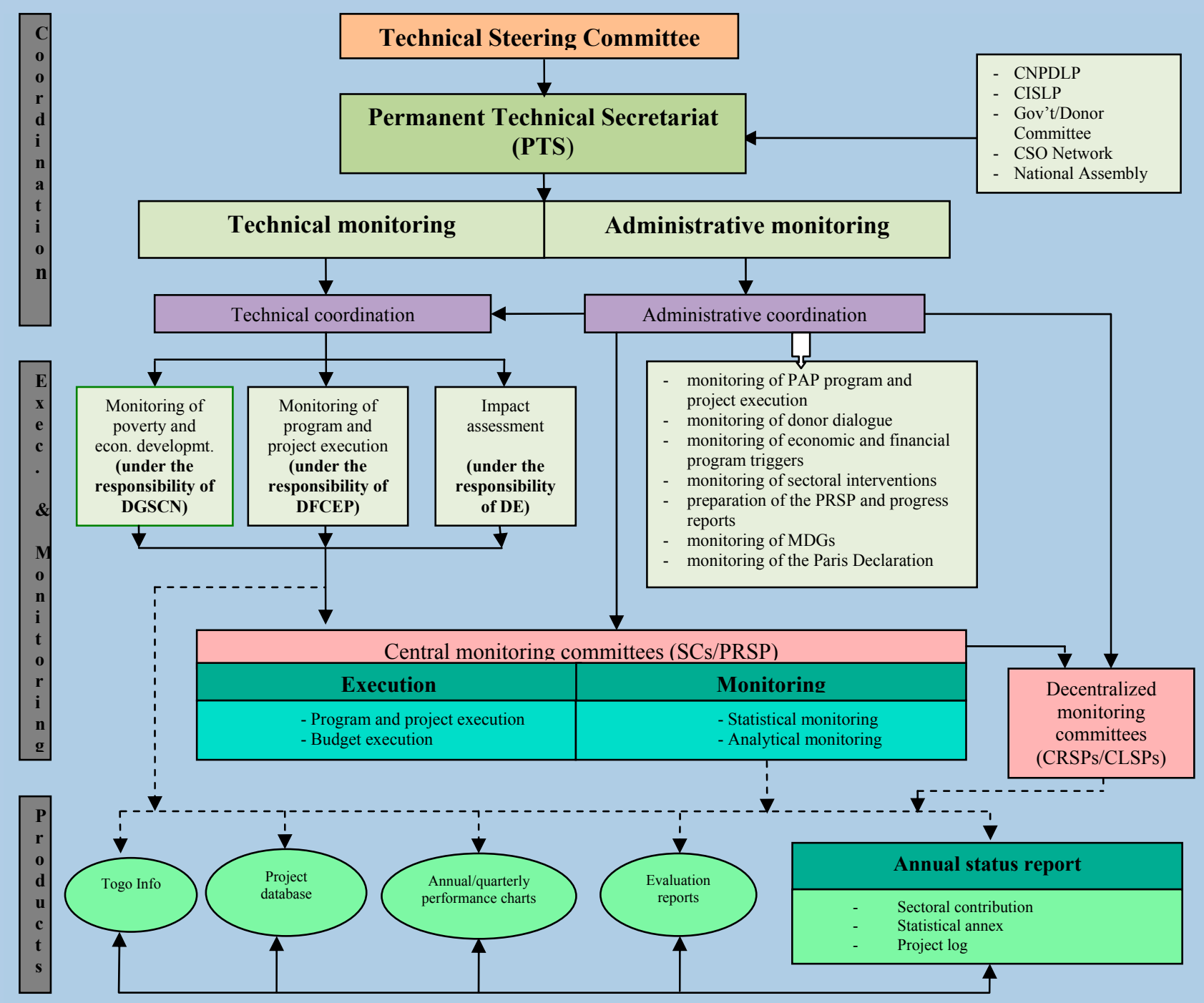

\section{IMPRoved Production AND DisSEMinAtion OF STATISTICAL INFORMATION}

The Togolese statistics system is a deconcentrated system in which the focal point of all statistics activities is DGSCN. The system is characterized by the absence of a statistics coordinating body and the absence of a statistics law to regulate statistics activities.

In recognition of the basic role of statistics in development and poverty reduction strategies, and in order to revitalize the national statistics system, the Government formulated a National Statistics Development Strategy (SNDS), which was validated on December 2, 2008.

DGSCN, as the focal point of all statistics activities, will be responsible, in partnership with PTS, the SCs, the CRSPs, and the CLSPs, for ensuring that the necessary information is produced for monitoring and evaluation of the F-PRSP. 
With the support of technical and financial partners, the Togolese Government has formulated a National Statistics Development Strategy (SNDS) covering the period 2009-2013. The vision behind this strategy is to build a functional, credible, and effective national statistics system that produces authoritative data and meets the needs of users. To achieve this vision, the SNDS revolves around the following strategic goals: (i) strengthen the legal and institutional framework; (ii) enhance the production of statistics; (iii) promote the use of statistical data and the development of a statistics culture; and (iv) build capacities in terms of human, physical, and financial resources. Implementation of the reforms and projects stemming from the SNDS is based on the following principles: encouragement of results-oriented management; a participatory planning framework for national development; meeting the needs for monitoring and evaluation of the PRSP and MDGs; and a strategy to improve and strengthen the capacities of the national statistics system. All agencies of the national statistics system are responsible for SNDS implementation.

Source: Ministry of Cooperation, Development, and Land Use

At regular intervals, DGSCN will be responsible for carrying out major statistical operations such as the general census of the population and housing, the demographic and health survey (DHS), the seroprevalence survey, the survey of the informal sector, the budget-consumption survey (1-2-3 survey), the MICS survey, and the agricultural surveys, as well as for collecting and processing data for the national database of administrative entities.

DGSCN will work in coordination with the international development agencies involved in the statistics sector and will seek technical, material, and financial support with a view to improving the quality of the data produced.

DGSCN will see to broad dissemination of the quantitative data necessary for monitoring and evaluation of the poverty reduction strategy by making use of appropriate channels, particularly the PRSP website and Togo Info. It will publish analyses of poverty in Togo on a regular basis.

DGSCN will also see to the creation of a data bank of databases from these surveys, which it will use to generate the poverty indicators. In addition, DGSCN is charged with coordinating data collection by entities that produce sectoral statistics, especially the planning and programming directorates in the various ministries.

\section{CaPaCity-BuILding}

The profound crisis that Togo has experienced for the past sixteen years has had significant repercussions on the Public Administration. The system is currently having difficulty functioning because its employees, while qualified, sometimes have poor morale. The Public Administration is also characterized by an aging corps of civil servants and a shortage of operating resources.

If the pillars of the Full PRSP are implemented by relying on the Public Administration in its current state, the impact of these measures may be compromised. Indeed, successful implementation of this program requires, over the long term, the reconstruction of a modern State based on a well-organized public administration staffed with youthful, qualified, and motivated employees. It is in this context that the States General of the Public Administration (Etats Généraux de l'Administration Publique) were held in December 2006, laying the foundations for reforms designed to modernize public administration. This reconstruction of a modern and effective public administration is expected to improve the provision of public services, especially in the priority areas of health care, education, transportation, energy, safe drinking water, and sanitation.

Thus, the initial phase of public administration reform requires a transitory capacity-building strategy, aimed at reactivating certain key administrative functions. This strategy targets a limited number of interventions, the selection of which should be guided by the necessity of recreating the foundations 
for planning public investments in these priority sectors. Considering the weakness of the existing capacities, efforts will be made to strengthen the targeted administrations, first of all so they can update or prepare policies and strategies and, secondly, so they can design, implement, and monitor development projects, specifically by tapping Togolese expertise (Togolese living abroad or retirees with recognized expertise). In addition, the employees currently in place will benefit from extensive training and retraining interventions.

In addition, to ensure the full success of this capacity-building process, the Government will take steps to: (i) boost the effectiveness of governmental action; (ii) monitor the implementation of interventions aimed at reaching the HIPC Initiative completion point by 2010; (iii) make the institutional mechanism for monitoring PRSP implementation fully operational; and (iv) rehabilitate the national statistics system.

In regard to the effectiveness of governmental action, the Government will make every effort to boost and coordinate interministerial action and will monitor the ministries' terms of reference. In addition, special emphasis will be placed on the flow of information between different ministries and on the Government's external communications.

With respect to monitoring the implementation of interventions aimed at reaching the HIPC Initiative completion point by 2010 , the Government will give special attention to the management capacities required for implementing the public finance reforms derived from the following studies: Public Expenditure Management and Financial Accountability Review (PEMFAR), Public Expenditure and Financial Accountability (PEFA), and Country Procurement Assessment Report (CPAR). On this last point, the contours of a transitory mechanism for government procurement and delegated contracting authority will be studied as part of the overall sector reform.

To make the institutional mechanism for monitoring PRSP implementation fully operational, the Government will make a special effort to revitalize consultation with partners, specifically by setting up the Government/Donor Committee and the Sectoral Committees.

Finally, in regard to rehabilitation of the national statistics system, a data collection program will be developed to feed the PRSP monitoring and evaluation system in accordance with the National Statistics Development Strategy. 


\section{CONCLUSION}

The Full Poverty Reduction Strategy Paper (F-PRSP) is the new unifying framework for all sectoral strategies and constitutes the reference document for government interventions during the period 2009-2011. It provides the foundations for developing the sectoral development plans and investment programs. With respect to the long-term National Development Strategy based on the Millennium Development Goals, the F-PRSP provides the framework for making this strategy operational and, as such, was developed with the participation of all components of Togolese society and the support of Togo's technical and financial partners.

The full support of the Public Administration, private sector, civil society, and technical and financial partners in embracing the F-PRSP as the frame of reference for growth and poverty reduction suggests a highly promising outlook.

The success of this strategy will mainly hinge on the degree of ownership of the strategy by the various stakeholders. In addition, success will require: (i) real ownership of the content of the strategy by the entities responsible for its implementation within the Public Administration, civil society organizations, the private sector, and local communities; (ii) sustained efforts by the Government to mobilize resources and use them, on a priority basis, for effective implementation of the strategy in accordance with the Paris Declaration; (iii) institutional and human capacity-building at the central, as well as the regional and local, levels; and (iv) on the part of technical and financial partners, alignment and harmonization of their operations within the F-PRSP frame of reference.

With this in mind, the Government intends to consolidate and perpetuate periodic consultations with all stakeholders and set in place a functional monitoring and evaluation system that will be used to assess the progress made and plan any necessary corrective measures.

To make the F-PRSP operational, the Government will develop a Priority Action Program for its implementation. This Priority Action Program will contain investments apt to boost the visibility of measures and actions that will contribute to accelerated growth and poverty reduction. It will link together the F-PRSP, the various sectoral strategies, and the ministries' program budgets. 